\title{
Register of New Fruit and Nut Cultivars List 49
}

\author{
Ksenija Gasic, Co-editor \\ Department of Plant and Environmental Sciences \\ Clemson University \\ 105 Collings Street \\ Clemson, SC 29634 \\ John E. Preece, Co-editor \\ National Clonal Germplasm Repository \\ USDA-ARS \\ One Shields Avenue \\ University of California \\ Davis, CA 95616 \\ David Karp, Co-editor \\ Associate in the Agricultural Experiment Station \\ University of California, Riverside, CA 92521
}

\begin{abstract}
Crop Listings ${ }^{\mathbf{z}}$. Almond Rootstocks, Apple, Apricot and Pubescent-skinned Prunophora Hybrids, Blackberry, Blue Honeysuckle, Blueberry, Grape, Hazelnut, Nectarine, Peach, Pear, Pear Rootstocks, Persian Walnut, Plum, Pomegranate, Raspberry, Strawberry
\end{abstract}

\section{ALMOND ROOTSTOCK}

\section{T.G. Beckman, USDA-ARS, Southeastern Fruit and Tree Nut Research Laboratory, Byron, GA}

Arthur V (Brights Hybrid ${ }^{\circledR}$ 5). Clonal almond $\times$ peach hybrid rootstock for almond. Origin: Bright's Nursery, Le Grand, CA, by W. Bright, V. Bright, J. Bright, and E. Bright. Titan almond $\times$ Nemared peach; crossed 1980. USPP 18,782; 6 May 2008. Plant: propagated via tissue culture. Rootstock performance: vigor high, $\sim 120 \%$ of Nemaguard, yield similar to Nemaguard; drought tolerant; tolerant to calcareous soil; well anchored; resistant to root-knot nematodes, susceptibility to lesion nematodes low, resistant to Verticillium (Verticillium dahliae); susceptible to crown rot and Phytophthora (Phytophthora spp.), armillaria root rot (A. mellea), crown gall (Agrobacterium tumefaciens), and bacterial canker (Pseudomonas syringae); compatible with almond, peach, nectarine, plum (European and Japanese), and apricot cultivars tested.

Brights Hybrid $^{\circledR}$ 5. See Arthur V.

SAM 1. Clonal almond rootstock for almond. Origin: Durham, CA, by P.A. Lewis; almond O.P. seedling; discovered 2005. USPP 27,952; 2 May 2017. Plant: propagated via hardwood cuttings.

\footnotetext{
${ }^{{ }^{2} \text { Special thanks }}$ to the crop contributors for compiling this information. Individuals with cultivars to describe should contact the crop editors directly. DISCLAIMER OF LIABILITY AND ACCURACY: This information is provided as a courtesy of the American Society for Horticultural Science (ASHS) and is presented with the explicit understanding that ASHS and its authors are not rendering any professional service or advice. While ASHS does its best to present current, accurate, and complete information, the information provided herein may be changed at any time by its owners, or become outdated. Readers are encouraged to inquire further for confirmation of all information on cultivar description and intellectual property protection. ASHS strictly disclaims the accuracy or completeness of the information contained herein. ASHS and its authors strictly disclaim any liability whatsoever, direct or indirect, for any damages of any kind resulting from the use of this material.

https://doi.org/HORTSCI049fn-18
}

Rootstock performance: resistant to Armillaria root rot comparable to Mariana 2624; resistant to root-knot nematodes (Meloidogyne spp.); well anchored; compatible with Nonpareil, Price, and Monterey almond.

\section{APPLE}

Sarah Kostick and Kate Evans, Washington State University Tree Fruit Research and Extension Center, Wenatchee, WA

ANABP 01 (Bravo $\left.{ }^{\text {TM }}\right)$. Purple-red apple with excellent flavor and texture. Origin: D.A.F.W.A. Bentley, Western Australia, Australia, by J.E. Cripps. Cripps-Two (Cripps Red) $\times$ Tenroy Gala (Royal Gala); crossed 1992; propagated 1999. USPP 27,420; 29 Nov. 2016. Fruit: size medium, diameter $7.5-8.5 \mathrm{~cm}$; obloid; dark purple red; flavor and texture excellent; late-season, ripens $\sim 27 \mathrm{~d}$ after Golden Delicious, $14 \mathrm{~d}$ after Cripps Pink; consistent cropping. Tree: vigor medium, similar to Golden Delicious; ramified; growth habit spreading; chilling requirement 400-500 h.

BL-14. Early maturing, intensely colored Gala apple. Origin: Wenatchee, WA, by B. Lewis. Limb mutation of Banning Gala; propagated 2011. USPP 27,867; 11 Apr. 2017. Fruit: size medium, diameter $\sim 7.0 \mathrm{~cm}$; round conical; color intense, striped; lower acidity and earlier season than Gale Gala, Banning Gala, and Simmons Gala; flesh crisp, juicy, melting; ripens early August in Wenatchee. Tree: blooms with Banning Gala; vigor moderate; growth habit upright, spreading; hardy to USDA Zone $6 \mathrm{~b}$.

Bravo $^{\text {TM }}$. See ANABP 01.

CIV323 (Isaaq ${ }^{\circledR}$ ). Precocious apple with good storability and resistance to apple scab. Origin: Consorzio Italiano Vivaista, Ferrara, Italy, by M. Leis, A. Martinelli, F. Tagliani, and G. Castagnoli. Galaxy $\times$ A3-7; selected 2004; propagated 2004. USPP 26,973; 26 July 2016. Fruit: size medium, diameter $7.1 \mathrm{~cm}$; cylindrical; intense red with yellow orange ground color; flesh cream; crisp, juicy; 13.5-14.0 ${ }^{\circ}$ Brix, 8.0-9.0 g/L malic acid; stores well; ripens mid- to late August in Ferrara. Tree: blooms early April in Ferrara; growth habit open; vigor medium; hardy to $-12{ }^{\circ} \mathrm{C}$; resistant to apple scab (Venturia inaequalis). 
FEM 1. Attractive apple with crisp, firm texture and good storability. Origin: Fondazione Edmund Mach, San Michele all'Adige, Trento, Italy, by P. Magnago. Pinova $\times$ Cripps Pink. EU PVR 43,816; 6 June 2016. Fruit: ovoid, height 7.0-8.0 cm; bright pink red with yellow green ground color, weakly defined stripes; flesh crisp, firm, juicy after storage; aroma similar to Cripps Pink; hint of citrus flavor, $15-17^{\circ}$ Brix, 6-9 g/L malic acid; late, ripens $45 \mathrm{~d}$ after Golden Delicious. Tree: blooms with Golden Delicious; vigor medium; growth habit spreading.

FEM 8. Bright red apple with well-defined stripes. Origin: Fondazione Edmund Mach, San Michele all'Adige, Trento, Italy, by P. Magnago. Tenroy $\times$ Pinova. EU PVR 43,817; 6 June 2016. Fruit: conical, 6.5$8.0 \mathrm{~cm}$; bright red with bright yellow ground color, strongly defined stripes; no russetting; flesh medium crisp, firmness decreases in storage like Gala; aroma and flavor similar to Gala; $12-13{ }^{\circ}$ Brix, $4-5 \mathrm{~g} / \mathrm{L}$ malic acid; ripens $7 \mathrm{~d}$ after Gala. Tree: blooms with Golden Delicious; vigor medium; growth habit spreading.

FUCIV51 (Fuji SAN-CIV ${ }^{\circledR}$ ). Intense purple-red Fuji sport. Origin: Consorzio Italiano Vivasti, Ferrara, Italy, by M. Leis and A. Martinelli. Mutation of Fuji NAGAFU-12; discovered 2005; propagated 2009. USPP 27,421; 29 Nov. 2016. Fruit: round to slightly flat; intense purple-red, covering large portion of fruit; 14.5-16. ${ }^{\circ}$ Brix, 5-6 g/L malic acid; ripens early October in Ferrara. Tree: blooms mid-April in Ferrara; growth habit upright; vigorous, similar to Fuji NAGAFU-12.

\section{Fuji SAN-CIV ${ }^{\circledR}$. See FUCIV51.}

Gala 2013. Solid purple-red Gala sport. Origin: GRIBA Baumschule Landwirtschaftliche Gesellschaft, Terlan, Italy, by A. Defranceschi. Limb mutation of Gala; propagated 2009. USPP 27,978; 9 May 2017. Fruit: color $100 \%$ intense purple-red, no stripes; young fruit fully red $40 \mathrm{~d}$ after full bloom; flesh sweet, 11-11.5 ${ }^{\circ} \mathrm{Brix}$, 4.7-5.2 g/L malic acid; aroma similar to Gala; juiciness and firmness moderate; ripens $30 \mathrm{~d}$ before Golden Delicious. Tree: red receptacle at full bloom; growth habit and vigor similar to Gala; leaves have red petiole and central vein.

Gala Schnico Red. Intense red-skinned Gala sport. Origin: Schniga, Bozen, Italy, by A. Gruber-Genetti, T. Braun, and W. Malleier. Mutation of Gala Schnitzer Schniga. USPP 27,577; 24 Jan. 2017. Fruit: size medium; $100 \%$ intense, dark red; $30 \%$ more lenticels per unit area than Gala Schnico; ripens midseason at Aniage Knoll, Italy, similar to Elstar, Gala, and Honeycrisp. Tree: blooms with Cox's Orange Pippin and Jonagold; pollinizers Red Delicious, Granny Smith, and Golden Delicious; tree ramified; growth habit spreading.

HS Red. Attractive red apple. Origin: Chelan, WA, by H.E. Schell. Mutation of Oregon Spur II; propagated 1998. USPP 26,538; 29 Mar. 2016. Fruit: size medium, diameter $8.7 \mathrm{~cm}$; conical, like Red Delicious; red; higher sugar and acid levels than Oregon Spur II; ripens early October at Chelan. Tree: blooms $3 \mathrm{~d}$ before Oregon Spur II; tip bearing; vigor low to moderate; hardy to at least USDA Zone 7a.

Isaaq $^{\circledR}$. See CIV323.

JFS-KW207. Dwarf ornamental crab apple with pinkish flowers and brightly colored fruit. Origin: J. Frank Schmidt \& Son, Boring, OR, by K.S. Warren. KW-8MX O.P.; seed collected 2003; selected 2011; propagated 2013. USPP 27,954; 2 May 2017. Fruit: diameter 0.8-1.9 cm; bright golden-orange; non-edible; $95 \%$ persistent into late November in Boring. Tree: pink-tinted white flowers; blooms early April at Boring; foliage dense; growth habit compact dwarf; resistant to fire blight (Erwinia amylovora) and apple scab.

Kizuri. Aromatic, sweet, dense-textured apple. Origin: Better3Fruit, Heverlee, Belgium, by I. De Wit, H. Eyssen, J. Keulemans, J. Nicolaï, and P. Van Laer. Golden Delicious $\times$ NY75413-30; crossed
1990; selected 2001; propagated 2003. USPP 27,926; 25 Apr. 2017. Fruit: large, globose; vibrant red; late, ripens $10 \mathrm{~d}$ after Golden Delicious; very aromatic, flavor sweet; texture very firm, firmer than Golden Delicious; stores well. Tree: blooms early, after Idared and Boskoop, before Jonagored; vigor medium to strong; tree ramified; growth habit spreading.

Lurechild. Red-fleshed apple with high fruit quality. Origin: Lubera, Buchs, Switzerland, by M. Kobelt. LubA793 × LubA264; selected 2006. USPP 27,625; 31 Jan. 2017. Fruit: round, 5.5-6.0 cm; flesh red; flavor berry-like, sugar-acid balance good, eating quality better than LubA264; ripens 10-15 Sept. at Buchs, before Luresweet. Tree: blooms mid- to late April at Buchs; vigor low; hardy to $-18{ }^{\circ} \mathrm{C}$; resistant to apple scab, similar to LubA793.

Luregust. Red-fleshed apple. Origin: Lubera, Buchs, Switzerland, by M. Kobelt. LubA793 × LubA264; selected 2006. USPP 27,624; 31 Jan. 2017. Fruit: roundish, oblong at top and bottom, $\sim 6 \mathrm{~cm}$; flesh red; eating quality good; aromatic, acidity high, similar to Luresweet, sweeter than LubA264, less sugar than Luresweet; ripens mid-September in Buchs. Tree: blooms late April at Buchs; vigor average; ramified; growth habit spreading; hardy to $-18{ }^{\circ} \mathrm{C}$; resistant to apple scab, similar to LubA793.

Luresweet. Red-fleshed, high-quality apple. Origin: Lubera, Buchs, Switzerland, by M. Kobelt. LubA688 × LubA275; selected 2006. USPP 27,502; 27 Dec. 2016. Fruit: conical, diameter $\sim 7.0 \mathrm{~cm}$; flesh red; aromatic; sugar and acidity high, $15^{\circ} \mathrm{Brix}$, similar to Lurechild; ripens early October at Buchs, with Golden Delicious, later than Lurechild. Tree: blooms mid- to end of April at Buchs; vigor medium; growth habit spreading; hardy to $-18{ }^{\circ} \mathrm{C}$; resistant to apple scab, similar to LubA688 and Lurechild.

MinnB42. Deeply red-colored, crisp-textured Honeycrisp sport. Origin: University of Minnesota, by D. Bedford and J. Luby. Limb mutation of Honeycrisp; tested as B42-3-16A; discovered 1999; propagated 2001. USPP 26,644; 26 Apr. 2016. Fruit: diameter 7-8.4 cm; greater area of more intense red than Honeycrisp, develops color in climates not conducive to well-colored Honeycrisp, such as southern Pennsylvania and southern New York; texture crisp; skin thin, easily penetrated; flavor subacid; ripens 2-3 weeks after Minneiska. Tree: blooms after Minnewasta; vigor moderate; cold hardy to USDA Zone 4; more resistant to apple scab than Minneiska.

MN55 (Rave ${ }^{\text {TM}}$ ). Early ripening, crisp, juicy, red apple with long storage life. Origin: University of Minnesota, by D. Bedford and J. Luby. Honeycrisp $\times$ MonArk; crossed 1997; propagated 1998. USPP 26,412; 16 Feb. 2016. Fruit: size medium-large; globose-conical; $75-95 \%$ red with yellow-green ground color; flesh crisp, juicy, 6.4-8.6 kg firmness; storage life long; ripens early, third week in August at Excelsior, MN, 3-4 weeks before Honeycrisp. Tree: blooms late April to late May at Excelsior, depending upon year; vigorous; growth habit spreading to upright; hardy USDA Zone 4.

Mored. Fully red-skinned, sweet apple with juicy, crisp texture. Origin: Cultura Jean Moors, Bilzen, Belgium, by J. J. Moors. Chance seedling; discovered 1999; propagated 2000. USPP 27,368; 15 Nov. 2016. Fruit: large; conical to globose conical; full red; flesh juicy, crisp, sweet, low acid; ripens midseason at Bilzen, with Red Delicious. Tree: blooms late April at Bilzen, with Golden Delicious; vigor moderate; spreading; hardy to $-20{ }^{\circ} \mathrm{C}$; tolerant to powdery mildew (Podosphaera leucotricha) and gloeosporium rot.

Pink Chief. Pink-red Cripps Pink sport with columnar bearing habit. Origin: Fruit Varieties International, Grove, Tasmania, Australia, by B. Francis. Limb mutation of Cripps Pink; discovered 2007; propagated 2009. USPP 27,187; 27 Sep. 2016. Fruit: diameter $7.9 \mathrm{~cm}$; $85 \%$ red with yellow-green ground color; color more intense than Cripps Pink; flesh fresh, crisp; $15^{\circ}$ Brix; ripens late season in 
Tasmania. Tree: blooms mid-October in Tasmania; vigor weak; bearing habit columnar.

Prema34. Attractive scab-resistant apple with excellent texture. Origin: Prevar, Hastings, New Zealand, by A.G. White. Sciros $\times$ A038R02T119 (Pinkie). USPP 28,366; 12 Sept. 2017. Fruit: oblate; red with yellow ground color; flesh crisp; juiciness medium; sweet with mild acid. Tree: flowers red-purple at balloon stage; vigor moderate: growth habit semi-spreading; resistant to apple scab.

Rave $^{\text {TM }}$. See MN55.

Regalstar. Large, red, firm apple with exceptional eating quality. Origin: Agro Selections Fruits, Elne, France, by A. Maillard and L. Maillard. Ariane 6407 RT $\times$ Rose Bow; tested as 03.3E194.08. USPP 26,766; 31 May 2016. Fruit: large, round, slightly flattened; luminous red; flesh firmer than Fuji, juicy; ripens late, $4 \mathrm{~d}$ after Fuji, end of October at Elne. Tree: blooms beginning to mid-April at Elne; vigorous; growth habit spreading; hardy to $\leq-12{ }^{\circ} \mathrm{C}$.

Salish $^{\text {TM }}$. See SPA493.

SPA493 (Salish $^{\text {TM}}$ ). Yellow with red blush, midseason, long storage apple. Origin: Agriculture and Agri-Food Canada, Summerland, BC, Canada, by W.D. Lane. Splendour $\times$ Gala; crossed 1981; selected 1997; propagated 1997. USPP 28,075; 6 June 2017. Fruit: medium, globose; yellow with heavy red blush; flavor, sweet-tart, $14{ }^{\circ}$ Brix, $5.5 \mathrm{~g} / \mathrm{L}$ malic acid; keeps 6 months in regular storage; ripens mid- to late-season in British Columbia. Tree: blooms early to mid-May in British Columbia; vigor moderate; growth habit spreading; hardy to USDA Zone 4.

TCL3. Early ripening, attractively colored apple. Origin: Te Mata Consultants, Havelock North, New Zealand, by D.F. Cranwell. Sciros $\times$ Tenroy. USPP 27,659; 14 Feb. 2017. Fruit: size average, diameter $7.5 \mathrm{~cm}$; conical; $75 \%$ pink color with green-yellow ground color; ripens late January at Havelock North, before Sciros. Tree: flowers red at balloon stage; vigor average; growth habit spreading.

Westfresh. Sport of Red Delicious with improved long-term storage. Origin: WestFresh, Royal City, WA, by B.J. Anderson and J.J. Anderson. Limb sport of Oregon Spur II; discovered in early 1990s. USPP 27,164; 20 Sept. 2016. Fruit: medium-large; very dark red, 90-100\% coverage, dark red stripes, reddish yellow ground color; aroma mild; ripens late September at Rock Island, WA; long-term storage excellent, $\geq 80 \%$ high quality after $12-14$ months in controlled atmosphere storage. Tree: blooms early May at Rock Island; very vigorous; resistant to apple scab, powdery mildew, and fire blight.

WUR200. Red-skinned, scab-resistant apple, suited to organic production. Origin: Stichting Dienst Landbouwkundig OnderzoekPPO/PRI, Wageningen, the Netherlands, by R. Smulders. 1971-20153 × 1877-10236; crossed 1990; selected 2002. USPP 27,953; 2 May 2017. Fruit: conical, diameter $7.5-8.0 \mathrm{~cm} ; 75 \%$ red, spotted with lenticels; flesh firm. Tree: vigor moderate; growth habit upright; resistant to apple scab; suited to organic production.

\section{APRICOT AND PUBESCENT-SKINNED PRUNOPHORA HYBRIDS}

Craig A. Ledbetter, USDA-ARS, San Joaquin Valley Agricultural Sciences Center, Parlier, CA

\section{Apricots}

Apridelice. Luminous red to orange-red blushed apricot of high eating quality, with a very long shelf life. Origin: Agro Selections
Fruits, Elne, France, by A. Maillard and L. Maillard. ASFCOT0405 O.P.; tested as 6N.07.88AB. USPP 25,631; 23 June 2015. Fruit: round to slightly oblong, symmetrical, $80 \mathrm{~g}$; blush $65-75 \%$; aroma pronounced; flavor slightly acid; freestone; kernel bitter; ripens early. Tree: vigor high; growth habit semi-upright; bearing productive, regular; flowers self-fertile.

Aprinew. Apricot with very long shelf life, high sugar and eating quality, and attractive luminous red to orange-red skin on an orange background. Origin: Agro Selections Fruits, Elne, France, by A. Maillard and L. Maillard. ASFCOT406 × ASFCOT0405; tested as 02.11.19AB. USPP 25,630; 23 June 2015. Fruit: round to slightly oblong, 71-86 g; blush 35\%; flavor and eating quality very good; kernel bitter; ripens mid- to late-season. Tree: vigor high; growth habit spreading; branching dense; bearing productive, regular.

Aprireve. Orange-fleshed apricot of high eating quality with very good firmness and self-fertility. Origin: Agro Selections Fruits, Elne, France, by A. Maillard, and L. Maillard. ASFCOT406 $\times$ ASFCOT0405. USPP 27,031; 9 Aug. 2016. Fruit: round to slightly oblong, symmetrical; $90 \mathrm{~g}$; blush 60-70\%; aroma pronounced; flavor very good; kernel bitter; ripens semi-early. Tree: vigor medium; growth habit semi-upright; size medium; bearing productive, regular; flowers self-fertile.

Asfcot0201. Luminous orange-red blushed apricot with high sugar and very long shelf life. Origin: Agro Selections Fruits, Elne, France, by A. Maillard and L. Maillard. Parentage unknown; tested as 01.20.44 AB ASF 0210. USPP 24,093; 17 Dec. 2013. Fruit: round, symmetrical; $60-70 \mathrm{~g}$; fibers generally not observed; flesh melting, juicy; blush 40-60\%; aroma pronounced; eating quality very good; kernel bitter. Tree: vigor high; bearing productive, regular; flowers self-sterile; production good; chilling requirement $350 \mathrm{~h}$.

Golden Gem. Midseason, self-fertile, freestone apricot with meaty texture and mildly acidic/sweet flavor. Origin: Le Grand, CA, by L. Bradford. Parentage unknown; selected 2005. USPP 25,743; 28 July 2015. Fruit: globose to slightly oblong, slightly asymmetrical, $82 \mathrm{~g}$; texture firm, tough, melting; fibers abundant, fine; eating quality very good; kernel bitter; ripens midseason. Tree: vigor high; growth habit spreading; branching dense; bearing productive, regular; flowers self-fertile.

Mac12/45. Large-fruited, late-season apricot with a deep rose blush and high soluble solids. Origin: New Zealand Institute for Plant and Food Research, Auckland, New Zealand, by A. Nixon and M. Malone. Parentage unknown; selected 2009. USPP 26,034; 3 Nov. 2015. Fruit: round with symmetrical cheeks, $120 \mathrm{~g}$; blush 25-50\%; firmness medium; texture fine; ripens late. Tree: vigor medium; growth habit upright to spreading; branching medium.

Mac12/54. Late-season fresh market apricot with orange colored, firm flesh, and high soluble solids. Origin: New Zealand Institute for Plant and Food Research, Auckland, New Zealand, by A. Nixon and M. Malone. Parentage unknown; selected 2008. USPP 26,084; 17 Nov. 2015. Fruit: round with symmetrical cheeks, large, $99 \mathrm{~g}$; blush 5\%, in isolated spots; ripens late. Tree: vigor medium; growth habit upright to spreading.

NJA151. Early-season freestone apricot having dark orange ground color and fine melting flesh with a moderately acidic flavor. Origin: Rutgers University, New Brunswick, NJ, by J. Goffreda and A. Voordeckers. Harcot $\times$ Bhart; selected as J21-107. USPP 25,862; 8 Sept. 2015. Fruit: elliptical to ovate, $40 \mathrm{~g}$; fibers unnoticeable; flavor above average; eating quality very good; freestone; ripens early- to midseason. Tree: vigor high; growth habit spreading to slightly upright. 
NJA152. Glabrous freestone apricot with late bloom and good production of juicy, sweet-tart and aromatic fruit. Origin: Rutgers University, New Brunswick, NJ, by J. Goffreda and A. Voordeckers. Parentage unknown; selected as D82-1. USPP 27,166; 20 Sept. 2016. Fruit: small-medium, $38 \mathrm{~g}$; round to slightly oblong; skin surface glossy, glabrous; flesh yellow-orange; texture melting; fibers generally not noticeable; flavor above average; aroma high; eating quality very good. Tree: vigor moderate; growth habit upright to spreading; size slightly below average.

Nzsummer3. Medium-size, late-season apricot with a deep red blush, firm flesh, and low ethylene production. Origin: New Zealand Institute for Plant and Food Research, Auckland, New Zealand, by A. Nixon and M. Malone. Bhart $\times$ Late Moorpark; selected 2006; tested as StB14/15. USPP 27,897; 18 Apr. 2017. Fruit: round, slightly asymmetrical; blush $25-40 \%$; texture fine, firm; freestone; flavor mild, low-acid; ethylene production of fruit held for $10 \mathrm{~d}$ at $20{ }^{\circ} \mathrm{C} \sim 0.0$ to $0.0008 \mathrm{nmol} / \mathrm{kg} / \mathrm{s}$; ripens late. Tree: vigor medium; growth habit upright to spreading; precocity medium.

StB14/22. Fine and firmly textured apricot with $25-40 \%$ deep red blush and high soluble solids. Origin: New Zealand Institute for Plant and Food Research, Auckland, New Zealand, by A. Nixon and M. Malone. Bhart $\times$ Late Moorpark; selected 2006. USPP 26,085; 17 Nov 2015. Fruit: size medium, 100g; skin blush $25-40 \%$ in patches on fruit surface; storability very good; ripens late. Tree: vigor medium; growth habit upright to spreading; precocity medium.

Suaprieleven. Very early-maturing, large apricot with orange ground color and abundant red blush. Origin: Sun World International, Bakersfield, CA, by T. Bacon. Parentage unknown; selected 2009; tested as AP1036. USPP 26,767; 31 May 2016. Fruit: size medium, $65 \mathrm{~g}$; round, nearly symmetrical; texture smooth and melting; taste slightly tart; flavor mild; aroma slight; eating quality fair; ripens very early. Tree: vigor medium; growth habit semiupright to spreading; bearing productive, regular; branching weak; chilling requirement $350 \mathrm{~h}$.

Suaprithirteen. Large, late-ripening apricot that rarely develops split and shattered stones. Origin: Sun World International, Bakersfield, CA, by T. Bacon. Parentage unknown; selected 2008; tested as AP933. USPP 26,176; 1 Dec. 2015. Fruit: large, 96 g; round, nearly symmetrical; texture smooth; taste neutral; aroma slight; clingstone; ripens midseason. Tree: vigor medium; growth habit semi-upright to spreading; bearing productive, regular; chilling requirement $600 \mathrm{~h}$.

Suapritwelve. Large apricot with high soluble solids and smooth skin. Origin: Sun World International, Bakersfield, CA, by T. Bacon. Parentage unknown; selected 2009; tested as AP1063. USPP 26,524; 22 Mar 2016. Fruit: large, 112 g; round, nearly symmetrical; texture smooth, melting; fibers few; taste slightly tart; aroma medium-high; ripens midseason. Tree: vigor medium; growth habit semi-upright to spreading; bearing productive, regular; chilling requirement $550 \mathrm{~h}$.

\section{Pubescent-skinned Prunophora hybrids}

Bella Baby. Vigorous and upright interspecific bearing small- to medium-size red-skinned fruit with excellent flavor and eating quality. Origin: Modesto, CA, by G.N. Zaiger, L.M. Gardner, and G.G. Zaiger. Parentage unknown; selected 2011. USPP 27,064; 16 Aug. 2016. Fruit: small-medium, $130 \mathrm{~g}$; globose; texture firm, meaty; fibers few, small, tender; aroma slight; eating quality and flavor very good; clingstone; ripens early. Tree: vigor high; growth habit upright; bearing productive, regular; flowers self-sterile, pollinator required; chilling requirement $600 \mathrm{~h}$.

Bella Jean. Regular and productive interspecific bearing large yellowfleshed fruit with attractive red skin and high soluble solids. Origin:
Modesto, CA, by G.N. Zaiger, L.M. Gardner, and G.G. Zaiger. Parentage unknown; selected 2007. USPP 27,826; 4 Apr. 2017. Fruit: large, $165 \mathrm{~g}$; globose; texture firm, meaty; fibers few, small, tender; aroma very slight; eating quality and flavor very good; clingstone; ripens midseason. Tree: vigor high; growth habit upright; bearing productive, regular; flowers self-sterile, pollinator required; chilling requirement $700 \mathrm{~h}$.

Bella Red. Regular and productive interspecific having a good balance between acid and sugar with attractive red skin and flesh color. Origin: Modesto, CA, by G.N. Zaiger, L.M. Gardner, and G.G. Zaiger. Parentage unknown; selected 2009. USPP 26,207; 15 Dec. 2015. Fruit: medium-large, 125 g; globose to slightly elongated; texture firm, meaty; fibers few, small, tender; aroma slight; eating quality and flavor very good; clingstone; ripens mid- to late-season. Tree: vigor high; growth habit upright; bearing productive, regular; flowers self-sterile; chilling requirement $850 \mathrm{~h}$.

Bella Sweet. Attractive red-skinned interspecific, a heavy and regular producer with excellent flavor and eating quality. Origin: Modesto, CA, by G.N. Zaiger, L.M. Gardner, and G.G. Zaiger. Parentage unknown; selected 2009. USPP 25,091; 25 Nov. 2014. Fruit: globose, $150 \mathrm{~g}$; texture firm, meaty; fibers few, small, tender; aroma slight; eating quality and flavor excellent; freestone; ripens mid- to lateseason. Tree: vigor high; growth habit upright; branch density medium; flowers self-sterile; chilling requirement $800 \mathrm{~h}$.

Carlsbad. Large yellow-orange freestone fruit with good flavor and eating quality. Origin: Modesto, CA, by G.N. Zaiger, L.M. Gardner, and G.G. Zaiger. Parentage unknown; selected 2011. USPP 28,367; 12 Sept. 2017. Fruit: large, 147 g; globose to slightly elongated; texture firm, meaty; fibers few, small, tender; aroma moderate; eating quality and flavor good; freestone; ripens early. Tree: vigor high; growth habit semi-spreading; bearing productive, regular; flowers self-fertile; chilling requirement $550 \mathrm{~h}$.

Hermosa. Medium-large orange-skinned fruit with very good flavor and eating quality. Origin: Modesto, CA, by G.N. Zaiger, L.M. Gardner, and G.G. Zaiger. Parentage unknown; selected 2010. USPP 28,137; 27 June 2017. Fruit: medium-large, 130 g; globose; texture firm, meaty; fibers few, small, tender; aroma slight; eating quality and flavor very good; freestone; ripens midseason. Tree: vigor high; growth habit semi-spreading; bearing productive, regular; flowers self-fertile; chilling requirement $800 \mathrm{~h}$.

Huntington. Large-fruited interspecific with attractive orange skin. Origin: Modesto, CA, by G.N. Zaiger, L.M. Gardner, and G.G. Zaiger. Parentage unknown; selected 2010. USPP 26,952; 19 July 2016. Fruit: large, 173 g; elongated; texture firm, meaty; fibers few, small, tender; aroma moderate; eating quality and flavor good; freestone; ripens midseason. Tree: vigor high; growth habit upright; bearing productive, regular; flowers partially self-fertile, pollinator recommended; chilling requirement $750 \mathrm{~h}$.

Laguna. Orange-skinned freestone interspecific with firm flesh and good handling and shipping quality. Origin: Modesto, CA, by G.N. Zaiger, L.M. Gardner, and G.G. Zaiger. Parentage unknown; selected 2003. USPP 24,775; 19 Aug. 2014. Fruit: globose to slightly elongated, $93 \mathrm{~g}$; texture firm, meaty; freestone; fibers few, small, tender; aroma moderate; eating quality good; ripens mid- to late-season. Tree: vigor high; growth habit upright; branch density medium; flowers self-fertile; chilling requirement $900 \mathrm{~h}$.

Malibu. Medium size, early- to midseason, orange/yellow-fleshed freestone fruit. Origin: Modesto, CA, by G.N. Zaiger, L.M. Gardner, and G.G. Zaiger. Parentage unknown; selected 2003. USPP 26,918; 12 July 2016. Fruit: size medium, 88 g; globose to slightly elongated; texture firm, meaty; fibers few, small, tender; aroma slight; eating quality and flavor very good; freestone; ripens early- to 
midseason. Tree: vigor high; growth habit semi-spreading; bearing productive, regular; flowers self-fertile; chilling requirement $800 \mathrm{~h}$.

Pismo. Attractive medium fruit with orange-red skin and good flavor and eating quality. Origin: Modesto, CA, by G.N. Zaiger, L.M. Gardner, and G.G. Zaiger. Parentage unknown; selected 2011. USPP 27,106; 30 Aug. 2016. Fruit: size medium, 99 g; globose to slightly elongated; texture firm, meaty; fibers few, small, tender; aroma slight; eating quality and flavor good; freestone; ripens early- to midseason. Tree: vigor high; growth habit semi-spreading; bearing productive, regular; flowers partially self-fertile, pollinator recommended; chilling requirement $700 \mathrm{~h}$.

Redondo. Medium-large, attractive orange-skinned fruit with very good flavor and eating quality. Origin: Modesto, CA, by G.N. Zaiger, L.M. Gardner, and G.G. Zaiger. Parentage unknown; selected 2010. USPP 27,188; 27 Sept. 2016. Fruit: medium-large, 119 g; globose to slightly elongated; texture firm, meaty; fibers few, small, tender; aroma moderate; eating quality and flavor very good; freestone; ripens midseason. Tree: vigor high; growth habit semi-spreading; bearing productive, regular; flowers self-fertile; chilling requirement $900 \mathrm{~h}$.

Rich Magic. Large yellow-fleshed clingstone fruit. Origin: Modesto, CA, by G.N. Zaiger, L.M. Gardner, and G.G. Zaiger. Parentage unknown; selected 2008. USPP 28,151; 4 July 2017. Fruit: large, $278 \mathrm{~g}$; globose; texture firm, meaty, crisp; fibers few, small, tender; aroma moderate; eating quality and flavor very good; clingstone; ripens early. Tree: vigor high; growth habit upright; bearing productive, regular; flowers self-fertile; chilling requirement $700 \mathrm{~h}$.

Seacliff. Large orange-skinned fruit with good flavor and eating quality. Origin: Modesto, CA, by G.N. Zaiger, L.M. Gardner, and G.G. Zaiger. Parentage unknown; selected 2004. USPP 27,868; 11 Apr. 2017. Fruit: large, 165 g; globose to slightly elongated; texture firm, meaty; fibers few, small, tender; aroma heavy; eating quality and flavor good; freestone; ripens midseason. Tree: vigor high; growth habit semi-spreading; bearing productive, regular; flowers self-fertile; chilling requirement $800 \mathrm{~h}$.

Trinidad. Medium-large orange-skinned fruit with good flavor and eating quality. Origin: Modesto, CA, by G.N. Zaiger, L.M. Gardner, and G.G. Zaiger. Parentage unknown; selected 2009. USPP 27,189; 27 Sept. 2016. Fruit: medium-large, $99 \mathrm{~g}$; globose to slightly elongated; texture firm, meaty; fibers few, small, tender; aroma heavy; eating quality and flavor good; freestone; ripens early. Tree: vigor high; growth habit semi-spreading; bearing productive, regular; flowers self-fertile; chilling requirement $300 \mathrm{~h}$.

Weston. Heavy and regular bearing interspecific with attractive orange skin and flesh color. Origin: Modesto, CA, by G.N. Zaiger, L.M. Gardner, and G.G. Zaiger. Parentage unknown; selected 2007. USPP 26,205; 15 Dec. 2015. Fruit: large, 190 g; texture firm, meaty; fibers few, small, tender; aroma moderate; eating quality and flavor very good; freestone; ripens early- to midseason. Tree: vigor high; growth habit upright; bearing productive, regular; flowers selffertile; chilling requirement $900 \mathrm{~h}$.

\section{BLACKBERRY}

Chad E. Finn, USDA-ARS, Horticultural Crops Research Laboratory, Corvallis, OR

Bethany M. Sebesta and John R. Clark, Dept. of Horticulture, University of Arkansas, Fayetteville, AR

APF-122. Thorny, primocane-fruiting, precocious plant with medium-sized fruit and high soluble solids, for fresh-market production. Origin: University of Arkansas, Fayetteville, AR, by J.R. Clark, E. Thompson, and M. Aguas-Alvarado. APF-45 × A-2286; crossed 2003; selected 2005; tested as APF-122; introd. 2015. USPP 27,401; 22 Nov. 2016. Fruit: size medium, $5.8 \mathrm{~g}$; round; $11.1^{\circ} \mathrm{Brix}$; first ripening on primocanes $1 \mathrm{Aug}$. in California; skin and flesh very firm; little color change (reversion) of drupelets in postharvest cold storage; for fresh consumption. Plant: thorny; erect; strongly primocane-fruiting; highly tolerant to powdery mildew (Podosphaera aphanis), anthracnose (Elsinöe veneta), crown gall (Agrobacterium tumefaciens), and botrytis (Botrytis cinerea).

APF-205T (Stark ${ }^{\circledR}$ Black Gem $\left.{ }^{\circledR}\right)$. Thornless, primocane-fruiting, erect plant with medium-large fruit and good flavor for home-garden or local fresh-market use. Origin: University of Arkansas, Fayetteville, AR, by J.R. Clark. APF-77 × APF-49T; crossed 2005; selected 2008; tested as APF-205T; introd. 2017. USPP applied for. Fruit: large, 7.9-11.5 g on primocanes, medium, 4.6-6.5 $\mathrm{g}$ on floricanes; ovate; up to $15.6{ }^{\circ}$ Brix for primocane, $10.0{ }^{\circ}$ Brix for floricane; $0.8 \%$ citric acid; firmness medium, soft or "melting" torus; first bloom of floricanes first to last week of April and third week of June for primocanes in Arkansas; for fresh consumption. Plant: thornless; erect; primocane-fruiting; good yield potential on floricanes, higher than Prime-Ark ${ }^{\circledR} 45$, in Arkansas; productivity substantially better for primocanes in areas with more moderate summers.

APF-236T (Baby Cakes ${ }^{\text {TM }}$ ). Thornless, primocane-fruiting, dwarf, erect plant and good fruit quality for home and container garden use. Origin: University of Arkansas, Fayetteville, AR, and Fall Creek Farm \& Nursery, Middle Fork Selections, Lowell, OR, by J.R. Clark and P.S. Boches. APF-120T $\times$ APF-132; crossed 2007; selected 2009; tested as APF-236T; introd. 2015. USPP 27,032; 9 Aug. 2016. Fruit: size medium, 6.4-7.0 g; oblong to slightly ovate; flavor sweet, $10.4{ }^{\circ}$ Brix, $1.02 \%$ citric acid; first bloom of floricanes 1 Apr. in Arkansas and 12 July for primocanes in Oregon; for fresh consumption. Plant: thornless; growth habit erect, dwarf, columnar due to shortened internode length; floricanes cold hardy to $-15{ }^{\circ} \mathrm{C}$.

\section{Baby Cakes ${ }^{\mathrm{TM}}$. See APF-236T.}

Black Cascade. Thornless, dwarf, primocane-fruiting blackberry for the home garden and landscape market. Origin: Hargreaves Plants, Kings Lynn, Norfolk, UK, by S. Belakov and J.R. Clark. APF-120T $\times$ APF-113; selected 2015. EU PVR applied for. Fruit: size medium. Plant: thornless; growth habit dwarf to spreading; primocanefruiting; intended for hanging basket and garden use.

\section{BlackJack $^{\text {TM }}$. See DrisBlackFifteen.}

Columbia Sunrise. Thornless trailing plant with excellent quality very early, large, uniformly shaped and sized, machine harvestable fruit. Origin: USDA-ARS, Corvallis, OR, by C.E. Finn, B.C. Strik, B.M. Yorgey, M.E. Peterson, P.A. Jones, and R.R. Martin. NZ 9629-1 $\times$ ORUS 1939-2; crossed 2005; selected 2008; tested as ORUS 3448-1; introd. 2017. USPP applied for. Fruit: large, $6.3 \mathrm{~g}$; conic; drupelets fairly uniformly sized, shaped and arranged; drupelet fertility excellent, uniform, and rated better than Marion; bright, glossy black; machine harvests easily; fresh fruit flavor very good, sweet; aroma good; sweet-acidic balanced, typical of western blackberries, $13.0{ }^{\circ} \mathrm{Brix}$; $\mathrm{pH} 3.4$; fairly low titratable acidity, $7.9 \mathrm{~g} \cdot \mathrm{L}^{-1}$ citric acid, as a processed product rated similar to Marion, Black Diamond, and Columbia Star; texture comparable to Marion and less crunchy than Chester Thornless; earliest ripening thornless cultivar, $10 \mathrm{~d}$ before Black Diamond and $14 \mathrm{~d}$ before Marion; firm enough to be sold fresh in regional markets. Plant: vigorous; growth habit trailing; thornless with the Lincoln Logan source of thornlessness; yield moderate; less susceptible to UV damage then Marion or Black Diamond; lateral length medium-long; machine harvests easily with clean fruit; not particularly susceptible to septoria leaf spot (Mycosphaerella rubi) and purple blotch (Septocyta ruborum); avoids spotted winged drosophila (Drosophila suzukii) with early ripening; cold hardiness not well tested, but appears 
hardier then Marion, but less hardy than Black Diamond or Chester Thornless.

DrisBlackEight. Thorny, upright to semi-upright, medium to high yielding, self-fruitful plant with long production season. Origin: Driscoll's, Watsonville, CA, by G.R. Sills, A.M. Pabon, and M. Crusha. BH934-7 × BH936-6; selected 2004. USPP 26,501; 15 Mar. 2016. Fruit: medium-large, $9.5 \mathrm{~g}$; long conical; $12.2^{\circ} \mathrm{Brix}$, $1.04 \%$ citric acid; firm; ripens early-midseason on floricanes, midJune to early October. Plant: thorny; growth habit upright to semiupright; yield medium to high.

DrisBlackNine. Thorny, upright, self-fruitful plant with long production season and high vigor. Origin: Driscoll's, Watsonville, CA, by G.R. Sills and A.M. Pabon. BK294 (460G1) × APF-40; selected 2006. USPP 26,774; 31 May 2016. Fruit: size medium, $4.4 \mathrm{~g}$; oblong; $11.5{ }^{\circ}$ Brix, $1.16 \%$ citric acid; ripens early on floricanes; ripens very late on primocanes; harvest midSeptember to mid-November. Plant: thorny; vigor high; growth habit upright; susceptible to red berry mite (Acalitus essigi) and botrytis.

DrisBlackTen. Thorny, upright to semi-upright; self-fruitful plant with high productivity and large berries. Origin: Driscoll's, Watsonville, CA, by G.R. Sills and A.M. Pabon. BK294 (460G1) × APF-40; selected 2006. USPP 26,611; 19 Apr. 2016. Fruit: large, 7.2 g; medium ovate; $10.8{ }^{\circ}$ Brix, $1.1 \%$ citric acid; ripens early on floricanes; ripens very late on primocanes; harvest mid-September to mid-November. Plant: thorny; growth habit upright to semiupright; productivity high.

DrisBlackEleven. Thorny; upright to semi-upright; medium to high vigor plant with medium size fruit and medium yield. Origin: Driscoll's, Watsonville, CA, by G.R. Sills, A.M. Pabon, and M. Crusha. BD467.1 × XX537.1; selected 2008. USPP 27,129; 6 Sept. 2016. Fruit: size medium, 7.4 g; elliptic; $11.4{ }^{\circ}$ Brix, $0.77 \%$ citric acid; ripens late on primocanes; harvest mid-August to midNovember. Plant: thorny; vigor medium to high; growth habit upright to semi-upright; yield medium.

DrisBlackTwelve (Chance ${ }^{\mathrm{TM}}$ ). Thornless, upright to semi-upright plant with medium size fruit and medium to high vigor and yield. Origin: Driscoll's, Watsonville, CA by G.R. Sills, A.M. Pabon, and M. Crusha. BM711 (858A5) × BJ111.1; selected 2008. USPP 27,746; 7 Mar. 2017. Fruit: size medium, 9.9 g; medium ovate; $9.3^{\circ}$ Brix; $0.91 \%$ citric acid; firmness medium; ripens July-October on primocanes. Plant: thornless; growth habit upright to semiupright; productivity medium.

DrisBlackThirteen (Elvira ${ }^{\mathrm{TM}}$ ). Thornless, semi-upright, medium to high productivity, self-fruitful plant with medium size berries. Origin: Driscoll's, Watsonville, CA, by G.R. Sills, A.M. Pabon, and M. Crusha. BP571 (259L4) × BP554 (252I5); selected 2009. USPP 27,681; 21 Feb. 2017. Fruit: size medium, 8.7 g; medium ovate; $10.5^{\circ}$ Brix; $0.41 \%$ citric acid; firmness medium to firm; ripens July-October on primocanes. Plant: thornless; growth habit semiupright; productivity medium to high; susceptible to verticillium wilt (Verticillium spp.).

DrisBlackFourteen. Thorny, upright to semi-upright, self-fruitful, high-yielding plant with medium-large fruit. Origin: Driscoll's, Watsonville, CA by G.R. Sills, A.M. Pabon, and M. Crusha. BM718.7 × BN804 (867G1); selected 2008. USPP 27,146; 13 Sept. 2016. Fruit: medium-large, $6.5 \mathrm{~g}$; medium ovate; $10.6^{\circ} \mathrm{Brix}, 0.66 \%$ citric acid; firmness medium; ripens late on primocanes; harvest midAugust to mid-November. Plant: thorny; growth habit upright to semi-upright; productivity medium; yield high; susceptible to verticillium wilt.
DrisBlackFifteen (BlackJack ${ }^{\mathbf{T M}}$ ). Thornless; semi-upright; self-fruitful; medium to high vigor plant with medium-large fruit. Origin: Driscoll's, Watsonville, CA, by G.R. Sills, A.M. Pabon, and M. Crusha. BF745.1 × BE543.2; selected 2005. USPP 27,130; 6 Sept. 2016. Fruit: medium-large, $8.1 \mathrm{~g}$; long conical; $11.8{ }^{\circ} \mathrm{Brix}, 0.92 \%$ citric acid; firmness medium; ripens medium to late on floricanes, mid-July to early September. Plant: thornless; growth habit semi-upright; productivity medium.

DrisBlackSixteen. Thorny, semi-upright to spreading, selffruitful, high-vigor plant with large, dark greyish-purple fruit. Origin: Driscoll's, Watsonville, CA, by G.R. Sills, J. Rodriguez Alcazar, A.M. Pabon, M.F. Crusha, R. Escobedo, and M. Bonifacio. DrisBlackFive $\times$ BL481.2; selected 2009. USPP 28,548; 24 Oct. 2017. Fruit: large, 11.6 g; long conical; soluble solids $12.1^{\circ}$ Brix; titratable acidity $0.96 \%$ citric acid; firm; dark greyish-purple; ripens April to May on floricanes; harvest early January to late May. Plant: thorny; vigor high; growth habit semi-upright to spreading; moderately susceptible to powdery mildew, susceptible to fusarium wilt (Fusarium oxysporum); moderately resistant to drought, high temperatures, and waterlogging.

Eclipse. Thornless semi-erect plant with medium-large, firm, dark fruit that ripen early for this type of blackberry. Origin: USDAARS, Corvallis, OR, by C.E. Finn, B.C. Strik, B.M. Yorgey, M.E. Peterson, P.A. Jones, and R.R. Martin. ORUS 1393-1 × Triple Crown; $1 / 4$ western trailing and $3 / 4$ eastern erect/semi-erect blackberry; crossed 2001; selected 2004; tested as ORUS 2816-4; introd. 2017. USPP applied for. Fruit: medium-large, 6.5 g; blockyconical; drupelets fairly uniformly sized, shaped and arranged, better than Chester Thornless; drupelet fertility excellent; uniform and attractively shaped; bright, glossy black; flavor very good, sweet, $13.9^{\circ}$ Brix; pH 3.4; titratable acidity fairly low, $9.9 \mathrm{~g} \cdot \mathrm{L}^{-1}$ as citric acid; texture less "crunchy" than other semi-erect cultivars; ripens with or before Navaho and Triple Crown, the midpoint is comparable to Navaho and 10-14 d before Chester Thornless and Triple Crown; firm, similar to Chester Thornless; stores very well. Plant: growth habit semi-erect to very erect; crown forming; thornless with the Merton Thornless source of thornlessness; vigorous; yield moderate, 6-7.2 $\mathrm{kg} /$ plant; less susceptible to UV and heat damage than many semi-erect cultivars despite $42{ }^{\circ} \mathrm{C}$ in California trials; susceptible to red berry mite; cold hardiness very good, has shown no injury in 10 seasons despite temperatures below $-20{ }^{\circ} \mathrm{C}$.

\section{Elvira $^{\text {TM }}$. See DrisBlackThirteen.}

Galaxy. Thornless semi-erect plant with large, firm, dark fruit that ripen early for this type of blackberry. Origin: USDA-ARS, Corvallis, OR, by C.E. Finn, B.C. Strik, B.M. Yorgey, M.E. Peterson, P.A. Jones, and R.R. Martin. ORUS 1393-1 $\times$ Triple Crown; $1 / 4$ western trailing and $3 / 4$ eastern erect/semi-erect blackberry; crossed 2000; selected 2003; tested as ORUS 2711-1; introd. 2017. USPP applied for. Fruit: large, $7.5 \mathrm{~g}$; blocky-conic to barrel; drupelets fairly uniformly sized, shaped and arranged, better than Chester Thornless but not as nice as Eclipse; drupelet fertility excellent; uniform and attractively shaped; bright, glossy black; flavor very good, sweet, $12.8^{\circ} \mathrm{Brix} ; \mathrm{pH} 3.5 ; 10.6 \mathrm{~g} \cdot \mathrm{L}^{-1}$ citric acid; texture less "crunchy" than other semi-erect and erect cultivars; ripens with Loch Ness and 5-10 d before Navaho; stores very well. Plant: growth habit semi-erect to erect; crown forming; thornless with the Merton Thornless source of thornlessness; vigorous; yield moderate, $6.8-8.3 \mathrm{~kg} /$ plant; less susceptible to UV and heat damage than many semi-erect cultivars despite $42{ }^{\circ} \mathrm{C}$ in California trials, susceptible to red berry mite; dry drupelet disorder, caused by anthracnose, was a problem in trials in Arkansas; very good cold hardiness, has shown no injury in 10 seasons despite temperatures below $-20{ }^{\circ} \mathrm{C}$. 
Hall's Beauty. Thornless trailing plant, machine harvestable, high-quality blackberry that has extremely large, attractive and ornamental flowers with double petals that produce large, wellformed berries for fresh or processed fruit markets. Origin: USDA-ARS, Corvallis, OR, by C.E. Finn, B.C. Strik, B.M. Yorgey, M.E. Peterson, P.A. Jones, and R.R. Martin. NZ 9629R$1 \times$ ORUS 1939-2; crossed 2005; selected 2008; tested as ORUS 3453-2; introd. 2017. USPP applied for. Fruit: large, $6.5 \mathrm{~g}$; conical; drupelets uniformly sized, shaped and arranged; drupelet fertility excellent; uniform, attractively shaped and rated comparable to Black Diamond but not as uniform as Columbia Star; bright, glossy black; machine harvests easily; flavor very sweet, $13.6^{\circ} \mathrm{Brix} ; \mathrm{pH} 3.3 ; 14.3 \mathrm{~g} \cdot \mathrm{L}^{-1}$ citric acid; aroma typical of western blackberries; as a processed product rated similar to Columbia Star and Marion; texture comparable to Marion and less crunchy than Chester Thornless; ripens early, with or slightly before Columbia Star, 5-7 d before Marion, and $45 \mathrm{~d}$ before Chester Thornless; firm enough to be sold fresh in regional markets. Plant: thornless, with the Lincoln Logan source of thornlessness; vigorous; growth habit trailing; yield moderate, 4.8-6.8 kg/plant; less susceptible to UV damage than Marion or Black Diamond; lateral length medium-long; machine harvests easily with clean fruit; not particularly susceptible to septoria leaf spot and purple blotch; avoids spotted winged drosophila with early ripening; hardiness not well tested but appears to be similar to Black Diamond, more hardy than Marion, and less hardy than Chester Thornless; ornamental flowers deep pink in bud stage and open with $10-20$ petals reaching a diameter of $5 \mathrm{~cm}$.

Mizao. Thornless, floricane-fruiting semi-upright plant, high yield, early season, recommended for processing. Origin: Institute of Botany, Jiangsu Province and Chinese Academy of Sciences, Nanjing, Jiangsu, China, by W.L. Wu, W.L. Li, L.F. Lyu, C.H. Zhang, H.Y. Yang, and H.F. Zhao. Kiowa $\times$ Hull Thornless; crossed 2006; selected 2009; tested as 5-8-2; introd. 2014. Su 2015-2-36; 30 Dec. 2015. Fruit: medium-large; round; flavor sweet, 10.0-11.0 ${ }^{\circ}$ Brix; $0.8-0.9 \%$ citric acid; firmness medium; bright, glossy black; easily removed from receptacle; ripening early- to midseason; recommended for machine harvesting for processing. Plant: thornless; vigor high; growth habit semi-upright; diseaseresistant and has very good field tolerance to root rot (Phytophthora fragariae var. rubi).

Shuofeng. Thornless, floricane-fruiting semi-upright plant with firm fruit, high yield, recommended for processing or fresh market. Origin: Institute of Botany, Jiangsu Province and Chinese Academy of Sciences, Nanjing, Jiangsu, China, by W.L. Wu, W.L. Li, L.F. Lyu, C.H. Zhang, H.Y. Yang, and H.F. Zhao. Kiowa $\times$ Hull Thornless; crossed 2006; selected 2010; tested as 6-6-3; introd. 2014. Su R-SV-RS-013-2014; 1 Dec. 2014. Fruit: medium-large; round; bright black; flavor tart to sweet, $9.8{ }^{\circ}$ Brix; $1.33 \%$ citric acid; firmness good; easily removed from receptacle; ripening mid- to late-season; recommended for machine harvesting for processing. Plant: thornless; vigor high; growth habit semi-upright; disease-resistant and has very good field tolerance to root rot.

Stark $^{\circledR}$ Black Gem $^{\circledR}$. See APF-205T.

\section{BLUE HONEYSUCKLE}

\section{Kim E. Hummer, USDA-ARS,National Clonal Germplasm Re- pository, Corvallis, OR}

Chito. High yield, vigorous, open habit, midseason ripening haskap, tart/sweet and firm, for fresh, frozen, dried, or processed use. Origin: Corvallis, OR, by M.M. Thompson. Lonicera caerulea Chitose selection O.P.; seed collected 2000; selected 2004; tested as 41-75; introd. 2016. USPP 28,663; 21 Nov. 2017; CPBR pending. Fruit: medium-large; ovoid; skin blue, bloom medium; firmness medium; ripens midseason, 12 June in Corvallis; flavor tart/sweet, 13-14 ${ }^{\circ}$ Brix; berry scar small; attachment medium; non-tearing skin; retains firmness and taste 3 weeks in cold storage. Plant: vigorous; flowers frost tolerant; cold hardy USDA Zones 4; yield $3.9 \mathrm{~kg} / 10$-year bush.

Hoka. Medium yield, short stature, very early ripening haskap, sweet/tart and firm, for home garden use and limited space. Origin: Corvallis, OR, by M.M. Thompson. L. caerulea \#8 O.P.; seed collected 2000; selected 2004; introd. 2016. USPP 28,593; 7 Nov. 2017; CPBR pending. Fruit: medium-large; cylindrical; skin blue; ornamental; firmness medium; ripens early, 10 June in Corvallis; flavor sweet/tart; $15-16^{\circ}$ Brix; berry scar small; attachment medium; reduced preharvest drop; non-tearing skin; retains firmness and taste 4 weeks in cold storage. Plant: short; flowers white, frost tolerant; cold hardy USDA Zones 4; yields $2.8 \mathrm{~kg} / 10$-year bush.

Kaido. High yield, short stature, early ripening haskap, sweet/tart and firm, for home garden use. Origin: Corvallis, OR, by M.M. Thompson. L. caerulea \#22-64 O.P.; seed collected 2000; selected 2007; introd. 2016. USPP 28,662; 21 Nov. 2017; CPBR applied for. Fruit: medium-large; cylindrical; skin blue, bloom white; firmness medium; ripens early, 13 June in Corvallis; flavor sweet/tart, 13-14 ${ }^{\circ}$ Brix; berry scar small; attachment medium; non-tearing skin; retains firmness and taste 4 weeks in cold storage. Plant: short; vigorous; growth habit upright-spreading; flowers frost tolerant; adapted well in USDA Zone $8 \mathrm{~b}$, expected hardy to Zone 4; no significant diseases or pest problems observed; yields $2.2 \mathrm{~kg} / 7$-year bush.

Kapu. High yield, vigorous, frost tolerant, midseason ripening haskap, sweet/tart and firm, with potential for fresh, dried, or processed use. Origin: Corvallis, OR, by M.M. Thompson. L. caerulea Bibai \#8 O.P.; seed collected in 2000; selected 2004; introd. 2016. USPP 26,820; 21 Nov. 2017; CPBR pending. Fruit: medium-large; ovoid; skin blue, bloom heavy white; very firm; ripens early midseason, 21 June in Corvallis; flavor sweet/tart, 14-15 ${ }^{\circ}$ Brix; berry scar small; attachment medium; non-tearing skin; retains firmness and taste 4 weeks in cold storage. Plant: vigorous; growth habit upright and spreading; flowers frost tolerant; cold hardy USDA Zones 4; minor damage from Botrytis sp., but no significant pest problems observed.

Kawai. High yield, vigorous, early ripening haskap, with sweet/ tart, persistent fruit. Origin: Corvallis, OR, by M.M. Thompson. L. caerulea \#21-78 $\times$ L. caerulea \# 41-75; crossed 2006; selected 2009; tested as 108-42; introd. 2016. USPP 28,664; 21 Nov. 2017; CPBR pending. Fruit: size medium; ovate-rectangular with a blunt concave apex, skin blue, bloom white; firmness medium; flavor sweet/tart, $13-15{ }^{\circ}$ Brix; fruit persistent; ripens early midseason, 7 June in Corvallis, 7-12 d before Kapu or Keiko. Plant: vigorous; growth habit upright-spreading; flowers frost tolerant; adapted well in USDA Zone $8 \mathrm{~b}$, expected hardy to Zone 4; no significant diseases or pest problems observed; yields high, $3.6 \mathrm{~kg} / 8$-year bush

Keiko. High yield, vigorous, late ripening haskap with frost-tolerant flowers; sweet/tart, firm, stores well. Origin: Corvallis, OR, by M.M. Thompson. L. caerulea Bibai \#8 O.P.; seed collected in 2000; selected 2004; tested as 22-26; introd. 2016. USPP 26,642; 26 Apr. 2016; CPBR pending. Fruit: medium-large; ovoid; skin blue, bloom white; firmness medium; flavor sweet/tart; $13-14{ }^{\circ}$ Brix, attachment medium; non-tearing skin; retains firmness and taste 4 weeks in cold storage; ripens early midseason, 17 June in Corvallis. Plant: vigorous; growth habit upright-spreading; flowers frost tolerant; adapted well in USDA Zone 8b, expected hardy to Zone 4; no significant diseases or pest problems observed; yields high, $3.4 \mathrm{~kg} / 7$-year bush. 
Kuchi. High yield, vigorous, upright, midseason ripening haskap, sweet/tart and firm, for fresh, frozen, and processed use. Origin: Corvallis, OR, by M.M. Thompson. L. caerulea Bibai \#8 O.P.; seed collected in 2000; selected 2004; introd. 2016. USPP 28,622; 14 Nov. 2017; CPBR pending. Fruit: medium-large; elongate; skin blue, bloom white; ovoid; medium firm; flavor sweet/tart, 12-13 ${ }^{\circ}$ Brix; attachment medium; non-tearing skin; retains firmness and taste 3 weeks in cold storage; ripens midseason, 11 June in Corvallis. Plant: vigorous; growth habit upright; flowers frost tolerant; cold hardy USDA Zones 4; no significant diseases or pest problems observed; yields high, $3.5 \mathrm{~kg} / 10$-year bush.

Pirika. Medium yield, vigorous, open branching, midseason ripening haskap; large, mild tasting, jug shaped, firm, sweet, with potential for fresh, frozen, or processed use. Origin: Corvallis, OR, by M.M. Thompson. L. caerulea 21-20 × L. caerulea \# 21-78; crossed in 2004; selected 2008; tested as 88-102; introd. 2016. USPP and CPBR applied for. Fruit: medium-large; ovoid; skin blue, bloom medium; medium firm; flavor sweet, $14-15^{\circ} \mathrm{Brix}$; berry scar small; attachment medium, reduced preharvest drop; non-tearing skin; retains firmness and taste 2 weeks in cold storage; ripens midseason, 12 June in Corvallis. Plant: vigor high; growth habit open; flowers frost tolerant; cold hardy USDA Zones 4 to 8; no pest or disease problems observed; yield $2.1 \mathrm{~kg} / 6$-year bush.

Willa. Medium yield, moderate vigor, open branching, early ripening haskap; large, mild taste, round, firm, sweet, early ripening, for fresh, frozen, or processed use. Origin: Corvallis, OR, by M.M. Thompson. L. caerulea 19-27× L. caerulea \# 20-04; crossed in 2004; selected 2008; tested as 57-49; introd. 2016. USPP and CPBR applied for. Fruit: large; round, small neck at base; skin blue, bloom white; medium firm; flavor sweet, 15-16 ${ }^{\circ}$ Brix; attachment medium, non-tearing skin; retains firmness and taste 2 weeks in cold storage; ripens early, 5 June in Corvallis. Plant: vigor high; growth habit open; flowers frost tolerant; cold hardy USDA Zones 4 to 8 ; no pest or disease problems observed; yield $1.6 \mathrm{~kg} / 4$-year bush.

\section{BLUEBERRY}

Mark K. Ehlenfeldt, USDA-ARS, Genetic Improvement of Fruits and Vegetables Laboratory, Beltsville, MD

A132-926 (Colibri $\left.^{\circledR}\right)$. Low-chill southern highbush, potentially selffruitful without pollination. Origin: Hartmann's Nursery, Grand Junction, MI, by D.S. Hartmann. Misty $\times$ Sharpblue; crossed 2005. USPP 27,895; 28 Apr. 2016. Fruit: large; firm; picking scar small; earliest fruiting among most commercial cultivars; ripens $10 \mathrm{~d}$ before Star; large fruits ripen uniformly; can be stored $21 \mathrm{~d}$ at $0.5-4.4{ }^{\circ} \mathrm{C}$; pollinated and non-pollinated fruits are approximately the same size, thus suitable for greenhouse production. Plant: multi-stemmed, erect shrub; growth habit spreading to $1.1 \mathrm{~m}$; flowers freely without the use of growth regulating chemicals; chilling requirement $150 \mathrm{~h}$; stems cold tolerant to $-23^{\circ} \mathrm{C}$; adapted to a wide variety of tropical to subtropical climates; propagation by softwood cuttings and in vitro.

Arcadia $^{\text {TM }}$. See FL07-399.

AtlasBlue $^{\mathrm{TM}}$. See FCM12-045.

Avanti $^{\text {TM }}$. See FL06-203.

BiancaBlue $^{\text {TM }}$. See FCM12-087.

Bountiful Blue $^{\circledR}$. See FLX-2.

Cabernet Splash ${ }^{\text {TM }}$. See VacBri1.
Chaoyue 1. Early to midseason southern highbush blueberry suitable for Southern China. Origin: Institute of Botany, Jiangsu Province \& Chinese Academy of Sciences, Nanjing, China, by Y. Jiang, J. Wei, Q. Zeng, G. Zhang, J. Yang, H. Yu, and D. Zhang. Southmoon O.P.; collected 2003; selected 2004; tested as A119. CNPVP 20170033 (approved by the State Forestry Administration Office for the Protection of New Varieties of Plants). Fruit: size medium; medium to dark blue; picking scar large, dry; firmness very good; flavor excellent; generally ripens with Star in Nanjing. Plant: vigorous; growth habit upright; $\sim 1.5 \mathrm{~m}(\mathrm{~h}) \times \sim 1.2 \mathrm{~m} \mathrm{(w)}$; flowers with Star; yield $\geq$ Star in Nanjing; resistance to waterlogging moderate-high in Southern China.

Colibri $^{\circledR}$. See A132-926.

Corablue. Compact ornamental $V$. myrsinites $-V$. corymbosum hybrid with vigorous growth, glossy leaves, and drought tolerance. Origin: Hawthorne, FL, by D. Dickerson. Unpedigreed seedling believed to be a hybrid of $V$. myrsinites and $V$. corymbosum; selected 2006. USPP 22,521; 28 Feb. 2012. Fruit: deep reddish purple; average $1.2 \mathrm{~cm}$. Plant: vigorous; growth habit semi-upright; deciduous; $\sim 45 \mathrm{~cm}(\mathrm{~h})$ x $60 \mathrm{~cm}(\mathrm{w})$; foliage highly glossy, glabrous; propagation by semi-hardwood cuttings.

Cutie Pie ${ }^{\mathrm{TM}}$. See TO-1088.

EB 8-50. Early-season highbush with large fruit, suitable for Western Australia. Origin: Joondalup, Australia, by V.D. Mazzardis. 03-2 $\times$ SB-1; crossed 2005; selected 2008. USPP 28,357; 5 Sept. 2017. Fruit: large to very large, $\sim 5 \mathrm{~g}$; round; picking scar small, dry; flavor excellent; firm; sweet; acidity low; ripens early; stores well. Plant: growth habit semi-upright; flowers early.

EB 9-2. Very early-season highbush with large fruit, suitable for Western Australia. Origin: Joondalup, Australia, by V.D. Mazzardis BB-1 × 03-2; crossed 2006; selected 2009. USPP 28,149; 4 July 2017. Fruit: large to very large; oblate; firm; flavor excellent; ripens very early. Plant: growth habit upright to semi-upright; flowers very early.

EB 9-4. Very early-season highbush with very large fruit, suitable for Western Australia. Origin: Joondalup, Australia, by V.D. Mazzardis. BB-1 × 99-4; crossed 2006; selected 2009. USPP 28,334; 29 Aug. 2017. Fruit: large to very large, $\sim 4.7 \mathrm{~g}$; slightly flat; very sweet; acidity low; flavor excellent; ripens very early; stores well. Plant: vigor average; growth habit semi-upright; flowers very early.

EB 9-12. Early-season highbush with large to very large fruit and very good flavor, suitable for Western Australia. Origin: Joondalup, Australia, by V.D. Mazzardis. BB-2 × 03-6; crossed 2006; selected 2009. USPP 28,358; 5 Sept. 2017. Fruit: large to very large, $\sim 2.9 \mathrm{~g}$; slightly flat; firm; flavor very good; very sweet; ripens early. Plant: growth habit semi-upright; flowering very early.

EB 10-1. Medium- to late-ripening highbush with large to very large fruit, suitable for Western Australia. Origin: Joondalup, Australia, by V.D. Mazzardis. 7-13 × 7-30; crossed 2007; selected 2010. USPP 28,217; 25 July 2017. Fruit: large to very large, $\sim 5.6 \mathrm{~g}$; oblate; firm; sweet; acidity low; flavor excellent; ripens medium to late. Plant: vigor medium to strong; growth habit semi-upright to intermediate.

Echo. Ornamental remontant blueberry with a spring and summer crop of small-medium size berries on a compact bush with attractive, glossy, dark green leaves. Origin: USDA-ARS, Horticultural Crops Research Unit, Corvallis, OR, by C.E. Finn, T. Mackey, B.C. Strik, and R.R. Martin. Perpetua $\times$ ORUS 55-1; selected 2010; tested as ORUS 289-1; introd. 2017. USPP applied for. Fruit: small-medium; uniform; somewhat oblong; medium blue; moderately soft; flavor mild; picking scar wet; $1^{\text {st }}$ crop ripens earlier than Duke's, and $2^{\text {nd }}$ 
crop ripens basipetally on new growth, typically 10-12 nodes, beginning in early-mid-August. Plant: vigor moderate; growth habit compact; attractive; foliage extremely dark green, lustrous; combination of flowers, ripe fruit and attractive foliage in late summer to fall is particularly desirable.

\section{Endura $^{\text {TM }}$. See FL06-377.}

FCM12-038. Very early-season southern highbush for the handharvest fresh market; low-chill or evergreen production. Origin: Fall Creek Farm and Nursery, Lowell, OR, by D.M. Brazelton, A.L. Wagner, P.S. Boches, and A.A.A. Bermudo. FF03-158 × FL01-06; crossed 2008; selected 2012; tested as FCM12-038. USPP applied for. Fruit: large, average $2.2 \mathrm{~g} ; 20.2 \mathrm{~mm}$; oblate; firm; picking scar small; medium-dark; ripens $\sim 6$ mo. after pruning in Tala, Mexico, with two picks of semi-concentrated production; earlier and more uniform than Biloxi. Plant: growth habit upright; internodes widely spaced; flowers quickly after pruning; self-fertile.

FCM12-045 (AtlasBlue ${ }^{\text {TM}}$ ). High-quality southern highbush for the hand-harvest fresh market; low-chill or evergreen production. Origin: Fall Creek Farm and Nursery, Lowell, OR, by D.M. Brazelton, A.L. Wagner, P.S. Boches, and A.A.A. Bermudo. FF$128 \times$ ZF04-002; crossed 2008; selected 2012; tested as FCM12-045. USPP applied for. Fruit: size medium, average $2.0 \mathrm{~g}, 16 \mathrm{~mm}$; uniform; medium blue; flavor mild aromatic; firmness good; picking scar small; ripens around Biloxi with a semi-concentrated peak of production $\sim 7$ months after pruning in Tala, Mexico. Plant: vigorous; growth habit round; yield high.

FCM12-087 (BiancaBlue $^{\text {TM}}$ ). Late-season southern highbush for the hand-harvest fresh market; low-chill or evergreen production. Origin: Fall Creek Farm and Nursery, Lowell, OR, by D.M. Brazelton, A.L. Wagner, P.S. Boches, and A.A.A. Bermudo. FL00-180 × FF-124; crossed 2008; selected 2012; tested as FCM12-087. USPP 29,287; 15 May 2018. Fruit: medium to large, average $18 \mathrm{~mm}$; high quality; light blue; flavor sweet and mild; ripens after Biloxi. Plant: vigor medium; bush shape round; readily produces suckers and new canes from crown; leaves dark green.

FCM12-097. Early-season southern highbush for the hand-harvest fresh market; low-chill or evergreen production. Origin: Fall Creek Farm and Nursery, Lowell, OR, by D.M. Brazelton, A.L. Wagner, P.S. Boches, and A.A.A. Bermudo. FF03-194 × FL00-180; crossed in 2008; selected 2012; tested as FCM12-097. USPP 28,437; 26 Sept. 2017. Fruit: large to very large, average $18.3 \mathrm{~mm}$; firm; flavor good; picking scar small; harvest starts with primocane fruiting 5 months after pruning, and ripe full crop $\sim 7$ months after pruning in Tala, Mexico. Plant: vigor low; growth habit moderately branched; flowering continuous in evergreen production systems.

FCM12-131 (JupiterBlue ${ }^{\text {TM}}$ ). Early-season southern highbush for the hand-harvest fresh market; low-chill or evergreen production. Origin: Fall Creek Farm and Nursery, Lowell, OR, by D.M. Brazelton, A.L. Wagner, P.S. Boches, and A.A.A. Bermudo. ZF04-002 × FL95-138; crossed 2009; selected 2012; tested as FCM12-131. USPP applied for. Fruit: size average 2.4 g vs. $1.2 \mathrm{~g}$ for Biloxi; light blue; picking scar small; flavor slightly tart and mild; firmness good; self-fertility good; ripens $\sim 6$ months after pruning in Tala, Mexico. Plant: vigor moderate; bush shape round or semierect; concentrated bloom following pruning; leaf color blue-green.

FF03-015 (CristinaBlue ${ }^{\text {TM}}$ ). Early-season southern highbush intended for the hand-harvest fresh market; low-chill or evergreen production. Origin: Fall Creek Farm and Nursery, Lowell, OR, by D.M. Brazelton, A.L. Wagner, P.S. Boches, and A.A.A. Bermudo, and P.M. Lyrene. FL95-52 $\times$ Sunshine Blue; crossed 2000; selected 2010; tested as FF03-015. USPP applied for. Fruit: size medium, $\sim 15 \mathrm{~mm}$; round to oblate; large for early season; light blue; balanced sugar-acid when ripe; picking scar small. Plant: vigorous; bush shape round to upright; self-fertile; leafing good.

FF03-178. Very early-season southern highbush for the handharvest fresh market; low-chill or evergreen production. Origin: Fall Creek Farm and Nursery, Lowell, OR, by D.M. Brazelton, A.L. Wagner, P.S. Boches, A.A.A. Bermudo, and P.M. Lyrene. FL00-63 $\times$ FL96-24; crossed 2000; selected 2003; tested as FF03-178. USPP 28,995; 27 Feb. 2018. Fruit: large, average $17.2 \mathrm{~mm}$; oblate; flavorful; moderately dark; very firm; calyx shallow. Plant: vigor low to moderate; bush shape round; readily produces suckers; leafing excellent.

FL03-228. Southern highbush suitable for fresh markets. Origin: Florida Foundation Seed Producers, Marianna, FL, by P. Lyrene. FL00-30 × Farthing; crossed 2000; selected 2003. USPP 27,576; 24 Jan. 2017. Fruit: large, 2.9 g; sweet; low-acid; very firm; picking scar small, dry; juicy; seeds small; ripening concentrated from late March through April under evergreen horticultural practices in Morocco; 50\% ripens around 30 Mar. Plant: vigorous; growth habit upright-spreading bush; vigor medium; chilling requirement low; propagated by softwood cuttings.

FL06-203 (Avanti $^{\text {TM}) . ~ V e r y ~ l o w-c h i l l, ~ e v e r g r e e n ~ s o u t h e r n ~ h i g h-~}$ bush. Origin: Florida Foundation Seed Producers, Marianna, FL, by P. Lyrene and J. Olmstead. FL02-12 × Farthing; crossed 2002; selected 2006; tested as FL06-203; introd. 2015. USPP 26,312; 19 Jan 2016. Fruit: large; very sweet; flavor good; firm; picking scar small, dry. Plant: vigorous; growth habit upright-spreading; blooms early; yield excellent; propagates readily from softwood; crosspollination required; chilling requirement 150-200 h.

FL06-377 (Endura $^{\text {TM }}$ ). Very low-chill, evergreen southern highbush. Origin: Florida Foundation Seed Producers, Marianna, FL, by P. Lyrene and J. Olmstead. FL03-19 × FL99-37; crossed 2003; selected 2006; tested as FL06-377; introd. 2015. USPP 26,679; 3 May 2016. Fruit: large; very firm; very sweet; flavor good; picking scar small, dry. Plant: vigorous; growth habit upright-spreading; prolific early leafing; leaf retention excellent in evergreen system; yield excellent; propagates readily from softwood; cross-pollination required; chilling requirement $150-200 \mathrm{~h}$.

FL06-556 (Keecrisp ${ }^{\mathrm{TM}}$ ). Early-midseason southern highbush with extremely firm, crisp texture. Origin: Florida Foundation Seed Producers, Marianna, FL, by P. Lyrene. Sweetcrisp $\times$ FL98-325 (Indigocrisp $^{\mathrm{TM}}$ ); crossed 2003; selected 2006; tested as FL06-556; introd. 2016. USPP 27,771; 14 Mar. 2017. Fruit: very large; crisp; extremely firm; picking scar excellent; very sweet; texture excellent. Plant: vigorous; growth habit upright; chilling requirement $300 \mathrm{~h}$; requires cross-pollination; propagates readily from softwood.

FL07-399 (Arcadia ${ }^{\text {TM}}$ ). Very low-chill, evergreen southern highbush. Origin: Florida Foundation Seed Producers, Marianna, FL, by J. Olmstead and P. Lyrene. FL03-79 × Scintilla; crossed 2003; selected 2007; tested as FL07-399; introd. 2015. USPP 26,313; 19 Jan. 2016. Fruit: large; sweet; flavor good; firm; picking scar small, dry. Plant: vigorous; growth habit upright-spreading; prolific early leafing; excellent leaf retention in evergreen system; yield excellent; propagates readily from softwood; cross-pollination required; chilling requirement $150-200 \mathrm{~h}$.

FLX-2 (Bountiful Blue ${ }^{\circledR}$ ). Ornamental hybrid patio plant with attractive form and foliage, and edible berries for pots or inground culture. Origin: Micanopy, FL, by P.M. Lyrene. FL92-9 $\times$ Sunshine Blue; crossed 1992; selected 1994. USPP 19,381; 28 Oct. 2008. Fruit: size medium; light blue; flavor and texture excellent; ripens mid-April through mid-May in central and north Florida. Plant: vigorous; growth habit intermediate between upright and spreading; $\sim 1.6 \mathrm{~m} \mathrm{(h)} \mathrm{x} \sim 1.7 \mathrm{~m} \mathrm{(w)}$; leaves blue-gray, smaller than 
typical southern highbush; evergreen to semi-evergreen; chilling requirement $200-300 \mathrm{~h}$; flowers early; hardy to $-15^{\circ} \mathrm{C}$ during winter dormancy; propagated by softwood cuttings.

Granite $^{\mathrm{TM}}$. See OBF0627.

Gumbo. Midseason southern highbush for fresh markets and home gardens. Origin: USDA-ARS, Poplarville, MS, by S.J. Stringer and A.D. Draper. Cara's Choice $\times$ MS 6; crossed 2000; selected 2003. USPP applied for. Fruit: size medium, $2.1 \mathrm{~g}$; light blue; firmness and flavor good; picking scar small; resistant to rain-induced splitting; blooms and ripens 7-10 d after Star in Poplarville. Plant: vigorous; growth habit upright; crowns small-medium; foliage dark green; spring leafing excellent; easily propagated; productivity medium; requires cross-pollination for maximum yields; chilling requirement $350-400 \mathrm{~h}$.

Huiwang No. 1. Cold-resistant northern highbush. Origin: Nanling County, Anhui, China, by Z. Ye, J. Fan, B. Jia, S. Fan, and L. Zhu. Clonal variant of O'Neal; selected 2008. Anhui Forest Variety Certification Committee in 2014. Fruit: flat-round, $\sim 2.3 \mathrm{~g}$; $12 .{ }^{\circ}$ Brix; titratable acidity $1.82 \%$; fruit development period $\sim 50 \mathrm{~d}$; ripens mid-late May in the Yangtze River District in Anhui Province. Plant: crown open; cold hardy.

Jaac. Large, oblate, sweet and crisp highbush. Origin: L.A. Jordan and J. Jordan, Gordonton, Waikato, New Zealand. Seedling of unknown parentage selected from a commercial field planting of Sunset Blue in 2014. USPP 27,658; 14 Feb. 2017. Fruit: large, $\sim 2.5$ g; oblate; color strong blue; sweet, $16^{\circ} \mathrm{Brix}$; texture crisp; ripens $1 \mathrm{Feb}$. to 1 May. Plant: vigor good, $\sim 1.2 \mathrm{~m} \mathrm{(h)} \mathrm{x} \sim 1.0 \mathrm{~m} \mathrm{(w);} \mathrm{growth} \mathrm{habit}$ upright with erect multiple canes; bloom abundant; propagated by softwood cuttings.

\section{JupiterBlue $^{\text {TM }}$. See FCM12-131.}

\section{Keecrisp $^{\mathrm{TM}}$. See FL06-556.}

Masena. See Ridley 4408.

OBF0627 (Granite ${ }^{\text {TM}}$ ). Midseason northern highbush with extremely firm fruit and concentrated ripening. Origin: Oregon Blueberry Farms and Nursery, Silverton, OR, by R. Gabriel. Parentage unknown. USPP 26,597; 12 Apr. 2016. Fruit: extremely firm; medium sweet; flavor floral; picking scar small, dry; ripening concentrated; excellent for mechanical harvest; shelf life long; ripening mid- to late-season. Plant: growth habit upright, moderately spreading, compact; chilling requirement $\sim 1000 \mathrm{~h}$; propagation by stem-tip cuttings.

Patrecia. Low-chill southern highbush. Origin: Florida Foundation Seed Producers, Marianna, FL, by D. Norden and A. Straughn. Star $\times$ Springhigh; crossed 2007; selected 2009; tested as UF 52-20; introd. 2016. USPP 27,740; 7 Mar. 2017. Fruit: very large; firmness good; sweet; ripens $10 \mathrm{~d}$ before Star, similar to Springhigh. Plant: vigorous; growth habit very upright; survival in the field excellent; chill requirement $300 \mathrm{~h}$; fruit development period short; propagates readily from softwood.

\section{Radiance. See Ridley 4609.}

Ridley 1812 (Twilight). Late-season southern highbush with very large, firm fruit and good storage characteristics. Origin: Mountain Blue Orchards, New South Wales, Australia, by R. Bell and A. Alamo. S01-28-01 × S01-23-01; crossed 2005; selected 2007; tested as M07-18-12. USPP applied for. Fruit: very large, 3.1-3.9 g; picking scar small, dry; firm; flavor sweet; acidity medium; ripening late; grown as an evergreen; does not shake well; more suited to hand harvest; suitable for fresh market. Plant: vigorous; growth habit upright; very tough; flowers late; bloom strong; self-fertile for block planting; can be crossed with other late varieties; yield medium to high, 4-5 kg/bush on 4-year plants; propagation by softwood cuttings or in vitro.

Ridley 4408 (Masena). Early to midseason southern highbush with large crisp fruit, for evergreen culture. Origin: Mountain Blue Orchards, New South Wales, Australia, by R. Bell. S01-15-01 $\times$ C00-009; crossed 2008; selected 2011; tested as M11-44-08. USPP applied for. Fruit: large, 2.5-3.0 g; bloom strong; picking scar very small, dry; very firm with a distinct crunch; flavor high; sweet; acidity medium; storage excellent; ripens early to midseason; grown as an evergreen; shakes well for mechanical harvesting; suitable for fresh market. Plant: vigor high; growth habit upright; flowers early to midseason; self-fertile; can be cross-pollinated by early and midseason cultivars; yields 7.5-8.5 kg/bush on 3-year plants; propagation by softwood cuttings or in vitro.

Ridley 4609 (Radiance). Late-season southern highbush with large fruit and very pleasant aromatic flavor. Origin: Mountain Blue Orchards, New South Wales, Australia, by R. Bell. C95-152 × C00-009; crossed 2006; selected 2008; tested as M08-46-09. USPP applied for. Fruit: large, 2-3 g; bloom good; picking scar dry; sweet; flavorful; acidity medium; firmness medium; ripens late; suitable for fresh market; not suited to mechanical harvest. Plant: vigorous; growth habit upright; round; tough; self-fertile; crosses well with Legacy and Twilight; yields $\sim 6.0 \mathrm{~kg} /$ bush on 3-year bushes; propagation by softwood cuttings.

Rosa's Blush. Ornamental $V$. darrowii selection with bright pink new growth in spring. Origin: Central FL, by S. Riefler. Pedigree unknown; selected, from native seed collected in Central Florida; released $\sim 2004$. Fruit: small, $\sim 9 \mathrm{~mm}$; edible; dark blue; ripens May-June. Plant: growth habit low-growing, compact, potentially reaching $0.9 \mathrm{~m}$ tall and wide; foliage evergreen, fine-textured; flowers light pink, bell-shaped in early spring; foliar shoots bright pink in spring, maturing to a dusty blue-green with hints of pink in summer; deep purplish-blue in fall; cold hardy USDA Zone 8.

Scarlet Ovation. See Vacsid1.

SMN-72 (Senmao No. 1). Early-season northern highbush for fresh market. Origin: Dalian Senmao Modern Agriculture Co., Dalian, China, by H. Wang and G. Xu. Patriot O.P.; seed sown 2008; selected 2013. NPNVRC applied for (20160102). Fruit: large to very large, average $4.5 \mathrm{~g}$, maximum $6.6 \mathrm{~g}$; dark blue; flavor good; sweetness medium; acidity medium to high; firmness medium-firm; stores well; ripens early. Plant: vigorous; growth habit upright; flowers early; recommended for hand harvest; self-fertile, but likely benefits from cross-pollination.

SMN-86 (Senmao No. 2). High-yielding, early-season northern highbush for fresh market. Origin: Dalian University and Dalian Senmao Modern Agriculture Co., Dalian, China, by Y. Chen and G. Xu. Sunrise O.P.; seed sown 2008; selected 2013. NPNVRC applied for (20160103). Fruit: large to very large, average $3.2 \mathrm{~g}$, maximum $4.2 \mathrm{~g}$; dark blue; flavor very good; sweet; acidity low; firmness high; stores very well. Plant: vigorous; growth habit very spreading; yield high; recommended for machine or hand harvest; self-fertile, but attains maximum yields with cross-pollination.

SMN-461 (Senmao No. 7). A mid-to-late-season northern highbush with high-quality fruit for fresh market. Origin: Dalian University and Dalian Senmao Modern Agriculture Co., Dalian, China, by G. Xu and H. Wang. Lateblue O.P.; seed sown 2008; selected 2013. NPNVRC applied for (20160108). Fruit: large to very large, average $3.4 \mathrm{~g}$, maximum $4.4 \mathrm{~g}$; dark blue; flavor good; especially sweet; acidity very low; firm; picking scar small, dry; ripens mid- to lateseason; stores very well. Plant: vigorous; growth habit spreading; 
productivity high; flowers late; recommended for machine or hand harvest; requires cross-pollination for maximum yields; chilling requirement $800-1000 \mathrm{~h}$.

TO-1088 (Cutie Pie ${ }^{\text {TM }}$ ). Ornamental dwarf hybrid involving $V$. corymbosum and $V$. darrowii, for home garden and landscape use. Origin: University of Georgia, Griffin, GA, by D.S. NeSmith. MS-840 (Bluecrisp $\times$ Magnolia) O.P.; sown and selected 2007. USPP 28,467; 3 Oct. 2017. Fruit: small, $\sim 0.8-1.2 \mathrm{~g}$; diameter 8-10 mm; dark; picking scar good; yield good for a dwarf plant. Plant: vigorous; growth habit very dwarf and compact, reaching 0.5-0.8 $\mathrm{m}(\mathrm{h}) \times 0.6-0.9 \mathrm{~m}(\mathrm{w})$ by 4 th year; flowering profuse; chilling requirement $\sim 400-500 \mathrm{~h}$; small degree of self-fruitfulness; may be pollinated by rabbiteye and southern highbush cultivars; leaves often retained in mild winters; propagated by softwood cuttings.

Twilight. See Ridley 1812.

VacBri1 (Cabernet Splash ${ }^{\mathbf{T M}}$ ). Ornamental mutation of Toro northern highbush. Origin: Briggs Nursery, Elma, WA, by L. Caton. Naturally occurring mutation in a liner crop of Toro discovered 2008; introd. 2017. USPP and CPBR applied for. Fruit: like Toro. Plant: new leaves emerge dark wine-purple in the spring; new growth slowly matures to a purple-red mottled, dark-green leaf; mature plant $1.2 \mathrm{~m} \mathrm{x} 1.2 \mathrm{~m}$ in 10 years; USDA Zone 4 .

Vacsid1 (Scarlet Ovation). V. ovatum (Evergreen huckleberry) selection for landscape use, with bright red young foliage. Origin: Sidhu \& Sons Nursery, Mission, BC, Canada, by G. Sidhu. Naturally occurring branch mutation from $V$. ovatum Thunderbird discovered 2006. USPP 25,067; 18 Nov. 2014. Fruit: average of $4 \mathrm{~mm}$ in diameter; not grown for fruit production; glossy, smooth, glabrous; mature color deep purplish-blue. Plant: growth habit compact with sturdy stems; new foliage bright red; propagation by stem cuttings and in vitro.

\section{Valor $^{\circledR}$. See ZF08-070.}

Winter Bell. High-yielding, large-fruited, low-chill southern highbush blueberry for evergreen production in Central Florida. Origin: Weber Genetics, Winter Haven, FL, by D. Weber. FL 95-174 O.P.; selected 2009. USPP 27,642; 7 Feb. 2017. Fruit: large, average 2 g; firm; picking scar excellent; slightly tart if harvested when fruit first turns blue; ripens starting March, peak production April; yields $>5 \mathrm{~kg} /$ plant on 3-year-old plants. Plant: very vigorous; growth habit upright, spreading; bloom excellent; leaves evergreen and persistent through spring vegetative flush, with good disease tolerance.

Xinxin 1. Early to midseason southern highbush cultivar suitable for Southern China. Origin: Institute of Botany, Jiangsu Province \& Chinese Academy of Sciences, Nanjing, China, by H. Yu, Y. Jiang, Q. Zeng, J. Wei, C. Wang, W. Wu, Y. Gu, and S. He. Bounty $\times$ US 237; crossed 1986; selected 1988; tested as Su-1. SUJIANGUO 201312, approved by Jiangsu Crop Variety Examination and Approval Committee; 6 Dec. 2013. Fruit: size medium; dark blue; firmness medium-firm; picking scar small, dry. Plant: vigorous; growth habit semi-upright; $\sim 1.7 \mathrm{~m}(\mathrm{~h}) \times \sim 1.5 \mathrm{~m}(\mathrm{w})$; flowers $5-7 \mathrm{~d}$ before Star in Nanjing; yield 3-4 kg/plant; resistant to high temperature stress in summer; suitable for heavy clay soils in Southern China.

ZF08-070 (Valor $^{\circledR}$ ). Midseason northern highbush blueberry for the fresh or processed market; high chill production. Origin: Fall Creek Farm and Nursery, Lowell, OR, by D.M. Brazelton, A.L. Wagner, P.S. Boches, and A.A.A. Bermudo. Legacy $\times$ Draper; crossed 2004 selected 2008; tested as ZF08-070. USPP 29,047; 6 Mar. 2018. Fruit: very large, average $2.5 \mathrm{~g}$; slightly oblate; highly uniform; light blue; firmness similar to Legacy; ripening concentrated; yield reliable, high. Plant: growth habit upright; canes large caliper; leaf-to-fruit ratio balanced; cold hardiness good; tolerant to heavy soils; very self-fertile.

\section{GRAPE}

\section{Christopher Owens, International Fruit Genetics, Bakersfield, CA}

Enchantment. Red wine grape adapted to the mid-South. Origin: University of Arkansas, Fayetteville, AR, by J.R. Clark, R. Threlfall, J.N. Moore, and J.R. Morris. Ark. $1628 \times$ Ark. 1481; tested as Ark. 2467; crossed 1990; selected 1993; introd. 2016. USPP applied for. Fruit: small, $1.5 \mathrm{~g}$; black; $18.9^{\circ} \mathrm{Brix}$; $\mathrm{pH} 3.4$; titratable acidity $0.8 \%$ tartaric acid; teinturier; ripens mid-late August in Arkansas. Cluster: $178 \mathrm{~g}$; compact. Vine: semi-procumbent; moderately resistant to powdery mildew (Erysiphe necator) and downy mildew (Plasmopara viticola); susceptible to black rot (Guignardia bidwellii) and Pierce's disease (Xylella fastidiosa).

Opportunity. White wine grape adapted to the mid-South. Origin: University of Arkansas, Fayetteville, AR, by J.R. Clark, R. Threlfall, J.N. Moore, and J.R. Morris. Cayuga White $\times$ Ark. 1754; tested as Ark. 2245; crossed 1987; selected 1991; introd. 2016. USPP applied for. Fruit: $2.7 \mathrm{~g}$; white; $17.3^{\circ} \mathrm{Brix}$; $\mathrm{pH}$ 3.5; titratable acidity $0.5 \%$ tartaric acid; ripens late August in Arkansas. Cluster: $234 \mathrm{~g}$; very full. Vine: semi-procumbent; moderately resistant to powdery and downy mildew, but susceptible to black rot and Pierce's disease.

Compassion. White, seedless fresh-market table grape with distinctive fruity flavor. Origin: University of Arkansas, Fayetteville, AR, by J.R. Clark. Ark. $2349 \times$ Ark. 2304; tested as Ark. 2932; crossed 2002; selected 2006; introd. 2017; released in 2017 as Passion but renamed Compassion in early 2018. USPP applied for. Fruit: $4.5 \mathrm{~g}$; elongated-oval; green; seedless with small residual seed traces present in Arkansas, but not in Oregon; very firm; crisp, nonslipskin; cracking limited; flavor excellent, fruity; $20.0^{\circ}$ Brix; ripens midseason, mid- to late August in Arkansas. Cluster: $470 \mathrm{~g}$; conical to cylindrical; well-filled to tight. Vine: semi-procumbent; vigor and productivity moderate; hardy to $-17^{\circ} \mathrm{C}$ to possibly colder; moderately resistant to powdery and downy mildew, but susceptible to black rot and Pierce's disease.

\section{HAZELNUT}

\section{Shawn A. Mehlenbacher, Dept. of Horticulture, Oregon State} University, Corvallis, OR

Allahverdi. Hazelnut for the blanched kernel market. Origin: Hazelnut Research Institute, Giresun, Turkey, by A. Okay and H.I. Balik. Selected $\sim 1995$ in an orchard along the Black Sea coast and evaluated in Giresun; introd. 2015. Nut: small, $1.8 \mathrm{~g}$; round; $49 \%$ kernel by weight; $90 \%$ of pellicle removed by dry heat; husk $100 \%$ longer than nut; husk clasping; $0 \%$ free-husking; flavor and texture good; $15 \%$ shriveled kernels; few other nut and kernel defects. Tree: bush; vigor medium; growth habit spreading; leaf budbreak $12 \mathrm{~d}$ after Tombul; incompatibility alleles not determined.

Burgundy Lace. Hazelnut with red leaf color and cutleaf trait for the ornamental market. Origin: Oregon State University, Corvallis, OR, by S.A. Mehlenbacher, D.C. Smith, and R.L. McCluskey. OSU $562.034 \times$ OSU 562.062; crossed 1998; selected 2007; tested as OSU 954.076; introd. 2015; USPP 28,215; 25 July 2017. Nut: small, 1.7 g; $44 \%$ kernel by weight; pellicle has moderate to much fiber; $10 \%$ of pellicle removed by dry heat; husk $50 \%$ of length of nut and slit on side; $98 \%$ free-husking; flavor and texture acceptable; few nut and kernel defects; nuts mature $3 \mathrm{~d}$ before Barcelona. Tree: vigor moderate, $70 \%$ of Barcelona; productivity low; female inflorescences receptive late; catkins small and produce very little pollen; very highly resistant to eastern filbert blight (Anisogramma 
anomala); moderately susceptible to bud mite (Phytoptus avella$n a e)$; incompatibility alleles $\mathrm{S}_{6} \mathrm{~S}_{20}$.

Dorris. Hazelnut for the blanched kernel market. Origin: Oregon State University, Corvallis, OR, by S.A. Mehlenbacher, D.C. Smith, and R.L. McCluskey. OSU 309.074 × Delta; crossed 1997; selected 2003; tested as OSU 876.041; introd. 2012. USPP 25,022; 3 July 2014. Nut: size medium, $3.3 \mathrm{~g} ; 43 \%$ kernel by weight; pellicle has little fiber; $90 \%$ of pellicle removed by dry heat; husk $25 \%$ longer than nut and most slit; $90 \%$ free-husking; flavor and texture excellent; few nut and kernel defects; nuts mature with Barcelona. Tree: vigor low, $60 \%$ of Barcelona; growth habit spreading; productive; very highly resistant to eastern filbert blight; highly resistant to bud mite; incompatibility alleles $S_{1} S_{12}$.

Felix. Hazelnut pollenizer. Origin: Oregon State University, Corvallis, OR, by S.A. Mehlenbacher, D.C. Smith, and R.L. McCluskey. OSU $384.095 \times$ Delta; crossed 1998; selected 2007; tested as OSU 941.016; introd. 2012. USPP 24,973; 21 Oct. 2014. Nut: small, $2.6 \mathrm{~g}, 50 \%$ kernel by weight; pellicle has much fiber; $90 \%$ of pellicle removed by dry heat; husk $50 \%$ longer than nut and most slit on side; $80 \%$ free-husking; flavor and texture very good; few nut and kernel defects; nuts mature $3 \mathrm{~d}$ before Barcelona. Tree: vigorous, $120 \%$ of Barcelona; growth habit upright-spreading; moderately productive; catkins abundant; pollen viability high; pollen sheds in late midseason with Hall's Giant; very highly resistant to eastern filbert blight; moderately resistant to bud mite; incompatibility alleles $\mathrm{S}_{15} \mathrm{~S}_{21}$.

Giresun Melezi. Hazelnut for the blanched kernel market. Origin: Hazelnut Research Institute, Giresun, Turkey, by A. Okay and H.I. Balik. Tombul $\times$ Kargalak, crossed $\sim 1983$; selected 1999; introd. 2012. Nut: small-medium, $2.4 \mathrm{~g}$; 52\% kernel by weight; pellicle has little fiber; $90 \%$ of pellicle removed by dry heat; husk $100 \%$ longer than nut; husk clasping; $0 \%$ free-husking; flavor and texture good; 19\% shriveled kernels; few other nut and kernel defects. Tree: bush; vigor medium; growth habit semi-erect; leaf budbreak $11 \mathrm{~d}$ after Tombul; incompatibility alleles not determined.

McDonald. Hazelnut for the blanched kernel market. Origin: Oregon State University, Corvallis, OR, by S.A. Mehlenbacher, D.C. Smith, and R.L. McCluskey. Tonda Pacifica $\times$ Santiam; crossed 1997; selected 2006; tested as OSU 880.027; introd. 2014. USPP 28,200; 18 July 2017. Nut: small-medium, 2.5 g; 52\% kernel by weight; pellicle has moderate fiber; $80 \%$ of pellicle removed by dry heat; husk $50 \%$ longer than nut and slit on side; $95 \%$ free-husking; flavor and texture excellent; few nut and kernel defects; nuts mature $14 \mathrm{~d}$ before Barcelona. Tree: vigor moderate, $75 \%$ of Barcelona; growth habit upright-spreading; productive; female inflorescences receptive in early midseason; very highly resistant to eastern filbert blight; moderately resistant to bud mite; incompatibility alleles $\mathrm{S}_{2} \mathrm{~S}_{15}$.

Okay 28. Hazelnut for the blanched kernel market. Origin: Hazelnut Research Institute, Giresun, Turkey, by A. Okay and H.I. Balik. Tombul $\times$ Kargalak, crossed $\sim 1983$; selected 1999; registered 2012 . Nut: size medium-large, $2.9 \mathrm{~g}$; $55 \%$ kernel by weight; pellicle has little fiber; $92 \%$ of pellicle removed by dry heat; husk $100 \%$ longer than nut; husk clasping; $0 \%$ free-husking; flavor and texture good; few nut and kernel defects. Tree: bush; vigor medium; growth habit semi-erect; leaf budbreak $7 \mathrm{~d}$ after Tombul; incompatibility alleles not determined.

Roverd. Hazelnut for in-shell, kernel, and ornamental market. Origin: Universitatea din Craiova, Romania, by I. Botu, A. Vicol, and M. Botu. Red Lambert $\times$ Daviana; crossed 1988; selected 2001; introd. 2012. Nut: small, 1.4 g; 50\% kernel by weight; shells light brown; husks intense red, $25-50 \%$ longer than nut; pellicle removed by dry heat; matures 5-7 d after Tonda Gentile delle Langhe. Tree: vigor moderate; globose; leaves red-purple, fading to green; very productive; incompatibility alleles $\mathrm{S}_{5} \mathrm{~S}_{11}$.

Tonda Etrusca. Hazelnut for the kernel market. Origin: Università di Perugia, Italy, by A. Tombesi, D. Farinelli, and M. Boco. Tonda Gentile Romana $\times$ Tonda di Giffoni; crossed 1982; selected 1987; tested as F25P29; introd. 2014. EU PVR applied for. Nut: size medium, $1.73 \mathrm{~g}, 53 \%$ kernel by weight; pellicle has little fiber; little of pellicle removed by dry heat; husk $25 \%$ longer than nut and slit on side; free-husking; flavor very good; nuts mature in midseason with Tonda Gentile Romana. Tree: vigor moderate; yield moderate; incompatibility alleles not determined.

Tonda Francescana. Hazelnut for the blanched kernel market. Origin: Università di Perugia, Italy, by A. Tombesi, D. Farinelli, and M. Boco. Tonda Gentile Romana $\times$ Tonda di Giffoni; crossed 1982; selected 1987; tested as F6P200; introd. 2012. EU PVR applied for. Nut: size medium, $2.43 \mathrm{~g}, 46 \%$ kernel by weight; pellicle has little fiber; $74 \%$ of pellicle removed by dry heat; husk $25 \%$ longer than nut and slit on side; free-husking; flavor very good; nuts mature very early with Tonda Gentile delle Langhe; shelf life long. Tree: vigor moderate; productivity high; incompatibility alleles $\mathrm{S}_{2} \mathrm{~S}_{20}$.

Valverd. Hazelnut for kernel market. Origin: Universitatea din Craiova, Romania, by M. Botu, A. Vicol, I. Botu, S. Preda, and G. Achim. Mutation of Red Lambert; selected 2002; introd. 2015. Nut: small, 1.9 g; 52.6\% kernel by weight; shells medium brown; husks green, longer than nuts, tight; pellicle has moderate fiber; ripens early September. Tree: vigor moderate; globose; productive; flowers midseason; distinguished from Red Lambert by green leaf color; incompatibility alleles $\mathrm{S}_{5} \mathrm{~S}_{10}$.

Wepster. Hazelnut for the blanched kernel market. Origin: Oregon State University, Corvallis, OR, by S.A. Mehlenbacher, D.C. Smith, and R.L. McCluskey. Tonda Pacifica $\times$ OSU 440.005; crossed 1997; selected 2006; tested as OSU 894.030; introd. 2013. USPP 27,141; 13 Sept. 2016. Nut: small, 2.3 g; $46 \%$ kernel by weight; pellicle has moderate fiber; $90 \%$ of pellicle removed by dry heat; husk $100 \%$ longer than nut and slit on side; $95 \%$ free-husking; flavor and texture very good; few nut and kernel defects; nuts mature $7 \mathrm{~d}$ before Barcelona. Tree: vigorous, $85 \%$ of Barcelona; growth habit uprightspreading; productivity high; female inflorescences receptive in midseason; resistance to eastern filbert blight and to bud mite high; incompatibility alleles $\mathrm{S}_{1} \mathrm{~S}_{2}$

York. Hazelnut pollenizer. Origin: Oregon State University, Corvallis, OR, by S.A. Mehlenbacher, D.C. Smith, and R.L. McCluskey. OSU $479.0217 \times$ OSU 504.065; crossed 1997; selected 2005; tested as OSU 878.048; introd. 2012. USPP 24,972; 21 Oct. 2014. Nut: size medium 2.7 g, 46\% kernel by weight; pellicle has moderate fiber; $50 \%$ of pellicle removed by dry heat; husk $25 \%$ longer than nut and slit on side; free-husking; flavor and texture good; few nut and kernel defects; nuts mature $7 \mathrm{~d}$ before Barcelona. Tree: vigor moderate, $70 \%$ of Barcelona; productivity moderate; catkins abundant; pollen highly viable; pollen sheds in midseason; resistance to eastern filbert blight and to bud mite high; incompatibility alleles $\mathrm{S}_{2} \mathrm{~S}_{21}$.

\section{NECTARINE}

Ralph Burrell III and Ksenija Gasic, Dept. of Plant and Environmental Sciences, Clemson University, SC

0322E82NB. White-fleshed, melting, semi-clingstone nectarine. Origin: Argo Selection Fruits, Elne, France, by L. Maillard and A. Maillard. 05.04.01NB ASF0635 $\times$ Nectardream; tested as 03.22E.82.10. USPP 26,768; 31 May 2016. Fruit: large to very large, 200-220 g, homogeneous; round; $80-85 \%$ purple-red blush; very firm; semisweet with high sugar levels, $15-17^{\circ}$ Brix; juicy; eating quality very 
good; keeping quality remarkable; shipping quality very good; ripens 7-12 Oct. in Pyrénées-Orientales Dept., France. Tree: large; vigor strong; very productive; growth habit semi-flared to semiupright, dense; very resistant to spring frosts; flowers showy, selffertile; leaf glands reniform.

Andes Nec-1. Yellow-fleshed, melting, clingstone nectarine. Origin: Viveros Asociados Chile, Paine, Chile, by R. Infante. Venus $\times$ Pr-07-J. USPP 26,403; 9 Feb. 2016. Fruit: size medium, 180-245 g; symmetrical; $98 \%$ red blush; balanced sugar/acid ratio, 11.2-13.5 ${ }^{\circ}$ Brix; shipping/keeping quality excellent, can last up to 50 days in postharvest storage; not susceptible to chilling injury; ripens with Fairhaven, 2-12 Jan. in Paine, Chile. Tree: size and vigor medium; growth habit horizontal; flowers showy; leaf glands reniform.

Arctic Zee. White-fleshed, clingstone nectarine. Origin: Modesto, CA, by G.N. Zaiger, L.M. Gardner, and G.G. Zaiger. 385LU140 O.P. USPP 28,854; 8 Jan. 2018. Fruit: large; globose; firm, meaty, crisp, very good; sugar/acid balance good, $13{ }^{\circ}$ Brix; shipping/keeping quality good; ripens 1-11 Aug. in San Joaquin Valley, CA. Tree: large; vigorous; productive; growth habit upright, medium dense; flowers showy, self-fertile; chilling requirement $800 \mathrm{~h}$; leaf glands medium, reniform.

Atomic Red. White-fleshed, clingstone nectarine. Origin: Modesto, CA, by G.N. Zaiger, L.M. Gardner, and G.G. Zaiger. 112LH324 [151LE81 (Arctic Queen O.P.) O.P.] O.P. USPP 26,647; 26 Apr. 2016. Fruit: size medium, $153.4 \mathrm{~g}$; globose; eating quality good, sugar acid/balance good, $11.1{ }^{\circ}$ Brix; shipping/keeping quality good; ripens 1-11 July in San Joaquin Valley, CA. Tree: large; vigorous; productive; growth habit upright, medium dense; flowers showy, self-fertile; chilling requirement $800 \mathrm{~h}$; leaf glands medium, reniform.

August Chief. Yellow-fleshed, clingstone nectarine. Origin: Modesto, CA, by G.N. Zaiger, L.M. Gardner, and G.G. Zaiger. 25LD605 (Honey Kist O.P.) $\times$ 41G131. USPP 27,143; 13 Sept. 2016. Fruit: large, $267 \mathrm{~g}$; globose; eating quality very good, mild, sweet, subacid; $16^{\circ}$ Brix; shipping/keeping quality good; ripens 7-17 Aug. in San Joaquin Valley, CA. Tree: large; vigorous; productive; growth habit upright, medium dense; flowers showy, self-fertile; chilling requirement $850 \mathrm{~h}$; leaf glands large, reniform.

August Moon. Yellow-fleshed, clingstone nectarine. Origin: Modesto, CA, by G.N. Zaiger, L.M. Gardner, and G.G. Zaiger. 380LN344 × Honey Royale. USPP 28,832; 2 Jan. 2018. Fruit: large; globose; firm, meaty, crisp; sugar/acid balance good, $12{ }^{\circ}$ Brix; shipping/keeping quality good; ripens 30 July - 10 Aug. in San Joaquin Valley, CA. Tree: large; vigorous; productive; growth habit upright, medium dense; flowers large, self-fertile; chilling requirement $800 \mathrm{~h}$; leaf glands medium to large, reniform.

Bowden. White-fleshed, non-melting, clingstone nectarine. Origin: University of Arkansas, Fayetteville, AR, by J.R. Clark. Ark. 699N $\times$ Ark. 663N; tested as Ark. 764. USPP 26,402; 9 Feb. 2016. Fruit: size medium-large, $144 \mathrm{~g}$; round, symmetrical; $75 \%$ bright red blush; sweet with standard acidity, $14.8{ }^{\circ}$ Brix; flavor excellent; holds up well in storage; resistant to bacterial fruit spot; ripens 4 July in Clarksville, AR. Tree: vigorous; productivity high, consistent; growth habit semi-upright; resistant but not immune to bacterial leaf spot; flowers non-showy, self-fertile; chilling requirement $800 \mathrm{~h}$; leaf glands reniform.

Burnectthirtyone. White-fleshed, clingstone nectarine. Origin: Burchell Nursery, Oakdale, CA, by J.K. Slaughter and T.J. Gerdts. J17.077 O.P.; tested as M15.078. USPP 27,438; 6 Dec. 2016. Fruit: large, uniform, $270 \mathrm{~g}$; rounded, symmetrical; $70-85 \%$ medium to dark red blush; ripens 21-28 July in San Joaquin Valley, CA. Tree: medium-large; vigor moderate; productive; growth habit upright, medium dense; flowers showy; chilling requirement $550 \mathrm{~h}$; leaf glands small, reniform.

Burnecttwentynine. Yellow-fleshed, non-melting, clingstone nectarine. Origin: Burchell Nursery, Oakdale, CA, by J.K. Slaughter and T.J. Gerdts. Burnecttwentyfour $\times$ J2.035; tested as N30.022. USPP 26,540; 29 Mar. 2016. Fruit: large, uniform, $230 \mathrm{~g}$; rounded to slightly oblate; $85-95 \%$ medium to dark red blush; sweet, acidic, pleasant, $13.5^{\circ}$ Brix; shipping quality good; keeping quality excellent; ripens 7-15 June in San Joaquin Valley, CA. Tree: mediumlarge; vigorous; productive; growth habit upright, medium dense; flowers showy, self-fertile; chilling requirement $450 \mathrm{~h}$; leaf glands reniform.

Cakereve. White-fleshed, melting, semi-clingstone flat nectarine. Origin: Argo Selection Fruits, Elne, France, by L. Maillard and A. Maillard; Nectarjewel $\times$ ASFNBF0471; tested as 03.21 W.39. USPP 26,769; 31 May 2016. Fruit: 120 g, homogeneous; round, flattened, generally with few bumps; $80-90 \%$ purple-red blush; very firm, semi-sweet, 12-13 ${ }^{\circ}$ Brix; eating quality very good, aromatic; keeping quality remarkable; shipping quality very good; susceptibility to brown rot (Monilinia fructicola) low; ripens 1-12 July in Pyrénées-Orientales Dept., France. Tree: large; vigor strong; very productive; growth habit semi-flared to semi-upright, dense; very resistant to spring frosts; flowers showy, self-fertile; leaf glands reniform.

Candysweet XII. Yellow-fleshed, melting, clingstone nectarine. Origin: Le Grand, CA, by L.G. Bradford and J.M. Quisenberry. 5P452 $\times$ Kay Diamond VII. USPP 27,580; 24 Jan. 2017. Fruit: large, uniform, $270 \mathrm{~g}$; globose to slightly oblong, slightly asymmetrical; sweet, subacid, 16-18 ${ }^{\circ}$ Brix; eating quality excellent; shipping/ keeping quality good; ripens 13-25 June in San Joaquin Valley, CA. Tree: large; vigorous; productive; growth habit spreading, dense; flowers showy, self-fertile; chilling requirement $525 \mathrm{~h}$; leaf glands medium; globose.

Kay Diamond VIII. Yellow-fleshed, melting, clingstone nectarine. Origin: Le Grand, CA, by L.G. Bradford and J.M. Quisenberry. Grand Bright $\times$ Kay Diamond VII. USPP 26,837; 21 June 2016. Fruit: medium to large, uniform, 224 g; globose, symmetrical, mostly uniform; eating quality very good, with traditional nectarine flavor; acidic, sweet, $14^{\circ}$ Brix; shipping/keeping quality good; ripens 27 May - 6 June in San Joaquin Valley, CA. Tree: size medium; vigorous; productive; growth habit spreading, dense; flowers showy, self-fertile; chilling requirement $500 \mathrm{~h}$; leaf glands small, globose.

Leila. Yellow-fleshed, clingstone nectarine. Origin: Modesto, CA, by G.N. Zaiger, L.M. Gardner, and G.G. Zaiger. 42ZN84 O.P. USPP 27,628; 31 Jan. 2017. Fruit: large, 224.4 g; globose to slightly elongated; eating quality good; sugar/acid balance good, $14{ }^{\circ}$ Brix; shipping/keeping quality good; ripens 20-30 May in San Joaquin Valley, CA. Tree: large; vigorous; productive; growth habit upright, medium dense; flowers showy, selffertile; chilling requirement $350 \mathrm{~h}$; leaf glands medium to large, reniform.

Nectaflash. Yellow-fleshed, melting, clingstone nectarine. Origin: Argo Selection Fruits, Elne, France, by L. Maillard and A. Maillard. Nectabang $\times$ Nectabelle; tested as 03.30W.109.11. USPP 26,771; 31 May 2016. Fruit: $160 \mathrm{~g}$, homogeneous; very round, regular, not pointed; $95-100 \%$ dark red blush; very firm, juicy, semi-sweet; flavor very good, high sugar, $14-16^{\circ}$ Brix; aromatic; keeping quality remarkable; shipping quality very good; ripens 16 June - 10 July in Pyrénées-Orientales Dept., France. Tree: large; vigor strong; productivity high; growth habit semi-flared to semi-upright; flowers non-showy, self-fertile; leaf glands round; very resistant to spring frosts. 
Nectajoy. Orange/yellow-fleshed, melting, clingstone nectarine. Origin: Argo Selection Fruits, Elne, France, by L. Maillard and A Maillard. Nectavista $\times$ ASF0600. USPP 27,775; 14 Mar. 2017. Fruit: $185-220$ g, homogeneous; round to slightly elevated; $90 \%$ red blush; very firm; semi-sweet, $12-18{ }^{\circ}$ Brix; very aromatic; flavor very good; keeping quality remarkable; shipping quality very good; ripens 31 June - 25 July in Pyrénées-Orientales Dept., France. Tree: large; vigor medium; productivity high; growth habit semi-flared to semi-upright, dense; flowers showy, self-fertile; leaf glands reniform; very resistant to spring frosts.

Nectaking. Orange/yellow-fleshed, melting, clingstone nectarine. Origin: Argo Selection Fruits, Elne, France, by L. Maillard and A. Maillard. Nectagala O.P.; tested as 4S.10W.44.08. USPP 26,770; 31 May 2016. Fruit: 200-230 g, homogeneous; round; $80-95 \%$ purple-red blush; very firm; semi-sweet with high sugar, $13-15^{\circ} \mathrm{Brix}$; aromatic; eating quality very good; keeping quality remarkable; shipping quality very good; ripens 12 July - 6 Aug. in PyrénéesOrientales Dept., France. Tree: large; vigor strong; productivity high; growth habit semi-flared to semi-upright; very resistant to spring frosts; flowers showy, self-fertile; leaf glands reniform.

Nectana. Orange/yellow-fleshed, melting, clingstone nectarine. Origin: Argo Selection Fruits, Elne, France, by L. Maillard and A. Maillard. Nectat O.P. × Nectariane. USPP 28,337; 26 Aug. 2017. Fruit: $220-240$ g, homogeneous; round; $80-90 \%$ purple-red blush; very firm; semi-sweet, $14-15^{\circ}$ Brix; very aromatic; eating quality very good; keeping quality remarkable; shipping quality very good; ripens August, sometimes early September in Pyrénées-Orientales Dept., France. Tree: large; vigor medium; productivity high; growth habit semi-flared to semi-upright, dense; very resistant to spring frosts; flowers non-showy, self-fertile; leaf glands reniform.

Nectarelse. White-fleshed, melting, clingstone nectarine. Origin: Argo Selection Fruits, Elne, France, by L. Maillard and A. Maillard. Nectavant O.P. $\times$ Nectarcrisp. USPP 27,774; 14 Mar. 2017. Fruit: 175-195 g, homogeneous; round; $75-85 \%$ purple-red blush; very firm; juicy; semi-sweet, $14-16^{\circ}$ Brix; very aromatic; keeping quality remarkable; shipping quality very good; ripens 22 June - 18 July in Pyrénées-Orientales, France. Tree: large; vigor medium; productivity high; growth habit semi-flared to semi-upright, dense; very resistant to spring frosts; flowers showy, self-fertile; leaf glands reniform.

Nectarnovala. White-fleshed, melting, clingstone nectarine. Origin: Argo Selection Fruits, Elne, France, by L. Maillard and A. Maillard. Nectavista $\times$ Nectaflora. USPP 27,773; 14 Mar. 2017. Fruit: $180-230 \mathrm{~g}$, homogeneous; round to slightly oblong; $80-95 \%$ purple-red blush; very firm, juicy; semi-sweet, 14-18 ${ }^{\circ}$ Brix; very aromatic; eating quality very good; keeping quality remarkable; shipping quality very good; ripens 12 Sept. - 4 Oct. in PyrénéesOrientales Dept., France. Tree: large; vigor medium; productivity high; growth habit semi-flared to semi-upright, dense; very resistant to spring frosts; flowers showy, self-fertile; leaf glands reniform.

Pearlicious X. Yellow/white-fleshed, melting, clingstone nectarine. Origin: Le Grand, CA, by L.G. Bradford and J.M. Quisenberry. Snow Princess $\times$ unnamed nectarine. USPP 26,797; 7 June 2016. Fruit: medium to large, variable, $241 \mathrm{~g}$; globose, somewhat compressed axially, symmetrical, uniform; eating quality excellent; sugar/acid balance tasty, very sweet, $18-22^{\circ}$ Brix; shipping/keeping quality good; ripens 12-22 July in San Joaquin Valley, CA. Tree: size medium; vigorous; productive; growth habit upright, dense; flowers showy, self-fertile; chilling requirement $450 \mathrm{~h}$; leaf glands small, globose.

Polar Gem. White-fleshed, clingstone nectarine. Origin: Modesto, CA, by G.N. Zaiger, L.M. Gardner, and G.G. Zaiger. 63MA524 O.P. USPP 27,627; 31 Jan. 2017. Fruit: large, 252.8 g; globose; eating quality very good; flavor excellent; mild, sweet, subacid, $16^{\circ} \mathrm{Brix}$; juice abundant; shipping/keeping quality good; ripens $18-28$ June in San Joaquin Valley, CA. Tree: large; vigorous; productive; growth habit upright, medium dense; flowers showy, self-fertile; chilling requirement $150 \mathrm{~h}$; leaf glands medium to large, reniform.

Polar Kist. White-fleshed, clingstone nectarine. Origin: Modesto, CA, by G.N. Zaiger, L.M. Gardner, and G.G. Zaiger. Parentage unknown. USPP 27,789; 21 Mar. 2017. Fruit: size medium, 164.7 g; globose; eating quality good; mild, sugar/acid balance good, $14{ }^{\circ}$ Brix; shipping/ keeping quality good; ripens 25 May - 4 June in San Joaquin Valley, CA. Tree: large; vigorous; productive; growth habit upright, medium dense; flowers showy, self-fertile; chilling requirement $500 \mathrm{~h}$; leaf glands large, reniform.

Polar Magic. White-fleshed, clingstone nectarine. Origin: Modesto, CA, by G.N. Zaiger, L.M. Gardner, and G.G. Zaiger. 184LT187 $(56 Z 762 \times$ Honey Royale) $\times 219$ LK242 (Honey Kist O.P.). USPP 27,626; 31 Jan. 2017. Fruit: large, 207.3 g; globose to slightly elongated; eating quality very good; flavor excellent, sugar/acid balance good, $14{ }^{\circ}$ Brix; shipping/keeping quality good; ripens 8-18 June in San Joaquin Valley, CA. Tree: large; vigorous; productive; growth habit upright, medium dense; flowers showy, self-fertile; chilling requirement $650 \mathrm{~h}$; leaf glands large, reniform.

Polar Snow. White-fleshed, clingstone nectarine. Origin: Modesto, CA, by G.N. Zaiger, L.M. Gardner, and G.G. Zaiger. Parentage unknown. USPP 27,450; 13 Dec. 2016. Fruit: large, 213 g; globose to elongated; eating quality excellent; mild, sweet, subacid, $16^{\circ} \mathrm{Brix}$; shipping/keeping quality good; ripens 15-22 Aug. in San Joaquin Valley, CA. Tree: large; vigorous; productive; growth habit upright, medium dense; flowers showy, self-fertile; chilling requirement 800 h; leaf glands small to medium, reniform.

Polar Zee. White-fleshed, clingstone nectarine. Origin: Modesto, CA, by G.N. Zaiger, L.M. Gardner, and G.G. Zaiger. Polar Magic O.P. USPP 27,520; 3 Jan. 2017. Fruit: large, 244.2 g; globose; eating quality very good; flavor excellent, sugar/acid balance good, $19{ }^{\circ}$ Brix; shipping and keeping quality good; ripens 12-22 June in San Joaquin Valley, CA. Tree: large; vigorous; productive; growth habit upright, medium dense; flowers large, self-fertile; chilling requirement $700 \mathrm{~h}$; leaf glands medium to large, reniform.

Reed. Yellow-fleshed, clingstone nectarine. Origin: Modesto, CA, by G.N. Zaiger, L.M. Gardner, and G.G. Zaiger. Honey May $\times$ 53ZH604. USPP 26,648; 26 Apr. 2016. Fruit: size medium-large, $159 \mathrm{~g}$; globose; eating quality good; sugar/acid balance good, $11{ }^{\circ}$ Brix; shipping and keeping quality good; ripens 11-21 May in San Joaquin Valley, CA. Tree: large; vigorous; productive; growth habit upright, medium dense; flowers showy, self-fertile; chilling requirement $300 \mathrm{~h}$; leaf glands medium to large, reniform.

Smooth Delight One. White-fleshed, clingstone nectarine. Origin: Texas A\&M University, College Station, TX, by D.H. Byrne and N. Anderson. Sunmist $\times$ Arctic Star; tested as TX2A232LWN. USPP 28,077; 6 June 2017. Fruit: size medium-large to large, uniform; $70-90 \%$ light to dark red blush; flavor very sweet, subacid; eating quality good to excellent; keeping quality good; shipping quality average; ripens early-mid-May in Fairfield, TX. Tree: average to above average; vigor high; productive; growth habit spreading, medium to high density; flowers showy; chilling requirement 350-400 h; leaf glands reniform.

Smooth Delight Two. Yellow-fleshed, clingstone nectarine. Origin: Texas A\&M University, College Station, TX, by D.H. Byrne and N. Anderson. Sunmist $\times$ Arctic Star; tested as TX2B233LN. USPP 28,443; 26 Sept. 2017. Fruit: size medium to medium-large; generally ovate; $70-90 \%$ red blush; flavor very sweet, subacid; shipping quality average; keeping quality good; ripens 
early-mid-May in Fairfield, TX. Tree: size average to above average; vigor high; productive; growth habit spreading, medium to high density; flowers showy; chilling requirement 350-400 h; leaf glands reniform.

Sunnectwentythree. Yellow-fleshed, melting, clingstone nectarine. Origin: Sun World International, Bakersfield, CA, by T.A. Bacon. Sunecttwentyone O.P. USPP 26,404; 9 Feb. 2016. Fruit: large, $168 \mathrm{~g}$; circular, rounded; mildly tart, sweet, flavor good, $12{ }^{\circ} \mathrm{Brix}$; shipping and keeping quality good; ripens 13-23 May in Wasco, CA. Tree: large; vigor strong; productive; growth habit upright to spreading, dense; flowers showy, self-fertile; chilling requirement $400 \mathrm{~h}$; leaf glands medium, globose.

Sweet Firegem. Yellow-fleshed, clingstone nectarine. Origin: Modesto, CA, by G.N. Zaiger, L.M. Gardner, and G.G. Zaiger. Honey Lite O.P. USPP 26,681; 3 May 2016. Fruit: large, 193.1 g; globose; eating quality very good; sugar/acid balance good, $16^{\circ}$ Brix; shipping and keeping quality good; ripens 31 May - 9 June in San Joaquin Valley, CA. Tree: large; vigorous; productive; upright; medium dense; flowers showy, self-fertile; chilling requirement $400 \mathrm{~h}$; leaf glands large, reniform.

\section{PEACH}

Ralph Burrell III and Ksenija Gasic, Dept. of Plant and Environmental Sciences, Clemson University, SC

2343 Jay Day. Yellow-fleshed, clingstone peach. Origin: Sanger, CA, by J. Yakligian. Parentage unknown. USPP 26,901; 5 July 2016. Fruit: $61-78 \mathrm{~mm}$ in diameter, uniform; slightly asymmetrical; firm; eating quality very good to excellent; shipping/keeping quality very good; similar to Calara in most aspects, but ripens much later, 15-31 Oct. in San Joaquin Valley, CA. Tree: size medium; vigor moderate; productivity very good; growth habit upright, spreading; flowers showy; leaf glands reniform.

Alpine Delight. White-fleshed, non-melting, clingstone peach. Origin: Oz Peach, Toowoomba, Queensland, Australia, by V. Mazzardis. 4-1 WN $\times$ 3-3WP; tested as TY-5. USPP 26,499; 15 Mar. 2016. Fruit: size medium-large, 150 g; slightly oblate; $95 \%$ red-purplish blush; firm; juicy; flavor well balanced, low-acid; 10-15 ${ }^{\circ}$ Brix; shipping quality good; keeping quality excellent; ripens 1-15 Oct. in Perth, Western Australia. Tree: large; vigorous; very productive; growth habit upright, moderately dense; flowers showy, self-fertile; chilling requirement $100 \mathrm{~h}$; leaf glands medium, globose.

American. Yellow-fleshed, non-melting, clingstone peach. Origin: Modesto, CA, by G.N. Zaiger, L.M. Gardner, and G.G. Zaiger. 225LV72 O.P. USPP 27,828; 4 Apr. 2017. Fruit: large; globose; firm; meaty; sugar/acid balance good, $\sim 10.7{ }^{\circ}$ Brix; eating quality very good; shipping/keeping quality good; ripens 24 June - 4 July in San Joaquin Valley, CA. Tree: large; vigorous; productive; growth habit upright, medium dense; flowers non-showy, self-fertile; chilling requirement $700 \mathrm{~h}$; leaf glands medium to large, reniform.

Burpeachforty. Yellow-fleshed, non-melting, clingstone peach. Origin: Burchell Nursery, Oakdale, CA, by J.K. Slaughter and T.J. Gerdts. Unnamed yellow-fleshed clingstone peach $\times$ Burpeachthrityfive; tested as Q13.052. USPP 28,875; 16 Jan. 2018. Fruit: medium-large, uniform; globose; $65-85 \%$ red blush; firm; crunchy, flavor very good, sweetness/acid balance good, considered low-acid; 11-13.5 ${ }^{\circ}$ Brix; shipping quality good; keeping quality excellent; ripens 12-19 June in San Joaquin Valley, CA. Tree: size medium to medium-large; moderately vigorous; productive; growth habit upright, moderately dense; flowers showy, self-fertile; chilling requirement $500 \mathrm{~h}$; leaf glands small, reniform.
Burpeachthirtyeight. Yellow-fleshed, non-melting, clingstone peach. Origin: Burchell Nursery, Oakdale, CA, by J.K. Slaughter and T.J. Gerdts. Summer Lady $\times$ unnamed clingstone peach; tested as J26.080. USPP 28,547; 24 Oct. 2017. Fruit: moderately large, uniform; globose; $45-65 \%$ dull red blush; firm; flesh dense; eating quality very good, sugar/acid balance good, 13-17 ${ }^{\circ}$ Brix; juice moderate to abundant; shipping/keeping quality excellent; ripens 18-23 Sept. in San Joaquin Valley, CA. Tree: medium to mediumlarge; moderately vigorous; productive; growth habit upright, moderately dense; flowers showy, self-fertile; chilling requirement $650 \mathrm{~h}$; leaf glands small, reniform.

Burpeachthirtynine. White-fleshed, non-melting, clingstone peach. Origin: Burchell Nursery, Oakdale, CA, by J.K. Slaughter and T.J. Gerdts. D2.054 × Galaxy; tested as N52.122. USPP 28,792; 26 Dec. 2017. Fruit: moderately large, uniform; saucer-shaped; $85-95 \%$ dull red blush; firm; crunchy; flavor very good; taste balanced, $12-16{ }^{\circ}$ Brix; juice moderate to abundant; keeping quality excellent; shipping quality good; ripens 25 May - 5 June in San Joaquin Valley, CA. Tree: medium-large to large; vigorous; productive; growth habit upright, moderately dense; flowers showy, self-fertile; chilling requirement $600 \mathrm{~h}$; leaf glands small, reniform.

Burpeachthirtyseven. Yellow-fleshed, non-melting, clingstone peach. Origin: Burchell Nursery, Oakdale, CA, by J.K. Slaughter and T.J. Gerdts. Fayette $\times$ unnamed yellow-fleshed peach; tested as C11.012. USPP 28,597; 7 Nov. 2017. Fruit: moderately large, uniform; globose; $45-65 \%$ dull red blush; crunchy; very firm; eating quality good, sugar/acid balance good, $14-17^{\circ}$ Brix; juice moderate to abundant; keeping quality excellent; ripens 23-29 Sept. in San Joaquin Valley, CA. Tree: size medium to medium-large; vigor moderate; productive; growth habit upright, moderately dense; flowers showy, self-fertile; chilling requirement $650 \mathrm{~h}$; leaf glands small, reniform.

Burpeachthirtysix. Yellow-fleshed, non-melting, freestone peach. Origin: Burchell Nursery, Oakdale, CA, by J.K. Slaughter and T.J. Gerdts. E49.046 (non-patented Burchell seedling) O.P.; tested as M36.031. USPP 27,423; 29 Nov. 2016. Fruit: large, very uniform; globose; $65-85 \%$ red blush; firm; flesh crunchy; flavor good, taste balanced, low-acid; 15-18 ${ }^{\circ}$ Brix; moderate juice; shipping/keeping quality excellent; ripens 11-19 Oct. in San Joaquin Valley, CA. Tree: size medium to medium-large; moderately vigorous; productive; growth habit upright, moderately dense; flowers showy, self-fertile; chilling requirement $375 \mathrm{~h}$; leaf glands small, reniform.

Calaveras. Yellow-fleshed, non-melting, clingstone peach. Origin: Modesto, CA, by G.N. Zaiger, L.M. Gardner, and G.G. Zaiger. 41LG80 O.P. USPP 27,351; 8 Nov. 2016. Fruit: large; globose; firm; meaty; sugar/acid balance good, $11^{\circ}$ Brix; flavor good; juice heavy; shipping and keeping quality good; ripens 28 June - 5 July in San Joaquin Valley, CA. Tree: large; vigorous; productive; growth habit upright, medium dense; flowers non-showy, self-fertile; chilling requirement $800 \mathrm{~h}$; leaf glands medium to large, reniform.

Clavey. Yellow-fleshed, non-melting, clingstone peach. Origin: Modesto, CA, by G.N. Zaiger, L.M. Gardner, and G.G. Zaiger. 14HA602 (Diamante O.P.) $\times$ 288LC126. USPP 27,422; 26 Nov. 2016. Fruit: large; globose; firm; meaty; sugar/acid balance good, $10.8^{\circ}$ Brix; flavor good; juice heavy; shipping and keeping quality good; ripens 16-26 July in San Joaquin Valley, CA. Tree: large; vigorous; productive; growth habit upright, medium dense; flowers non-showy, self-fertile; chilling requirement $800 \mathrm{~h}$; leaf glands small, globose.

Crimson Fire. Yellow-fleshed, clingstone peach. Origin: Modesto, CA, by G.N. Zaiger, L.M. Gardner, and G.G. Zaiger. 11ZP33 (Rich Snow O.P.) O.P. USPP 27,869; 11 Apr. 2017. Fruit: large; globose 
to slightly elongate; firm; meaty; sugar/acid balance good, $\sim 11.4{ }^{\circ}$ Brix; eating quality good; shipping/keeping quality good; ripens 29 Apr. - 7 May in San Joaquin Valley, CA. Tree: large; vigorous; productive; growth habit upright, medium dense; flowers showy, self-fertile; chilling requirement $350 \mathrm{~h}$; leaf glands large, reniform.

Crispdiva. Yellow-fleshed, melting, clingstone peach. Origin: Argo Selection Fruits, Elne, France, by L. Maillard and A. Maillard. Nectapi $\times$ Sweetprim. USPP 26,649; 26 Apr. 2017. Fruit: large to very large, homogenous; round; $90-95 \%$ purple-red blush; very firm; crunchy, melting; juicy; aromatic; $15-16^{\circ}$ Brix; acidity moderate; keeping quality remarkable; not very sensitive to powdery mildew (Sphaerotheca pannosa); ripens 13-20 Aug. in Pyrénées-Orientales Dept., France. Tree: large; vigorous; productive; growth habit semiflared to semi-upright, dense; flowers showy, self-fertile; leaf glands globose.

Crispdream. Yellow-fleshed, melting, clingstone peach. Origin: Argo Selection Fruits, Elne, France, by L. Maillard and A. Maillard. Sweetprim $\times$ Nectabelle. USPP 28,723; 5 Dec. 2017. Fruit: homogeneous, $175-215 \mathrm{~g}$; very round; $95-100 \%$ red blush; very firm; crunchy; eating quality very good; aromatic; $17-19{ }^{\circ}$ Brix; shipping quality very good; keeping quality remarkable; not very sensitive to powdery mildew or other conservation diseases/decay due to thick skin; ripens late July - early August in PyrénéesOrientales Dept., France. Tree: large; vigor strong; productivity high; growth habit semi-flared to semi-upright, dense; resistance to spring frosts high; flowers showy, self-fertile; leaf glands reniform.

Crisponda. Yellow-fleshed, melting, clingstone peach. Origin: Argo Selection Fruits, Elne, France, by L. Maillard and A. Maillard. Nectabelle $\times$ ASF I0104. USPP 28,774; 19 Dec. 2017. Fruit: homogeneous, $135-175 \mathrm{~g}$; round to slightly flattened; $75-80 \%$ red blush; very firm; crunchy; semi-sweet, 10-14 ${ }^{\circ}$ Brix; aromatic; shipping quality very good; keeping quality remarkable; not very sensitive to powdery mildew or other conservation diseases due to thick skin; ripens 20-27 June in Pyrénées-Orientales Dept., France. Tree: large; vigor strong; very productive; growth habit semi-flared to semi-upright, dense; resistant to spring frost; flowers non-showy, self-fertile; chilling requirement low; leaf glands reniform.

Flat Delight One. White-fleshed, melting, clingstone flat peach. Origin: Texas A\&M University, College Station, TX, by D.H. Byrne and N. Anderson. TexFirst $\times$ P1; tested as TX3C395LWP. USPP 27,741; 7 Mar. 2017. Fruit: size medium to medium-large, uniform; flat with equal halves; 50-75\% red blush; firm; very sweet; eating quality very good to excellent; shipping/keeping quality average; suited to local fresh market/home garden; ripens 23 May in Fairfield, TX. Tree: size average to above average; vigor high; productive; growth habit semi-spreading, medium to high density; moderately susceptible to bacterial leaf spot; flowers showy; chilling requirement 450-500 h; leaf glands reniform.

Flat Delight Two. Yellow-fleshed, semi-freestone flat peach. Origin: Texas A\&M University, College Station, TX, by D.H. Byrne and N. Anderson. Flordacrest $\times$ Stark Saturn; tested as TX3D353LP. USPP 27,776; 14 Mar. 2017. Fruit: size medium to medium-large, uniform; flat with unequal halves; $50-80 \%$ orangered blush; firm; sweet, subacid; shipping/keeping quality average; ripens 10 June in Fairfield, TX. Tree: size average to above average; vigor high; productive; growth habit semi-spreading, medium to high density; flowers showy, self-fertile; chilling requirement 500-550 h; leaf glands reniform.

Flatdiva. White-fleshed, melting, semi-clingstone flat peach. Origin: Argo Selection Fruits, Elne, France, by L. Maillard and A. Maillard. Flatstar $\times$ Nectaflora; tested as 02.2W.20.11. USPP 26,772; 31 May 2016. Fruit: size medium-large, homogenous; flattened;
90\% purple-red blush; firm, crunchy; melting; semi-sweet, sugary, 18-19 ${ }^{\circ}$ Brix; aromatic; acidity moderate; keeping quality remarkable; not very sensitive to brown rot; ripens 12 Aug. - 2 Sept. in Pyrénées-Orientales Dept., France. Tree: large; vigorous; productive; growth habit semi-flared, dense; flowers showy, self-fertile; leaf glands reniform.

Golden Zest. Yellow-fleshed, non-melting, clingstone peach. Origin: Texas A\&M University, College Station, TX, by D.H. Byrne and N. Anderson. Crimson Lady $\times$ Agata; tested as TX4E220C. USPP 28,019; 16 May 2017. Fruit: size medium-large to large, uniform; generally round; 40-65\% attractive red-orange blush; firm; sweet, slightly acidic; $11.7^{\circ} \mathrm{Brix}$; keeping quality good to very good; shipping quality above average; ripens mid-late June in Fairfield, TX. Tree: size average to above average; vigor high; productive; growth habit semi-spreading, medium dense; flowers showy, selffertile; chilling requirement $600 \mathrm{~h}$; leaf glands globose.

GulfAtlas. Yellow-fleshed, non-melting, clingstone peach. Origin: University of Georgia, University of Florida, and USDA, Attapulgus, GA, by T.G. Beckman, J.X. Chaparro, and P.J. Conner. Flavorcrest $\times$ FL98-10C. USPP 27,128; 6 Sept. 2016. Fruit: size medium-large to large, uniform; slightly squat; 80-100\% red blush; firm; juicy; nonmelting; flavor good, moderately sweet, slightly acidic, $11.2{ }^{\circ}$ Brix; shipping quality highly acceptable, keeping quality excellent; highly resistant to bacterial spot (Xanthomonas campestris pv. pruni) ripens mid-June in Attapulgus. Tree: size medium; vigor moderate; productive; growth habit semi-spreading, light to medium dense; flowers showy, self-fertile; chilling requirement $400 \mathrm{~h}$; leaf glands small, reniform.

Ice Zee. White-fleshed, clingstone peach. Origin: Modesto, CA, by G.N. Zaiger, L.M. Gardner, and G.G. Zaiger. 62MA130 O.P. USPP 27,296; 25 Oct. 2016. Fruit: large; globose; firm; meaty; flavor very good, mild; juice abundant; $11{ }^{\circ}$ Brix; shipping/keeping quality good; ripens 9-17 June in San Joaquin Valley, CA. Tree: large; vigorous; productive; growth habit upright, medium dense; flowers showy, selffertile; chilling requirement $700 \mathrm{~h}$; leaf glands small to medium, reniform.

June Honey. Yellow-fleshed, freestone peach. Origin: Modesto, CA, by G.N. Zaiger, L.M. Gardner, and G.G. Zaiger. 209LP573 × 216LK450. USPP 26,919; 12 July 2017. Fruit: large; globose; firm; meaty crisp; eating quality very good; $\sim 19{ }^{\circ}$ Brix; shipping and keeping quality good; ripens 15-25 June in San Joaquin Valley, CA. Tree: large; vigorous; productive; growth habit upright, medium dense; flowers showy, self-fertile; chilling requirement $250 \mathrm{~h}$; leaf glands large, reniform.

Kader. Yellow-fleshed, non-melting, clingstone peach. Origin: University of California, Davis, CA, by T.M. Gradziel and M.A. Thorpe. Ross $\times$ R1-1; tested as 90,9-116. USPP 26,871; 28 June 2016. Fruit: large, uniform; globose to slightly oblate; $20-60 \%$ blush; eating quality high; canning quality very good; keeping quality good; susceptibility to brown rot low; ripens 15 July - 1 Aug. in Davis. Tree: size medium; vigor medium; productive; growth habit spreading to upright-spreading; flowers showy; chilling requirement low to medium; leaf glands small to medium, globose.

Krista. Yellow-fleshed, clingstone peach. Origin: Modesto, CA, by G.N. Zaiger, L.M. Gardner, and G.G. Zaiger. 54ZH822 (37ZD298 × Super Lady) $\times 170$ LX160. USPP 27,167; 20 Sept. 2016. Fruit: large; globose; firm; meaty; crisp; eating quality good; $\sim 9.9{ }^{\circ}$ Brix; shipping and keeping quality good; ripens 3-13 May in San Joaquin Valley, CA. Tree: large; vigorous; productive; growth habit upright, medium dense; flowers showy, self-fertile; chilling requirement $500 \mathrm{~h}$; leaf glands large, reniform.

Mazee. Yellow-fleshed, clingstone peach. Origin: Modesto, CA, by G.N. Zaiger, L.M. Gardner, and G.G. Zaiger. 390LU304 × 
53ZH1029 (Super Zee $\times$ Super Lady). USPP 27,168; 20 Sept. 2016. Fruit: large; globose; firm; meaty; sugar/acid balance good, $11.2^{\circ} \mathrm{Brix}$; flavor very good; shipping/keeping quality good; ripens 30 Apr. - 10 May in San Joaquin Valley, CA. Tree: large; vigorous; productive; growth habit upright, medium dense; flowers showy, self-fertile; chilling requirement $250 \mathrm{~h}$; leaves eglandular.

P.F. Fashionably Late. Yellow-fleshed, non-melting, freestone peach. Origin: Coloma, MI, by P.J. Friday. Parentage unknown. USPP 26,452; 8 Mar. 2016. Fruit: spherical, diameter $7 \mathrm{~cm}$; 50-80\% dark red blush; firm; flavor very good; $15{ }^{\circ}$ Brix; shipping/keeping quality very good; resistant to brown rot/bacterial fruit spot; ripens 30 Sept. - 5 Oct. in Southwestern Michigan. Tree: size medium; vigorous; production very good; growth habit upright, medium dense; resistant to bacterial spot; flowers showy, self-fertile; leaf glands globose.

Pearl Princess III. White-fleshed, melting, clingstone peach. Origin: Le Grand, CA, by L.G. Bradford and J.M. Quisenberry. Pearl Princess V O.P. USPP 28,505; 10 Oct. 2017. Fruit: large, uniform; globose; very dark red with minor amount of pale yellowish-pink; firm; crisp; melting; mild, somewhat sweet, subacid, $\sim 14{ }^{\circ}$ Brix; ripens 2-12 June in San Joaquin Valley, CA. Tree: small to medium; vigor moderately weak; productive; growth habit spreading, dense; flowers showy, self-fertile; chilling requirement $350 \mathrm{~h}$; leaf glands medium, reniform.

Pearl Princess IV. White-fleshed, melting, freestone peach. Origin: Le Grand, CA, by L.G. Bradford. Snow Princess $\times$ unnamed selection. USPP 27,467; 20 Dec. 2016. Fruit: large, uniform; globose to somewhat oblate; dark red over a strong red background; firm; crisp; melting; sugar/acid balance tasty, $16-18^{\circ}$ Brix; shipping/ keeping quality good; ripens 20-29 June in San Joaquin Valley, CA. Tree: size medium; vigorous; productive; growth habit upright, dense; flowers showy, self-fertile; chilling requirement $450 \mathrm{~h}$; leaf glands medium, reniform.

Pearl Princess IX. White-fleshed, freestone peach. Origin: Le Grand, CA, by L.G. Bradford and J.M. Quisenberry. Snow Princess $\times$ Rose Bright. USPP 28,249; 8 Aug. 2017. Fruit: large, uniform; globose; dark red over a light yellowish pink background with some pale greenish yellow; firm, crisp; flavor balanced; $\sim 17{ }^{\circ}$ Brix; shipping and keeping quality good; ripens 1-10 July in San Joaquin Valley, CA. Tree: size medium; vigorous; productive; growth habit spreading, moderately dense; flowers showy, self-fertile; chilling requirement $400 \mathrm{~h}$; leaf glands medium, globose.

Pearl Princess XIII. Yellow-fleshed, melting, freestone peach. Origin: Le Grand, CA, by L.G. Bradford and J.M. Quisenberry. Diamond Princess $\times$ unnamed selection. USPP 27,629; 31 Jan. 2017. Fruit: large, uniform; globose to slightly oblate; dark red, smoothly blending to moderate pink; firm; crisp; melting; mild, subacid, $\sim 17{ }^{\circ}$ Brix; shipping/keeping quality good; ripens 19-28 Aug. in San Joaquin Valley, CA. Tree: size medium-large; vigorous; productive; growth habit upright, spreading; flowers showy, self-fertile; chilling requirement $650 \mathrm{~h}$; leaf glands medium, globose.

Red Princess II. Yellow-fleshed, non-melting, clingstone peach. Origin: Le Grand, CA, by L.G. Bradford and J.M. Quisenberry. Ivory Duchess $\times$ May Princess. USPP 28,338; 29 Aug. 2017. Fruit: large, uniform; oblate, compressed axially; very dark red tigerstriped, with moderate red ground color, and slight amount of pale orange-yellow; firm; non-melting; classic peach flavor; $\sim 13{ }^{\circ} \mathrm{Brix}$; shipping/keeping qualities good; ripens 15-25 May in San Joaquin Valley, CA. Tree: small; vigor weak; productive; growth habit spreading, dense; flowers showy, self-fertile; chilling requirement $300 \mathrm{~h}$; leaf glands small, reniform.
Red Princess III. Yellow-fleshed, non-melting, clingstone peach. Origin: Le Grand, CA, by L.G. Bradford and J.M. Quisenberry. Bright Princess $\times$ 7P1. USPP 28,339; 29 Aug. 2017. Fruit: large, uniform; globose with slight axial compression; very dark red with slight amounts of light orange yellow; firm; tough; non-melting; classic peach flavor; $\sim 14{ }^{\circ}$ Brix; shipping/keeping quality good; ripens 23 May - 5 June in San Joaquin Valley, CA. Tree: large; vigorous; productive; growth habit spreading, dense; flowers showy, self-fertile; chilling requirement $500 \mathrm{~h}$; leaf glands medium, reniform.

Rich Pride. Yellow-fleshed, clingstone peach. Origin: Modesto, CA, by G.N. Zaiger, L.M. Gardner, and G.G. Zaiger. $59 Z 695$ (Rich May $\times$ Super Rich) $\times 226$ LK505. USPP 28,203; 18 July 2017. Fruit: large; globose; firm; meaty; crisp; flavor very good; $\sim 10.5{ }^{\circ}$ Brix; shipping/keeping quality good; ripens 23 June - 1 July in San Joaquin Valley, CA. Tree: large; vigorous; productive; growth habit upright, medium dense; flowers showy, self-fertile; chilling requirement $850 \mathrm{~h}$; leaf glands large, reniform.

Sauzee Giant. White-fleshed, clingstone flat peach. Origin: Modesto, CA, by G.N. Zaiger, L.M. Gardner, and G.G. Zaiger. 358LN87 × 30LR286. USPP 27,955; 2 May 2017. Fruit: large; flat, peento; firm; meaty; mild, sweet, flavor very good, $\sim 14{ }^{\circ}$ Brix; shipping/keeping quality good; ripens 10-20 Sept. in San Joaquin Valley, CA. Tree: large; vigorous; productive; upright; medium dense; flowers showy; self-fertile; chilling requirement $850 \mathrm{~h}$; leaf glands medium, reniform.

Sauzee Jewel. White-fleshed, clingstone flat peach. Origin: Modesto, CA, by G.N. Zaiger, L.M. Gardner, and G.G. Zaiger. 358LN87 × 30LR286. USPP 26,839; 21 June 2016. Fruit: large; flat, peento; firm; meaty; flavor very good, mild, sweet, subacid, $13.6{ }^{\circ}$ Brix; juice abundant; shipping/keeping quality good; ripens 1-11 Sept. in San Joaquin Valley, CA. Tree: large; vigorous; productive; growth habit upright, medium dense; flowers showy, self-fertile; chilling requirement $950 \mathrm{~h}$; leaf glands small, reniform.

Snow Baby. White-fleshed, clingstone peach. Origin: Modesto, CA, by G.N. Zaiger, L.M. Gardner, and G.G. Zaiger. 196LT639 × 35M358. USPP 27,532; 10 Jan. 2017. Fruit: large; globose; firm; meaty; flavor good, mild, sweet, subacid, $11.2{ }^{\circ}$ Brix; shipping/ keeping quality good; ripens 4-11 June in San Joaquin Valley, CA. Tree: large; vigorous; productive; growth habit upright, medium dense; flowers showy, self-fertile; chilling requirement $600 \mathrm{~h}$; leaf glands medium to large, reniform.

Snow Fox. White-fleshed, clingstone peach. Origin: Modesto, CA, by G.N. Zaiger, L.M. Gardner, and G.G. Zaiger. 196LT639 × 35M358. USPP 27,790; 21 Mar. 2017. Fruit: large; globose; firm; meaty; sugar/acid balance good, $\sim 11{ }^{\circ}$ Brix; eating quality very good; shipping/keeping quality good; ripens 30 May - 9 June in San Joaquin Valley, CA. Tree: large; vigorous; productive; growth habit upright, medium dense; flowers showy, self-fertile; chilling requirement $550 \mathrm{~h}$; leaf glands medium to large, reniform.

Snow Gypsy. White-fleshed, freestone peach. Origin: Modesto, CA, by G.N. Zaiger, L.M. Gardner, and G.G. Zaiger. 233LK471 × 373LH55 (246LC568 × Sweet Dream). USPP 26,900; 5 July 2016. Fruit: large; globose; firm; meaty; crisp; eating quality very good; $\sim 12{ }^{\circ}$ Brix; shipping/keeping quality good; ripens 1-8 Sept. in San Joaquin Valley, CA. Tree: large; vigorous; productive; growth habit upright, medium dense; flowers showy, self-fertile; chilling requirement $950 \mathrm{~h}$; leaf glands medium to large, reniform.

Snow Ryder. White-fleshed, clingstone peach. Origin: Modesto, CA, by G.N. Zaiger, L.M. Gardner, and G.G. Zaiger. 56Z130 $(45 \mathrm{GH} 243 \times$ Sweet Shasta $) \times$ Snow Lady Rose. USPP 27,295; 25 Oct. 2016. Fruit: large; globose; firm; meaty; crisp; flavor very good, mild, sweet, subacid, $13.5^{\circ}$ Brix; shipping/keeping quality 
good; ripens 7-17 June in San Joaquin Valley, CA. Tree: large; vigorous; productive; growth habit upright, medium dense; flowers showy, self-fertile; chilling requirement 300 h; leaf glands small, reniform.

Snow Sprite. White-fleshed, clingstone peach. Origin: Modesto, CA, by G.N. Zaiger, L.M. Gardner, and G.G. Zaiger. 233LK471 × 373LH55 (246LC568 × Sweet Dream). USPP 26,838; 21 June 2016. Fruit: large; globose; firm; meaty; flavor very good, mild, sweet, subacid, $14.4{ }^{\circ}$ Brix; shipping and keeping quality good; ripens 30 Aug. - 6 Sept. in San Joaquin Valley, CA. Tree: large; vigorous productive; growth habit upright, medium dense; flowers showy, selffertile; chilling requirement $900 \mathrm{~h}$; leaf glands medium, reniform.

Spring Bliss. Yellow-fleshed, clingstone peach. Origin: Modesto, CA, by G.N. Zaiger, L.M. Gardner, and G.G. Zaiger. 178LE177 (Country Sweet $\times$ Rich Lady) $\times$ Earlitreat. USPP 27,297; 25 Oct. 2016. Fruit: large; globose; firm; meaty; crisp; sugar/acid balance good, $12{ }^{\circ}$ Brix; flavor very good; shipping/keeping quality good; ripens 21-31 May in San Joaquin Valley, CA. Tree: large; vigorous; productive; growth habit upright, medium dense; flowers showy, self-fertile; chilling requirement $650 \mathrm{~h}$; leaf glands small to medium, reniform

Supechnineteen. White-fleshed, melting, clingstone peach. Origin: Sun World International, Bakersfield, CA, by T.A. Bacon. PE921 $\times$ unknown (bulk pollen). USPP 26, 525; 22 Mar. 2016. Fruit: 205 g; rounded; firm; melting; mild, eating quality good; $12{ }^{\circ} \mathrm{Brix}$; shipping/keeping quality good; ripens 3-11 May in Wasco, CA. Tree: size medium; vigor moderate; productive; semi-upright; dense; flowers non-showy; self-fertile; chilling requirement $200 \mathrm{~h}$; leaf glands medium, reniform.

Supechtwenty. Yellow-fleshed, non-melting, clingstone peach. Origin: Sun World International, Bakersfield, CA, by T.A. Bacon. Supechseventeen $\times$ unknown (bulk pollen). USPP 26,500; 15 Mar. 2016. Fruit: 196 g; rounded; firm; non-melting; low-acid; eating quality good; $13{ }^{\circ}$ Brix; shipping/keeping quality good; ripens 29 Apr. - 8 May in Wasco, CA. Tree: size medium; vigor moderate; productive; growth habit semi-upright, dense; flowers non-showy, self-fertile; chilling requirement $200 \mathrm{~h}$; leaf glands medium, globose.

Supechtwentyone. Yellow-fleshed, non-melting, semi-freestone peach. Origin: Sun World International, Bakersfield, CA, by T.A Bacon. PE226 × Supechseventeen. USPP 26,773; 31 May 2016. Fruit: 205 g; rounded; firm; non-melting; mildly sweet, acidity medium-low, $13{ }^{\circ}$ Brix; shipping/keeping quality good; flesh becomes red as it ripens; ripens 13-23 May in Wasco, CA. Tree: size medium; vigor medium; productive; growth habit semi-upright, dense; flowers non-showy, self-fertile; chilling requirement $250 \mathrm{~h}$; leaf glands medium, reniform.

Sweet Aurora. Yellow-fleshed, clingstone peach. Origin: Modesto, CA, by G.N. Zaiger, L.M. Gardner, and G.G. Zaiger. 214LP37 × 214LK573. USPP 27,870; 11 Apr. 2017. Fruit: large; globose; firm; meaty; mild, sweet, low-acid, $\sim 13.1{ }^{\circ}$ Brix; very juicy; shipping/ keeping quality good; ripens 25 May - 4 June in San Joaquin Valley, CA. Tree: large; vigorous; productive; growth habit upright, medium dense; flowers showy, self-fertile; chilling requirement $650 \mathrm{~h}$; leaf glands medium, reniform.

Sweetember. White-fleshed, melting, clingstone peach. Origin: Argo Selection Fruits, Elne, France, by L. Maillard and A. Maillard. Nectapi $\times$ Sweetprim. USPP 28,506; 10 Oct. 2017. Fruit: homogeneous, generally $180-200 \mathrm{~g}$, round to slightly flattened; $75-80 \%$ purple-red blush; firm; crunchy; melting; semi-sweet, 11-16.5 ${ }^{\circ} \mathrm{Brix}$; very aromatic; acidity moderate; shipping quality excellent; not sensitive to powdery mildew, aphids, or mites; ripens 28 Aug. - 26
Sept. in Pyrénées-Orientales Dept., France. Tree: large; vigor strong; productive; growth habit semi-flared to semi-upright, dense; flowers showy, self-fertile; leaf glands globose.

Taz. Yellow-fleshed, clingstone peach. Origin: Modesto, CA, by G.N. Zaiger, L.M. Gardner, and G.G. Zaiger. 226LV474 × 152LT601. USPP 27,827; 4 Apr. 2017. Fruit: large; globose; firm; meaty; sugar/acid balance good, $10.2{ }^{\circ}$ Brix; eating quality very good; shipping/keeping quality good; ripens 28 June - 8 July in San Joaquin Valley, CA. Tree: large; vigorous; productive; growth habit upright, medium dense; flowers showy, self-fertile; chilling requirement $900 \mathrm{~h}$; leaf glands medium, reniform.

Zee Rich. Yellow-fleshed, clingstone peach. Origin: Modesto, CA, by G.N. Zaiger, L.M. Gardner, and G.G. Zaiger. 11ZL1010 (Vista $\times$ Sweet Henry) O.P. USPP 27,928; 25 Apr. 2017. Fruit: large; globose; firm; meaty; sugar/acid balance good, $\sim 10{ }^{\circ}$ Brix; eating quality good; shipping quality good; ripens 4-14 July in San Joaquin Valley, CA. Tree: large; vigorous; productive; growth habit upright, medium dense; flowers showy, self-fertile; chilling requirement $700 \mathrm{~h}$; leaf glands medium, reniform.

\section{PEAR}

Gökhan Oztürk ${ }^{1}$ and Kate Evans, Washington State University Tree Fruit Research and Extension Center, Wenatchee, WA

\section{Joseph Postman, USDA-ARS, National Clonal Germplasm} Repository, Corvallis, OR

ANP-0118 (Lanya $^{\circledR}$ ). Attractive, red-blushed, early-season, freshmarket European pear. Origin: APFIP, Tatura, Victoria, Australia, by S. Turpin. Butirra Precoce Morettini $\times$ Corella; crossed 1995; selected 2001. USPP 25,741; 28 July 2015. Fruit: size medium, 82-97 mm long, 62-68 mm wide; smooth, pyriform, symmetrical; yellow-green with pinkish-red blush; skin thin, glossy; flesh white, crisp, fine, moderately juicy; eaten directly off tree, free of grit, 11-16 ${ }^{\circ}$ Brix; ripens slightly before Bartlett. Tree: vigorous; growth habit semi-upright; blooms $7 \mathrm{~d}$ after Corella; yield medium, consistent, similar to Corella; pollinizers Hosui, Corella, Packham's Triumph.

ANP-0131 (Deliza $\left.{ }^{\circledR}\right)$. Attractive, red-blushed, large-fruited European pear with long storage life. Origin: APFIP, Tatura, Victoria, Australia, by S. Turpin. Corella $\times$ Doyenné du Comice; crossed 1995; selected 2001. USPP 25,742; 28 July 2015. Fruit: size medium, 68-89 $\mathrm{mm}$ long, $66-70 \mathrm{~mm}$ wide; obovate pyriform to turbinate, symmetrical; yellow-green with strong dark red blush; skin thin; flesh white, fine, moderately juicy, free of grit; flavor medium sweet, $13-16{ }^{\circ}$ Brix; aroma excellent; ripens slightly after Bartlett, stores up to 10 months in controlled atmosphere (CA). Tree: vigorous; growth habit semi-upright; blooms $7 \mathrm{~d}$ before Packham's Triumph; yield medium, consistent, similar to Corella; pollinizers Hosui, Corella, ANP-0118.

Arlingham Squash (Old Squash, Old Taynton Squash, Squash Pear). Heirloom perry pear from England. Origin: common in southwest Gloucestershire, particularly near the Severn. Often confused with Taynton Squash. Possibly the Green Squash Pear of Evelyn. Fruit: small; broadly turbinate, almost round, 43-56 mm long, diameter $45-57 \mathrm{~mm}$; stem thick, usually swollen at union with spur; stem basin small, sometimes absent; eye basin slight, wide and shallow; calyx upright, rarely reflexed; skin light green, sometimes with a slight red blush; flesh sometimes tinged yellow, with stone cells around core; ripens mid-October in Gloucestershire; susceptible to internal browning; produces medium-acid, low-to-medium

${ }^{1}$ Isparta, Turkey 
tannin perry; pleasant and full-bodied. Tree: size medium; limbs slender, growth habit upright; branch system open; production heavy; susceptible to pear scab (Venturia pirina) and stem cankers.

Armida. Naturally semi-dwarf, midseason European dessert pear. Origin: Jules Guyot $\times$ Doyenné du Comice; selected about 1971 and maintained at the fruit gene bank in Dresden-Pillnitz, Germany; field tested since 1980 in Germany; named 1995. Fruit: large, 170 g; oblong, slim; green with yellow overcolor; ripens late September in Dresden, after Bartlett; flavor good, with some stone cells. Tree: productive, precocious; growth habit compact; resistant to spring frost, tolerant to pear scab and powdery mildew (Podosphaera leucotricha), susceptible to fire blight (Erwinia amylovora); diploid; pollinizers Bartlett, Conference.

Atago. Large, midseason, russet-skinned Asian pear. Origin: Seed from self-pollination of Nijisseiki collected in 1915; fruit characteristics suggest a cross of Nijisseiki $\times$ Imamura Aki; named 1927 for the Atago region of Japan; introd. 1928 by Ninomiya-Engei Testing Center. Fruit: large; round, slightly asymmetrical; golden brown russet; flesh crisp, juicy, less astringent than Imamura Aki; ripens 3-4 weeks before Ya Li, mid-September in Niigata; storage life good. Tree: diploid; size medium; fruiting abundant, produces large fruit with very little thinning.

\section{Awrel. See Oldfield.}

BestEver (Best Ever). Midseason dessert pear from southern Oregon that holds up well in common storage. Origin: Southern Oregon Experiment Station, Central Point, OR, by F. Reimer. Doyenné du Comice $\times$ Louis Pasteur; crossed 1935; tested as OSU 2-301. Fruit: resembles Comice in shape, but somewhat smaller and darker green in color; covered with fine russet; flesh sweet, spicy and very juicy; flavor rich vinous, similar to Louis Pasteur; harvested just after Comice and before Bosc, Sept. 15-20 in Medford, OR; generally marketed starting in January; keeps well in conventional storage until April. Tree: blooms with Comice; quite productive and reasonably farmer-friendly; moderately susceptible to fire blight.

Carmen. Attractive, precocious European pear with consistently high yields. Origin: Istituto Sperimentale per la Frutticoltura, Forlì Station, Italy, by L. Rivalta. Dr. Guyot $\times$ Bella di Giugno; crossed 1980; selected 1989; tested as 80-18-69; released 2000. EU PVR 17,843; 6 June 2006. Fruit: large, $190 \mathrm{~g}$; oblong-pyriform, similar to Bosc; yellow-green with $20-30 \%$ red blush; flesh medium-fine, melting, juicy, aromatic; no black core; resistant to handling; ripens late July, 15-20 d before Bartlett; keeps well in cold storage for early cultivar. Tree: vigor intermediate-high; growth habit upright; yield medium-high; bloom intermediate-late; cropping early, mainly on spurs; good grafting compatibility on quince; pollinizers Bartlett, Conference, Coscia.

Celina (QTee $\left.{ }^{\circledR}\right)$. Redblushed, high-yielding, fresh-market European pear with resistance to pear scab. Origin: SLU Balsgard, Sweden and Graminor, Norway, by S.H. Hjeltnes. Colorée de Juillet $\times$ Bartlett; crossed 1985; selected 1997; tested as NP 6246. USPP 25,291; 17 Feb. 2015. Fruit: size medium, 150-180 g; pyriform, straight to convex; green-yellow with dark red blush, small red dots at lenticels; flesh fine, tender, juicy; $11-13{ }^{\circ}$ Brix, $1.3-2 \mathrm{~g} / \mathrm{L}$ malic acid; ripens early, 16-18 d before Conference; one-pick harvest; cold storage up to 3 months, at least 1 week shelf life. Tree: vigor high; growth habit spreading and pyramidal; tolerant to $-20{ }^{\circ} \mathrm{C}$; productivity high; flowers midseason; resistant to pear scab; pollinizers Packham's Triumph, Conference, Belle Lucrative.

Cepuna $\left(\right.$ Migo $\left.^{\circledR}\right)$. Attractive, non-russeting, productive European pear. Origin: Angers, France, by B. Thibault. Conference $\times$ Doyenné du Comice; crossed 1963, selected 1974. USPP 24,963; 14 Oct. 2014. Fruit: size good, $220 \mathrm{~g}$, averaging $70 \mathrm{~mm}$ diameter, $100 \mathrm{~mm}$ long; pyriform, similar to Conference; skin smooth, yellowgreen, almost no russeting; flesh medium-fine; flavor good, juicy,
13-14.5 ${ }^{\circ}$ Brix; ripens first week of September, immediately after Conference; storability and shelf life good. Tree: vigor moderate; growth habit upright-spreading; productive; winter hardiness good; blooms early April in Beaucouzé, France; pollinizers Comice, Concorde, Conference; moderately susceptible to fire blight.

CH201. Crunchy bicolored European pear with long storage and resistance to fire blight. Origin: Agroscope, Switzerland, by D. Christen. Harrow Sweet $\times$ Verdi; crossed 2000. USPP 27,772; 14 Mar. 2017. Fruit: pyriform; average length $90 \mathrm{~mm}$, width $66 \mathrm{~mm}$; green with grey-purple blush; flesh white, medium juicy, crunchy, sweet with slight astringency, $11^{\circ} \mathrm{Brix}$; ripens 1 week after Conference; cold storage good. Tree: size medium-weak; growth habit drooping; early cropping; pollinizer Conference; susceptibility to fire blight low.

Cheeky. Attractive, large-fruited, fresh-market European pear with an early blush and strong pear flavors. Origin: Agricultural Research Council Infruitec-Nietvoorbij, Stellenbosch, South Africa, by T. Human and L. von Mollendorff. Parentage not confirmed; released 2009. German PBR applied for. Fruit: turbinate/oblongovate-pyriform; yellow-green, $30-70 \%$ red blush; relatively heatresistant, maintains color in warmer conditions, no russet; flesh juicy, sweet, $12.8{ }^{\circ}$ Brix, $0.17 \%$ acidity; texture melting, eating quality high; matures 3 weeks before Forelle and $10 \mathrm{~d}$ before Williams; stores well up to 12 weeks, tastes pleasant after storage. Tree: vigorous; growth habit spreading; bears on spurs and shoots; blooms between Forelle and Packham's Triumph; pollinizers Forelle, Abate Fetel, Rosemarie, Flamingo.

Choju (Chouju, Ichiban Nashi ${ }^{\mathrm{TM}}$ ). Very early-season, mediumsize Asian pear. Origin: Prefectural Horticultural Experiment Station, Kanagawa, Japan. Asahi $\times$ Kitsukawasei; crossed 1954; selected 1969; named Choju (meaning 'long life') and released in 1973. Fruit: size medium, 125 g; oblate; skin russeted; flesh very sweet; ripens very early, before Shinsui, $110 \mathrm{~d}$ after first bloom. Tree: vigor medium to strong; blooms mid- to late season; pollinizers Chojuro, Kosui, Hosui; susceptible to fire blight and bacterial blight (Pseudomonas syringae); resistant to black spot (Alternaria alternata) in Japan.

Choke Pear. See Moorcroft.

Chokers. See Moorcroft.

\section{Chouju. See Choju.}

Debby Green ${ }^{\mathrm{TM}}$. See PE3UNIBO.

Deliza $^{\circledR}$. See ANP-0131.

Early Giulia ${ }^{\text {TM }}$. See PE2UNIBO.

Gem. Fire blight-resistant, fresh-market European dessert pear with long storage potential. Origin: USDA-ARS, Kearneysville, WV, by R. Bell. Sheldon $\times$ US62563-004; crossed 1970; selected 1981; evaluated for fruit quality, fire blight resistance, and productivity in replicated trials by USDA-ARS, Washington State University, Oregon State University, Michigan State University, Cornell University, and Clemson University; named and released 2014; source of fire blight resistance from Barseck. Fruit: size medium, $77 \mathrm{~mm}$ long $\times 71 \mathrm{~mm}$ wide; stems uniform in diameter, $29 \mathrm{~mm}$ long $\times 3 \mathrm{~mm}$ diameter, slightly clubbed at base, upright or occasionally oblique; cavity acute, 1 to $2 \mathrm{~mm}$ deep; basin wide $(17-25 \mathrm{~mm}$ ) and shallow (2-6 mm); calyx convergent; skin smooth, waxy with a glossy finish, yellow-green with $25-50 \%$ orange-red blush on sun side; flesh creamy white with little grit, comparable to Bartlett or Anjou; harvest early September, 1-2 weeks after Bartlett in West Virginia and Oregon; texture fine, similar to Bartlett, requires at least 3 weeks of cold storage, ripening to either a soft buttery or firm crunchy 
texture depending on storage conditions; lasts for at least 28 weeks in cold storage without core breakdown or superficial scald; can also be eaten immediately after harvest without softening, for a crisp, juicy texture; flavor sweet and mildly aromatic; similar to Bartlett in appearance and flavor. Tree: precocious and high yielding; blooms with Bartlett and $\sim 4 \mathrm{~d}$ after Anjou; resistance to fire blight moderate; susceptible to powdery mildew, scab, and Fabraea leaf spot (Diplocarpon mespili); recommended as a fresh-market pear for both commercial and home orchards.

Green Horse (Horse Pear, White Horse, White Longland). Heirloom perry pear from England. Origin: Old trees are found scattered throughout north and northwest Gloucestershire. Fruit: oblate to slightly turbinate, $36-61 \mathrm{~mm}$ long, $45-60 \mathrm{~mm}$ in diameter; stem 14-44 mm; stem basin small, narrow, fairly deep, sometimes absent; eye basin often well defined; calyx usually upright; sepals jointed, sometimes free, sometimes fleshy at base, often pubescent; skin green or yellowish green, sometimes with a slight orange flush, russet around stem, more around eye, spreading to cheek; lenticels usually almost white, often conspicuous on russet; flesh with a ring of stone cells around the core; harvest mid- to late October, mill up to 3 weeks after harvest; vintage quality good, high in acid, low in tannin. Tree: large with characteristic stiff appearance; numerous large, heavy, upright limbs with narrow crotches terminate in small, stiff branches; cropping regular and good; susceptible to pear scab.

Hakko (Hakkou). Midseason, medium-size, attractive Asian pear. Origin: Yakumo $\times$ Kosui; crossed 1953; selected 1959; released 1972. Fruit: small to medium, $125 \mathrm{~g}$; roundish-oblate; yellow-green, clear, smooth, attractive; flesh texture excellent, good eating; ripens with or slightly before Kosui, 115-125 d after first bloom; storage poor to medium. Tree: vigorous; blooms mid- to late-season; pollinizers Chojuro, Shinseiki, Yakumo, Kosui, Nijisseiki; resistant to black spot; susceptible to fire blight.

Hakkou. See Hakko.

Hawfield. See Oldfield.

Hortensia. Mid-late-season, precocious European pear with high yield. Origin: Fruit Breeding Institute Dresden-Pillnitz, Germany. Nordhäuser Winterforelle $\times$ Clapp Favorite. Fruit: medium-large, 220 g; green-yellow, 75\% red to brown red; flesh good; ripens midSeptember, 2-3 d before Conference. Tree: size medium-vigorous, stronger than Bartlett; upright; yield regular, better than Bartlett; cold hardy, but flowers susceptible to spring frost; early cropping; pollinizers Paris, Conference, Clapp Favorite, Bartlett, Anjou; tolerant to scab and mildew, susceptible to fire blight.

Ichiban Nashi ${ }^{\mathrm{TM}}$. See Choju.

Lanya $^{\circledR}$. See ANP-0118.

Lucy $\operatorname{Red}^{\mathrm{TM}}$. See PE4UNIBO.

Lucy Sweet $^{\text {TM }}$. See PE1UNIBO.

Malvern Hills. See Moorcroft.

Malvern Pear. See Moorcroft.

Manon. Excellent tasting European pear with tolerance to scab and mildew. Origin: Fruit Breeding Institute Dresden-Pillnitz, Germany. Beurre Bosc O.P. Fruit: large, 250-300 g; yellow to green-yellow; blush gold-bronze; slight russet; flesh good to excellent; ripens midSeptember, after Bartlett. Tree: size medium-dwarf; growth habit flat pyramid; yield medium, regular; needs pollinizers but good pollinizers not yet tested; tolerant to scab and mildew, susceptible to bacterial blight (Pseudomonas syringae), somewhat susceptible to fire blight.

Migo $^{\circledR}$. See Cepuna.

Mishirazu (Mishirasu). Very large Asian pear hybrid. Origin: may trace back to seed from China and is likely a natural hybrid between $P$. pyrifolia and $P$. communis. Found $\sim 1887$ in Hokkaido, where it was originally called Iida Nashi; tested at Aomori 1933; became main cultivar in Hokkaido by 1956, named Mishirazu by Dr. Hoshino. Fruit: large to very large, often more than $450 \mathrm{~g}$, considered unattractive; skin rough brown russet; flesh crisp, crunchy; flavor good; used for salads and for fresh eating; ripens late September to early October, with Taihaku. Tree: productive and cold hardy, easily survives $-30{ }^{\circ} \mathrm{C}$; vigor low, suitable for close planting; has been used in breeding and is a parent of Amatama, Hokuto, Hatsuhi, Kangyoku, Kitahoshi, and Zaosu.

Moorcroft (Choke Pear, Chokers, Malvern Hills, Malvern Pear, Stinking Bishop). Heirloom perry pear from England praised for its flavor. Origin: believed to have originated at Moorcroft Farm, Colwall. First record 1884, found throughout England's perry districts. In the late 1800s Percy Bishop, nicknamed 'Stinking Bishop', lived at Moorcroft Farm and this name became synonymous with this variety; there is some uncertainty whether Moorcroft and Malvern Hills Pear are synonyms. Fruit: size medium, 48-64 mm long, 50-60 mm wide; turbinate to pyriform; greenish-yellow to yellow with russet at ends, numerous large lenticels; stem mediumlong, 24-31 mm; flesh sweet-sharp, astringent; harvest mid- to late September, mill up to $2 \mathrm{~d}$ after harvest; flavor good, said to make a good single-variety perry. Tree: may be very large with few long upright limbs; bark has distinctive, deep, vertical striations; susceptible to pear scab.

NCPX1. Fastigiate interspecific ornamental pear with red to purple flower buds. Origin: North Carolina State University, by T.G. Ranney. P. calleryana Cleveland Select $\times P$. pyrifolia Ohara Beni. USPP 26,539; 29 Mar. 2016. Fruit: very small, 12-25 mm in diameter; round to ovoid; gray-orange to gray-brown. Tree: growth habit fastigiated, narrow, upright; highly resistant to fire blight.

Offield. See Oldfield.

Old Squash. See Arlingham Squash.

Old Taynton Squash. See Arlingham Squash.

Oldfield (Awrel, Hawfield, Offield, Oleville, Ollville). Heirloom high-acid, medium-tannin perry pear from England producing a high-quality vintage in some localities. Origin: known since early 1700s in Herefordshire. Fruit: small, $35-45 \mathrm{~mm}$ long, $40-45 \mathrm{~mm}$ wide; oblate or round; stem slender, 19-26 mm, stem basin absent; skin light green, becoming yellowish with russet around stem; flesh has stone cells around core, sweet-sharp, astringent; harvest mid- to late October, mill 3-6 weeks after harvest. Tree: small to medium with wide-angled crotches; tends to biannual production; susceptible to pear scab.

Oleville. See Oldfield.

Ollville. See Oldfield.

Paragon. Unspectacular looking European pear with extraordinary flavor and texture. Origin: Southern Oregon Experiment Station, Medford, OR, by F. Reimer. Presumed Max Red Bartlett $\times$ Doyenné du Comice; crossed in 1940s; trialed as 633E; attracted the attention of local fruit growers in the 1990s for its exceptional fruit quality. Fruit: about the size and shape of Bartlett, perhaps a bit lumpier; 
skin green, ripening to yellow; although Max Red Bartlett is presumed to be a parent, skin does not exhibit any red color; flesh fine-textured, with exquisite flavor, fewer stone cells and less acid than Bartlett, similar to Comice but with more tender skin; matures between Bartlett and Comice, stores $\sim 4$ months. Tree: vigorous with good annual crop; blooms with Bosc.

PE1UNIBO (Lucy Sweet ${ }^{\mathrm{TM}}$ ). Attractive, early-season fresh-market European pear that stores well. Origin: Bologna University, Italy, by S. Musacchi, V. Ancarani, and S. Sansavini. Abate Fetel O.P.; planted 1990; selected 1998. USPP 27,029; 9 Aug. 2016. Fruit: size medium, $\sim 170 \mathrm{~g}$; pyriform; skin green, medium thin, smooth, slight russet; flesh fine, tender, juicy, melting; flavor good, sweet, 14.5-16.6 ${ }^{\circ}$ Brix; matures $9 \mathrm{~d}$ before Bartlett; keeps 5-6 months in cold storage. Tree: vigor medium-high; growth habit upright-conical; bears normally on 2-year-old wood; blooms just before Carmen; consistent high yield; no evidence of biennial bearing.

PE2UNIBO (Early Giulia ${ }^{\text {TM }}$ ). Attractive, large, early-season freshmarket European pear that stores well. Origin: Bologna University, Italy, by S. Musacchi, V. Ancarani, and S. Sansavini. Harvest Queen $\times$ Abate Fetel; crossed 1992; selected 2001. USPP 27,028; 9 Aug. 2016. Fruit: medium-large, $\sim 250 \mathrm{~g}, 102 \mathrm{~mm}$ long, $78 \mathrm{~mm}$ wide; pyriform truncate; skin green with $20-30 \%$ red-orange blush, thin, smooth; flesh white, crisp, fine, juicy; flavor good, sweet, $12.6^{\circ} \mathrm{Brix}$, quite acid; matures $15 \mathrm{~d}$ before Bartlett; keeps 5-6 months in cold storage. Tree: vigor medium, growth habit semi-upright, conical; bears on 2-3-year-old wood and on 1-year shoots; blooms in midseason; yield high and constant; no evidence of biennial bearing.

PE3UNIBO (Debby Green ${ }^{\text {TM}}$ ). Late blooming, early-midseason fresh-market European pear. Origin: Bologna University, Italy, by S. Musacchi, V. Ancarani, and S. Sansavini. Abate Fetel O.P.; planted 1992; selected 2001. USPP 26,989; 2 Aug. 2016. Fruit: size medium, $\sim 223 \mathrm{~g}, 105 \mathrm{~mm}$ long, $71 \mathrm{~mm}$ wide; elongated pyriform; skin green, slight russet; flesh white, medium-fine, melting, juicy; flavor good, sweet, 13.1-14.4 ${ }^{\circ}$ Brix, quite acid; matures 1-2 d before Bartlett, keeps 5 months in cold storage. Tree: vigor medium; growth habit slightly compact, upright, conical; bears on 2-3-yearold wood, sometimes on 1-year shoot; blooms late; yield high and constant; no evidence of biennial bearing.

PE4UNIBO (Lucy Red ${ }^{\text {TM }}$ ). Late blooming, attractive, large-fruited, mid-late-season fresh-market European pear. Origin: Bologna University, Italy, by S. Musacchi, V. Ancarani, and S. Sansavini. Abate Fetel $\times$ Cascade; crossed 1992; selected 2003. USPP 27,027; 9 Aug. 2016. Fruit: large, $\sim 300$ g, $114 \mathrm{~mm}$ long, $67 \mathrm{~mm}$ wide; pyriform-elongated, long neck similar to Abate Fetel; skin yellowgreen, $80-90 \%$ red blush; flesh white, crunchy, tender, juicy, slightly aromatic; flavor good, sweet, 13.1-13.6 ${ }^{\circ}$ Brix; matures $15 \mathrm{~d}$ after Bartlett; keeps 6 months in cold storage. Tree: vigor medium; growth habit semi-upright; bears on 1-year-old shoot and 2-3-year-old wood; blooms late; yield medium; no evidence of biennial bearing.

Piqa $^{\circledR}$ Boo $^{\circledR}$. See PREMP009.

PREMP009 (Piqa ${ }^{\circledR}$ Boo $^{\circledR}$ ). Attractive, dark red skinned, crisp, interspecific pear hybrid with long shelf life. Origin: Plant and Food Research, New Zealand, by A.G. White. P128R068T003 × P204R135T058; selected 2005. USPP applied for. Fruit: size medium-large, $70 \mathrm{~mm}$ long, $60 \mathrm{~mm}$ wide; short pyriform; bright mid- to dark red; flesh white, fine, crisp, slightly coarse, juicy; combines European and Nashi flavors, slightly sweet, mild, 13-14 ${ }^{\circ}$ Brix; ripens mid- to late season, 1-2 weeks before Comice; keeps 10-16 weeks in cold storage; shelf life $14 \mathrm{~d}$. Tree: size medium; growth habit upright; blooms late; resistant to pear scab, moderately susceptible to fire blight.
PREMP109. Attractive, good-textured interspecific pear hybrid with long shelf life. Origin: Plant and Food Research, New Zealand, by A.G. White. P125R74T032 × P125R95T002. USPP 24,408; 29 Apr. 2014. Fruit: size medium-large, 250 g, $67 \mathrm{~mm}$ long, $80 \mathrm{~mm}$ wide; yellow with red blush; flesh crisp, slightly coarse, very juicy; keeps 10-16 weeks in cold storage; shelf life $14 \mathrm{~d}$. Tree: size medium; growth habit upright; pollinizers Yali, Hosui; resistant to scab, susceptible to fire blight.

PREMP33 (Velvetine ${ }^{\circledR}$ ). Large-fruited, good-textured European pear with long shelf life. Origin: Plant and Food Research, New Zealand, by R. Hart and L.R. Brewer. Patrick Barry $\times$ Conference. USPP 24,699; 29 July 2014. Fruit: large, $116 \mathrm{~mm}$ long, $65 \mathrm{~mm}$ wide; long pyriform; partially russeted over green; flesh fine, buttery, juicy; flavor rich, sweet; ripens late; shelf life long. Tree: growth habit upright-spreading; susceptible to fire blight.

PREMP52. Attractive, yellow-skinned European pear with light red blush and long shelf life. Origin: Plant and Food Research, New Zealand, by A.G. White. T002 × Prem1P. USPP 28,335; 29 Aug. 2017. Fruit: spherical; green-yellow, 20-30\% red blush, smooth; flesh crisp, firm, juicy, sweet with some tartness, somewhat gritty; shelf life long. Tree: vigorous; growth habit semi-upright.

QTee $^{\circledR}$. See Celina.

Squash Pear. See Arlingham Squash.

Stinking Bishop. See Moorcroft.

Turandot. Early-season, precocious European pear with mediumhigh yield. Origin: Istituto Sperimentale per la Frutticoltura, Forlì Station, Italy, by L. Rivalta. Dr. Guyot $\times$ Bella di Giugno; crossed 1980; selected 1989; tested as 80-15-69; released 2000. EU PVR 17,845; 6 June 2006. Fruit: size medium; pyriform, similar to Coscia; skin yellow-green with $10 \%$ red blush; flesh medium-fine, juicy, slightly aromatic; no black core, resistant to handling; harvest early, 30-35 d before Bartlett; stores well for an early cultivar. Tree: vigor intermediate; growth habit upright; yield medium-high; blooms very early, 5-6 d before Bartlett; early cropping on spurs and brindles; graft compatibility on quince good; pollinizers Coscia, Tosca, Santa Maria, Abate Fetel; susceptible to fire blight.

Uta. Late-season European pear with excellent texture, taste and storage. Origin: Fruit Breeding Institute Dresden-Pillnitz, Germany. Madame Verte $\times$ Beurre Bosc. Fruit: large; round; skin golden brown; flesh excellent in texture and taste, aromatic; ripens mid-October, with Alexander Lucas; stores well until February/March. Tree: vigor low; growth habit compact, spreading; yield high, regular; cold hardy, but flowers susceptible to spring frost; resistant to scab.

Velvetine $^{\circledR}$. See PREMP33.

White Horse. See Green Horse.

White Longland. See Green Horse.

\section{PEAR ROOTSTOCK}

Kate Evans, Washington State University Tree Fruit Research and Extension Center, Wenatchee, WA

EMH. Dwarfing, precocious clonal quince rootstock for pear. Origin: Horticulture Research International, East Malling, UK. C.51 O.P.; selected 1981; tested as QR193-16; introd. 2000. EU PVR 20,100; 21 May 2007. Plant: readily propagated via softwood and hardwood cuttings and layering; almost no stem or root suckers. Rootstock performance: compared to Quince C and Quince A, 
vigor intermediate; imparts increased fruit size to Bartlett, Concorde, Conference, with similar cumulative total yields; suitable for highdensity orchards with good soil conditions (rich loamy soil).

Pyriam. Dwarfing clonal Pyrus rootstock for pear. Origin: INRA, France. Old Home O.P.; tested as OH11; introd. 1997. French PVR 13,031; 16 Feb. 2006. Plant: readily propagated via softwood and half-hardwood cuttings. Rootstock performance: tolerant to fire blight (Erwinia amylovora); graft compatibility excellent; nursery growth habit good; productivity similar to BA29; higher induced vigor and production; fruit size greater than OHF333; well adapted to Bartlett cultivation in SE France.

Pyro $^{\text {TM }}$ 2-33. See Rhenus 3.

Rhenus 3 (Pyro ${ }^{\text {TM }}$ 2-33). Semi-dwarfing, precocious, high-yielding clonal Pyrus rootstock for pear. Origin: Research Station of Viticulture and Horticulture, Geisenheim, Germany, by H.B. Jacob. Old Home $\times$ Bonne Louise d'Avranches; crossed 1980; tested as BU/ 233. USPP 12,$771 ; 16$ July 2002 . Plant: readily propagated via softwood and hardwood cuttings; no suckering. Rootstock performance: $\sim 50 \%$ more vigorous than Quince $\mathrm{A}$; anchorage very good; frost hardiness high $\left(-15^{\circ} \mathrm{C} / 15 \mathrm{~d}\right)$; soil adaptation good; precocious; yield efficiency high; fruit size uniform; compatible with all pear varieties tested; moderately tolerant to fire blight; tolerant to iron chlorosis.

\section{PERSIAN WALNUT}

Charles A. Leslie, Walnut Improvement Program, University of California, Davis, CA

Durham. Midseason harvesting walnut with extra-light kernel color, well-filled nuts, and smooth, light-colored shell. Origin: University of California, Davis, by G. McGranahan and C. Leslie. Chandler $\times$ PI159568; crossed 1993; selected 2001; tested as UC93-028-20; introd. 2016. USPP 28,529; 17 Oct. 2017. Nut: 15.2 g; smooth, oval; seals strong; 55\% kernel; suitable for use in-shell. Kernel: $8.4 \mathrm{~g}$; easily removed in halves; high proportion of extra-light color. Tree: vigor similar to Chandler; growth habit upright; bears on terminals and laterals; protandrous; yield high; harvest similar to Tulare and $10 \mathrm{~d}$ before Chandler; occurrence of blight low.

\section{PLUM}

Rachel Spaeth, Garden Curator, Luther Burbank Home \& Gardens, Santa Rosa, CA

Blackred XXI. Firm, medium to large, clingstone Japanese plum, with almost entirely black skin, and red and yellow flesh. Origin: Le Grand, CA, by L.G. Bradford and J.M. Quisenberry. 42P1156 O.P. USPP 28,441; 26 Sept. 2017. Fruit: oblate; mostly uniform; juice abundant; $22-24{ }^{\circ}$ Brix; aroma slight; good for fresh market and longdistance shipping; ripens mid-August in Le Grand. Tree: large; vigorous; growth habit dense, upright; bloom moderate-heavy, medium-late; flowers fragrant; bearing regular; self-incompatible, requires cross-pollination from apricot, interspecific, or midseason bloomer such as September Yummy.

Plumcandy XI. Firm, large, clingstone Japanese plum with full red skin and pure orange yellow flesh. Origin: Le Grand, CA, by L.G. Bradford and J.M. Quisenberry. Black Majesty $\times$ September Yummy O.P. USPP 29,050; 6 Mar. 2018. Fruit: uniform, oblate, slightly asymmetrical, compressed axially; aroma very slight; blend of acid and sugar; 23-24 ${ }^{\circ}$ Brix; good for fresh market and long-distance shipping; ripens early September in Le Grand. Tree: size and vigor medium; foliage upright, dense; self-incompatible, requires crosspollination by a suitable mid- to late-season blooming plum or interspecific such as Plumsweet XVI.
Plumcandy XII. Firm, very large, freestone Japanese plum, with full red skin and pure yellow flesh. Origin: Le Grand, CA, by L.G. Bradford and J.M. Quisenberry. September Yummy O.P. USPP 24,442; 26 Sept. 2017. Fruit: uniform; symmetrical; globose; aroma slight; $18{ }^{\circ}$ Brix with blend of acid and sugar; good for fresh market and long-distance shipping; ripens early-mid-October in Le Grand. Tree: large; blooms medium to late, $2 \mathrm{~d}$ after Santa Rosa; selfincompatible, requires cross pollination from apricot, interspecific, or midseason bloomer such as its seed parent, September Yummy.

Plumcandy XIII. Very firm, medium-size, freestone Japanese plum, with full red skin and pure yellow flesh. Origin: Le Grand, CA, by L.G. Bradford and J.M. Quisenberry. Plumsweettwo O.P. USPP 28,468; 3 Oct. 2017. Fruit: oblong and oblate; aroma slight; 22-24 ${ }^{\circ}$ Brix with blend of acid and sugar; good for fresh market and longdistance shipping; ripens mid- to late October in Le Grand. Tree: large; bloom extended, onset early, continues beyond midseason cultivars; self-incompatible, requires cross-pollination from apricot, interspecific, or midseason bloomer such as Yummyrosa.

Plumred XII. Firm, uniformly medium to large, semi-freestone Japanese plum, with full red skin and flesh. Origin: Le Grand, CA, by L.G. Bradford and J.M. Quisenberry. Black Majesty O.P. USPP 28,400; 19 Sept. 2017. Fruit: shape variable, mostly oblate with a few compressed axially, cordate; $25^{\circ}$ Brix; aroma slight; good for fresh market and long-distance shipping; ripens late September in Le Grand. Tree: size medium-large; vigorous, produces 3' surplus top growth in spring and summer; bearing regular; blooms medium-late; self-incompatible, requires cross-pollination from apricot, interspecific, or midseason bloomer such as September Yummy.

Plumsweet XVII. Firm, medium-size, clingstone Japanese plum, with two-tone red and green skin, and full red flesh. Origin: Le Grand, CA, by L.G. Bradford and J.M. Quisenberry. Plumsweet VI O.P. USPP 28,504; 10 Oct. 2017. Fruit: symmetrical; aroma slight; $20^{\circ}$ Brix with blend of acid and sugar; eating quality excellent; good for fresh market and long-distance shipping; ripens late May to early June in Le Grand. Tree: large and vigorous; bloom onset early; selfincompatible, requires cross-pollination from apricot, interspecific, or early bloomer such as Yummygem.

Plumsweet XVIII. Very firm, large, clingstone Japanese plum, yellow with heavy red dappling and full red flesh. Origin: Le Grand, CA, by L.G. Bradford and J.M. Quisenberry. 42P1156 O.P. USPP 28,469; 3 Oct. 2017. Fruit: oblong and heart-shaped; aroma slight; $18{ }^{\circ}$ Brix with blend of acid and sugar; good for fresh market and long-distance shipping; ripens late June to mid-July in Le Grand. Tree: large; bloom onset medium, 2 d before Santa Rosa; selfincompatible, requires cross-pollination from apricot, interspecific, or midseason bloomer such as September Yummy.

Plumsweet XIX. Firm, medium-size, clingstone Japanese plum, red over green with dark red dappling, and full red flesh. Origin: Le Grand, CA, by L.G. Bradford and J.M. Quisenberry. OC579 O.P. USPP 28,596; 7 Nov. 2017. Fruit: moderately asymmetrical; hangs firm for $\sim 3$ weeks; aroma slight; eating quality excellent; 18-22 ${ }^{\circ}$ Brix with blend of acid and sugar; good for fresh market and longdistance shipping; ripens mid-late July in Le Grand. Tree: vigor moderate; growth habit upright, dense; requires regular irrigation; requires cross-pollination from apricot, interspecific, or midseason bloomer such as September Yummy.

Plumsweet XX. Clingstone, fresh-market Japanese plum with twotone skin, red and green, and full red flesh. Origin: Le Grand, CA, by L.G. Bradford and J.M. Quisenberry. EY RF O.P. USPP 28,997; 2 Feb. 2018. Fruit: large to medium; oblate and mostly symmetrical; firm; $16-18{ }^{\circ}$ Brix; flavor blends acid and sugar; fresh eating quality very good; aroma wanting; ripens late May to mid-June in Le Grand. Tree: vigorous; growth habit upright, dense; bloom onset early to 
medium; self-incompatible, requires cross-pollination from apricot, interspecific, or early bloomer such as Yummygem.

Suplumfortyseven. Semi-freestone Japanese plum with nearly black skin and dark red flesh. Origin: Bakersfield, CA, by D. Cain and T.A. Bacon. 91P-098 O.P. USPP 27,503; 27 Dec. 2016. Fruit: mostly rounded; $\sim 17^{\circ}$ Brix; juice abundant; aroma slight; good for fresh market and shipping; ripens late July in Wasco, CA. Tree: size and vigor medium; growth habit semi-upright; productive; blooms $\sim$ Mar. 2-6 in Wasco.

Suplumfortyeight. Firm, clingstone Japanese plum with pure yellow skin and yellow-orange flesh. Origin: Bakersfield, CA, by T.A. Bacon. Suplumfourteen O.P. USPP 27,449; 13 Dec. 2016. Fruit: flavor sweet-neutral, $\sim 19^{\circ}$ Brix; aroma slight, fruity; good for fresh market and shipping; ripens late August in Wasco, CA. Tree: size medium; bearing regular; needs thinning; bloom period medium, Mar. 4-8 in Wasco.

Suplumfortynine. Firm, clingstone, very early Japanese plum with reddish-purple skin and deep red flesh. Origin: Bakersfield, CA, by T.A. Bacon. Suplumthirtyseven $\times$ PL526YB. USPP 27,326; 1 Nov. 2016. Fruit: symmetrical with flat base; juicy with sweet-mild flavor; $\sim 16{ }^{\circ}$ Brix; slight tendency to crack; good for fresh market and shipping; ripens late May to early June in Wasco, CA. Tree: size medium; growth habit semi-upright; chilling requirement $\sim 700 \mathrm{~h}$; blooms early, duration $\sim 10 \mathrm{~d}$.

Suplumfifty. Clingstone Japanese plum with nearly black skin and dark red flesh. Origin: Bakersfield, CA, by T.A. Bacon. 98P039035-291 × 96P024-003-430. USPP 27,327; 1 Nov. 2016. Fruit: symmetrical, rounded; juicy; flavor sweet-mild; $\sim 20{ }^{\circ}$ Brix; slight tendency to crack; good for fresh market and shipping; ripens midlate August in Wasco, CA. Tree: size medium; growth habit upright; productive; fertility unknown.

\section{POMEGRANATE}

John E. Preece, USDA-ARS, National Clonal Germplasm Repository, Davis, CA

John M. Chater, Donald J. Merhaut, Zhenyu Jia, Dept. of Botany and Plant Sciences, University of California, Riverside, CA

Early Red. Bright, dark red, uniformly round, with soft seeds and sweet arils. Origin: near Orange Cove, CA, by B.Y. Kamada. Bud sport of Wonderful. USPP 2,723; 7 Mar. 1967. Fruit: round, height $88.9 \mathrm{~mm}$, diameter $88.9 \mathrm{~mm}$; brighter dark red than Wonderful; rind thin, resists splitting; arils sweet, with soft seeds; ripens 3 weeks before Wonderful. Tree: vigorous; small and round; somewhat thorny; suckers freely.

Emek. Medium-size, dark pink to red with sweet, red arils and relatively soft seeds, ripens in mid-August. Origin: Yizre'el Valley, Israel, by D. Holland, I. Bar-Ya'akov and K. Hatib. Pedigree unknown; observed 2003, selected 2006. USPP 21,907; 10 May 2011. Fruit: size medium, height $86 \mathrm{~mm}$ without calyx, diameter $86.9 \mathrm{~mm}$; dark pink to red with sweet, red arils; seeds relatively soft. Tree: growth habit upright and spreading; size medium, 2.5-2.6 $\mathrm{m}$ tall and 2.3-2.4 $\mathrm{m}$ spread; vigor good; productivity good; tolerates down to $-3{ }^{\circ} \mathrm{C}$.

Kamel. Medium-size tree with large, dark red fruit with red arils and a sweet-sour flavor. Origin: Yizre'el Valley, Israel, by D. Holland, I. Bar-Ya'akov, and K. Hatib. Pedigree unknown; observed 2003, selected 2006. USPP 21,966; 31 July 2009. Fruit: large, $79 \mathrm{~mm}$ high without calyx, diameter $96.4 \mathrm{~mm}$; uniform, dark red with red arils; rind may crack; aril separation easy; flavor sweet-sour, seeds medium-hard; ripens late, in early October. Tree: growth habit upright and spreading; size medium, 2.2-2.8 $\mathrm{m}$ tall and 2.6-3.1 m wide; vigor good; tolerates down to $-3{ }^{\circ} \mathrm{C}$; productive.

Ki-Zakuro. Ornamental cultivar with variegated double reddish pink and white flowers. Origin: Shibamichi Nursery, Saitama, Japan, by S. March, A. Shibamichi, and F.P. Drake. Pedigree unknown; collected in 1985 for the United States National Arboretum; given to the USDA-ARS National Clonal Germplasm Repository, Davis, CA in 1990. Fruit: plant generally sterile, but may rarely set inedible fruitlets. Flower: large and showy variegated double with bright reddish pink petal bases with white outer edges; $>100$ petals per flower; durable with good postharvest shelf life; can be dried and displayed for years. Tree: growth habit upright, $2 \mathrm{~m}$ tall after 4 years; no thorns; suckers readily.

PQ2009. Yellow with bright red arils, sweet with low acidity and medium-soft seeds. Origin: Atlanta, GA, by M.A. Miller. Pedigree unknown; selected from seed of unknown cultivar grown by a home gardener; seed sown in 2009. USPP 27,747; 7 Mar. 2017. Fruit: rind yellow; arils bright red, seeds medium-soft; flavor sweet, low-acid; height $9.5 \mathrm{~cm}$, diameter $8.5 \mathrm{~cm}$; globose with persistent calyx; ripens late summer to late autumn. Tree: selected as an ornamental and large container or landscape plant; multi-stemmed; produces on year-old container plants; 2-year plants were $1.5 \mathrm{~m}$ tall and $1.2 \mathrm{~m}$ spread in 15-gallon containers in Georgia; cold hardy to at least USDA Zone 8.

Red Jay. Early-season, very dark red-fruited, similar to Wonderful. Origin: Y \& Y Management Company, Bakersfield, CA, by J.A. Yurosek. Bud sport of Wonderful; selected near McFarland, CA. USPP 27,981; 9 May. 2017. Fruit: round with protruding calyx; diameter 82.5-90 mm; 450-500 g; rind dark red; arils very dark red; seeds medium-hard, more uniform in color than Wonderful; acidity low; ripens $60 \mathrm{~d}$ before Wonderful. Tree: similar to Wonderful with an upright fountain shape; petioles shorter than Wonderful; 3-4 m tall, somewhat more vigorous than Wonderful, sucker production similar to Wonderful; slightly thorny.

Smith. Soft-seeded, deep red rind with moderate red to deep red arils with higher acidity than Granada. Origin: near Visalia, CA, by G.R. Smith. Volunteer seedling $15.5 \mathrm{~m}$ from a commercial orchard of Granada; first observed 1996. USPP 16,578; 30 May. 2006. Fruit: deeply red fruit, similar to Granada; arils moderate to deep red; seeds soft; acidity higher than Granada; ripens $\sim$ Sept. 11; fruit globular, height $71.5 \mathrm{~mm}$, diameter $79.3 \mathrm{~mm}$; calyx crown prominent. Tree: size medium, $3.3 \mathrm{~m}$ tall and $3.3 \mathrm{~m}$ spread; has thorns.

\section{RASPBERRY}

Patrick P. Moore, Dept. of Horticulture, Washington State University, Puyallup, WA

Chad Finn, USDA-ARS, Horticultural Crops Research Laboratory, Corvallis, OR

Michael Dossett, BC Berry Cultivar Development, Agriculture and Agri-Food Canada - Agassiz Research and Development Centre, Agassiz, BC

AAC Eden. High-yielding, early to midseason, floricane-fruiting red raspberry for fresh market. Origin: Agriculture and Agri-Food Canada, Kentville Research and Development Centre, Kentville, NS, by A.R. Jamieson. Glen Ample $\times$ K93-11; crossed 2002; selected 2006; tested as K06-2; introd. 2013. Canadian Plant Breeders' Rights certificate 4567; 3 July 2013. Fruit: large; conical; medium red; drupelets small; firm; easily removed from receptacle; flavor well-balanced; postharvest life good. Plant: canes upright, spineless; sucker production moderate; pest and disease resistance unknown. 
Advabertwee (Kwanza ${ }^{\circledR}$ ). Late-season, primocane-fruiting red raspberry for fresh market. Suitable for professional growers in cool and Mediterranean climates. Origin: Fuel Plants and Allberry, De Kwakel, the Netherlands, by G. de Weert and A. Smaal. 207157-12 × 207015; crossed 2005, selected 2006, tested as Nr. 62; introd. 2014. USPP 23,914; 24 Sept. 2013; revised and reissued as USRE 46,030; 21 June 2016. Fruit: large, $8 \mathrm{~g}$; conical; orange to red; juicy and tasty; ripens $15 \mathrm{~d}$ after Polka. Plant: canes sturdy, upright; growth habit compact; number of basal shoots small; suitable for double cropping systems.

Advabereen (Kweli $\left.{ }^{\circledR}\right)$. Late-season, primocane-fruiting red raspberry for fresh market. Suitable for growing in cool, Mediterranean and tropical climates. Origin: Fuel Plants and Allberry, De Kwakel, the Netherlands, by G. de Weert and A. Smaal. $207005 \times 207126$; crossed 2005, selected 2006, tested as Nr. 35; introd. 2014. USPP 23,915; 24 Sept. 2013; revised and reissued as USRE 46,041; 28 June 2016. Fruit: size medium, 4-5 g; round; red; flavor good; shelf life excellent; ripens $5 \mathrm{~d}$ after Polka. Plant: vigorous; develops laterals at all levels; yield high; suitable for double cropping systems.

Advaberimar (Imara $\left.{ }^{\circledR}\right)$. Late-season, primocane-fruiting red raspberry for fresh market. Suitable for growing in cool and Mediterranean conditions. Origin: Fuel Plants and Allberry, De Kwakel, the Netherlands, by G. de Weert and A. Smaal. 207102-24 × 207003; crossed 2005, selected 2006, tested as Nr. 66; introd. 2014. USPP 23,916; 24 Sept. 2013. Fruit: size medium, 5 g; conical; red to dark red; flavor good; ripens with Polka. Plant: vigorous; laterals many; flower buds develop down almost the full length of cane; yield high; suitable for double cropping systems.

Advabemap (Mapema ${ }^{\circledR}$ ). Late-season, primocane-fruiting red raspberry for fresh market. Suitable for growing in cool conditions. Origin: Fuel Plants and Allberry, De Kwakel, the Netherlands, by G. de Weert. Crossed 2005, selected 2006, tested as Nr. 8; introd. 2015. USPP 27,812; 28 Mar. 2017. Fruit: large, 5-7 g; conical; red to dark red; flavor good; ripens with Polka. Plant: vigorous and sturdy, needs only limited support; yield high; suitable for double cropping systems.

Glen Dee. Highly productive, floricane-fruiting red raspberry for fresh market. Origin: James Hutton Institute, by S.N. Jennings. JHI 00123A5 $\times$ JHI 0019B11; crossed 2004; selected 2007; tested as JHI 0447C-5; introd. 2014. EU PVR applied for. USPP 27,660; 14 Feb. 2017. Fruit: slightly conical; pink-red; flavor sweet; texture creamy; easily removed from receptacle; shelf life excellent; recommended for fresh market; ripens mid-to-late-season, first pick between Glen Ample and Octavia. Plant: vigorous cane and good root vigor; resistant to main biotypes of European large raspberry aphid (Amphorophora idaei); remains free of raspberry bushy dwarf virus 5 years.

Imara ${ }^{\circledR}$. See Advaberimar.

Julcsi. Early-season, floricane-fruiting red raspberry for fresh market; regularly has primocane crop in October at ends of canes. Origin: NARIC Fruitculture Research Institute Research Station Fertőd, Hungary, by F. Dénes. Autumn Bliss $\times$ Fertődi Aranyfürt; crossed 2000; selected 2003; tested as 6891/8/1; introd. 2014. Fruit: large; conical; dark red; ripens 10-12 d before Fertödi Zamatos; easily removed from receptacle. Plant: vigor hard; growth habit upright, canes very tall; sucker production high; tolerant of raspberry bushy dwarf virus.

Kwanza $^{\circledR}$. See Advabertwee.

Kweli $^{\circledR}$. See Advabereen.

Mapema $^{\circledR}$. See Advabemap.

Santa Catalina. Large, conical primocane-fruiting cultivar with excellent flavor. Origin: Pontificia Universidad Católica de Chile, by M. Gambardella, E. Contreras, J. Grez, and P. Bañados. P.08.05.2× Coho; crossed 2010; selected 2011. Fruit: large, $4.5 \mathrm{~g}$ average, $7.0 \mathrm{~g}$ maximum; conical; easily detached during harvest; firmness medium; flavor excellent; average $10.3^{\circ} \mathrm{Brix}$, maximum $12^{\circ} \mathrm{Brix}$; flowers late October; ripens late November to late January; for primocane fruiting, differentiation begins late January, harvest mid-February to May. Plant: vigor high; growth habit erect, tall; lateral shoots medium size; fruits mainly on primocanes; canes for fruiting of dormant buds $\sim 70-80 \mathrm{~cm}$; cane and shoots have high-density, large spines.

Santa Clara. Attractive, trapezoidal primocane-fruiting cultivar. Origin: Pontificia Universidad Católica de Chile, by M. Gambardella, E. Contreras, J. Grez, and P. Bañados. P.08.05.2 $\times$ Coho; crossed 2010; selected 2011. Fruit: size medium, 4.1 g average, $6.2 \mathrm{~g}$ maximum; trapezoidal; attractive; easily detached from plant; drupelets small; firmness medium; flavor good, average $10.1{ }^{\circ}$ Brix, maximum $12{ }^{\circ}$ Brix; flowers early November; ripens late November to late January; for primocane fruiting differentiation begins January; harvest mid-February to May. Plant: vigorous; growth habit erect, tall; lateral shoots medium size; fruits mainly on primocanes; cane for fruiting of dormant buds $\sim 100 \mathrm{~cm}$; cane and shoots have average density thorns.

Santa Teresa. Large, trapezoidal primocane-fruiting cultivar. Origin: Pontificia Universidad Católica de Chile, by M. Gambardella, E. Contreras, J. Grez, and P. Bañados. P.08.05.2 × Coho; crossed 2010; selected 2011. Fruit: large, average 6.1 g, maximum 9.3 g; trapezoidal; appearance very good; easily detached; firmness medium; flavor good; average $9.8^{\circ} \mathrm{Brix}$, maximum $12.1^{\circ} \mathrm{Brix}$; flowers early November; ripens late November to late January; for primocane fruiting, differentiation begins January, ripens mid-February to May. Plant: vigorous; growth habit erect, tall; lateral shoots medium size; fruits mainly on primocanes, cane for fruiting of dormant buds 90-100 cm; cane and shoots have low density, small thorns.

\section{STRAWBERRY}

Kim S. Lewers, USDA-ARS, Genetic Improvement of Fruits and Vegetables Laboratory, Beltsville, MD

Archer. Short-day strawberry adapted to perennial matted row and annual plasticulture production in temperate climates. Origin: New York State Agricultural Experiment Station-Geneva, Cornell University, Ithaca, NY, by C.A. Weber. NY1786 × L'Amour; crossed 1997; selected 2001, Ithaca; tested as NY01-16; introd. 2016. USPP applied for. Fruit: very large; wide conical; medium-dark red; moderately firm; flavor very good; early-midseason, ripens with Honeoye. Plant: vigorous; growth habit spreading; runner production high; productive; resistant to powdery mildew (Podosphaera aphanis); moderately tolerant to replant diseases.

Cabrillo. Dayneutral strawberry adapted to coastal Central California. Origin: The Regents of the University of California, Oakland, CA, by D. Shaw and K. Larson. Cal 3.149-8 $\times$ Cal 5.206-5; crossed 2008; selected 2009, Winters, CA; tested as Cal 8.181-1 and CN236. USPP 27,830; 4 Apr. 2017. Fruit: very large, $32 \mathrm{~g}$; variable conic to wedge-conic; glossy bright orange-red (Munsell 7.5R 4/11); very firm, flesh orange-red (Munsell 5R 5/13); flavor outstanding; calyx medium, surface to inset, reflexed; achenes surface to inset; early. Plant: vigor strong; stolons numerous, 22/plant; yield very high, 3,669 g/plant; growth habit upright, medium density; flowers at canopy, fruiting trusses prostrate; moderately resistant to powdery mildew, verticillium wilt (Verticillium dahliae), phytophthora crown rot (Phytophthora cactorum), and common leaf spot (Ramularia tulasnei); tolerant to two-spotted spider mite (Tetranychus urticae) and California strawberry viruses; moderately susceptible to anthracnose fruit rot (Colletotrichum acutatum). 
Calinda. Short-day strawberry adapted to protected cultivation, Southern Europe. Origin: Fresh Forward Holding, Zetten, the Netherlands, by E.J. Meulenbroek. E2003-285 × E2003-287; crossed 2005; selected 2007 in a controlled environment, Bonares, Andalusia, Spain. USPP 26,904; 5 July 2016. Fruit: large, 26 g; uniform conic; glossy vivid red-orange (RHS 42A); flesh vivid red-orange (RHS 44B), firm, juicy, flavorful, sweet; calyx large, surface, reflexed; achenes inset; ripens early, December-May; shelf life long, $10 \mathrm{~d}$. Plant: vigor medium to strong; yield good, $837 \mathrm{~g} / \mathrm{plant}$; growth habit compact, semi-upright, medium density; flowers at canopy, fruiting trusses prostrate; resistant to botrytis fruit rot (Botrytis cinerea); moderately resistant to phytophthora crown rot.

Charlene. Short-day strawberry adapted to plastic tunnels in Italy. Origin: Nova Siri Genetics, Nova Siri, Matera, Italy, by N. Tufaro. Marisol $\times$ A050389; crossed 2010; tested as EE-10-14. USPP 28,220; 25 July 2017. Fruit: size medium to large, 22 g; uniformly cordate; very glossy strong red (RHS 45B-46A); flesh orange-red (RHS 34A - 34B), firm; flavor good, $9^{\circ} \mathrm{Brix}, 3.8 \mathrm{pH}$; calyx medium, surface, spreading; achenes inset; ripens semi-early. Plant: vigor medium, stolon number adequate; yield good, similar to Camarosa, $588 \mathrm{~g} /$ plant; growth habit upright globose, medium density; flowers above canopy, fruiting trusses prostrate; mildly susceptible to powdery mildew.

Diligent. Short-day strawberry adapted to coastal Central California. Origin: Berry Genetics, Freedom, CA, by S. Nelson, M. Nelson, and L. Stoeckle. BG-959 × BG-2010; crossed 2004; selected 2006, Ventura County, CA. USPP 27,441; 6 Dec. 2016. Fruit: very large, $35 \mathrm{~g}$; uniformly broad conic; glossy vivid red (RHS 46B); flesh variable vivid red (RHS 44A); flavor good, $7.6^{\circ}$ Brix; calyx small, inset, spreading to reflexed; achenes at surface; ripens early. Plant: vigor medium, stolon number adequate; yield medium high, 1,098 marketable g/plant; small; growth habit upright, sparse to medium density; flowers above canopy, fruiting trusses prostrate; moderately susceptible to powdery mildew, verticillium wilt, botrytis fruit rot, and two-spotted spider mite; susceptible to bacterial angular leafspot (Xanthomonas fragariae).

Flame. Dayneutral strawberry adapted to coastal Central California. Origin: Sweet Darling Sales, Aptos, CA, by J. Larse. $102850 \times 106734$; crossed 2010; selected in Watsonville, CA; tested as 108229. USPP 28,470; 3 Oct. 2017. Fruit: large, 25 g; uniformly conic; moderately glossy red (RHS 41A); flesh entirely red (RHS 41A), firm, moderately sweet and aromatic, $7.6^{\circ} \mathrm{Brix}$; calyx small, at surface, spreading; achenes at surface to inset; ripens March-October, peak June; 90\% salable, stores 7-10 d. Plant: vigor medium, stolons few, 4/plant; yield medium-high, $912 \mathrm{~g} /$ plant; growth habit semi-upright, light to medium density; flowers at to above canopy, fruiting trusses erect; moderately tolerant to rain.

Florida Beauty. Dayneutral strawberry adapted to Florida. Origin: University of Florida, Wimauma, FL, by V. Whitaker. 2010-119 × Florida Radiance; crossed 2012; selected winter 2012-2013, Wimauma; tested as FL 12.121-5; introduced 2017. USPP applied for. Fruit: mid-size, $20 \mathrm{~g}$; broad conic; glossy even red; flesh red, moderately firm, juicy; flavor good, $8.3^{\circ}$ Brix, $3.6 \mathrm{pH}$; calyx large, showy, at surface, reflexed; achenes inset; ripens from early November; shelf life similar to Florida Radiance. Plant: vigor low, compact, stolons numerous; yield good, 647 g/plant; growth habit compact, open, medium density; flowers at or below canopy, fruiting trusses prostrate; resistant to phytophthora crown rot; tolerant to rain; moderately susceptible to anthracnose fruit rot and powdery mildew.

Fronteras. Short-day strawberry adapted to coastal Southern and Central California. Origin: The Regents of the University of California, Oakland, CA, by K. Larson and D. Shaw. Cal $4.18 \times$ Cal 5.165-1; crossed 2008; selected 2009, Irvine, CA; tested as Cal
8.132-608 and C235. USPP 26,709; 10 May 2016. Fruit: very large, $35 \mathrm{~g}$; variable long-conic to cylindrical; orange-red (Munsell 7.5R 4/11); flesh light orange-red (Munsell 7.5R 5/3), firm; flavor excellent; calyx small, inset to surface, clasping to reflexed; achenes inset to raised; ripens semi-early. Plant: vigor medium, stolons numerous, 23/plant; yield very high, 2,793 g/plant; growth habit upright, open; flowers at or below canopy, fruiting trusses prostrate; moderately resistant to powdery mildew, verticillium wilt, phytophthora crown rot, and common leaf spot; tolerant to two-spotted spider mite and California strawberry viruses; moderately susceptible to anthracnose fruit rot.

Grenada. Short-day strawberry adapted to coastal Central California. Origin: The Regents of the University of California, Oakland, CA, by D. Shaw and K. Larson. Cal 4.4.1-6 $\times \mathrm{Cal}$ 5.109-2; crossed 2008; selected 2009, Winters, CA; tested as Cal 8.55-2 and C232. USPP 26,708; 10 May 2016. Fruit: very large, $33 \mathrm{~g}$; uniform short conic; glossy red (Munsell 5R 3/7); flesh light orange-red (Munsell 5R 3/13); very firm; flavor excellent; calyx medium, inset to surface, reflexed; achenes inset; ripens early. Plant: vigor medium, stolons numerous, 29/plant; yield very high, $2,511 \mathrm{~g} /$ plant; growth habit upright, open; flowers at or above canopy, fruiting trusses prostrate; moderately resistant to powdery mildew, phytophthora crown rot, and common leaf spot; tolerant to two-spotted spider mite and California strawberry viruses; moderately susceptible to anthracnose fruit rot and verticillium wilt.

Jive. Short-day strawberry adapted to Western Europe north of the Alps, and protected cultivation, Southern Europe. Origin: Fresh Forward Holding, Zetten, the Netherlands, by E.J. Meulenbroek. E1998-142 × E1997-054; crossed 2004; selected 2006 in a controlled environment, Elst, Gelderland, the Netherlands. USPP 26,711; 10 May 2016. Fruit: large, $27 \mathrm{~g}$; conic; glossy vivid red (RHS 43A); flesh vivid red-orange (RHS 33B); firm, sweet, pleasant aroma; calyx medium, at surface, spreading; achenes at surface to raised; ripens late; shelf life long, $10 \mathrm{~d}$. Plant: vigor medium to strong, stolons few; yield high, $1,463 \mathrm{~g} / \mathrm{plant}$; growth habit compact, semi-upright, medium density; flowers at canopy, fruiting trusses prostrate; resistant to heat stress, rain, powdery mildew; moderately resistant to phytophthora crown rot.

Lucia. Short-day strawberry with dayneutral tendencies, adapted to coastal Central California. Origin: Lassen Canyon Nursery, Redding, CA, by J. Bagdasarian. 5E10 × Sweet Ann; crossed 2008; selected 2010, Watsonville, CA; tested as 42J4. USPP 26,974; 26 July 2016. Fruit: very large, $33 \mathrm{~g}$; uniform long conic; very glossy red (Pantone 1788C); flesh variable light red (Pantone 179C); firm; sweet; flavor excellent; calyx medium to large, at surface, reflexed; achenes at surface; ripens semi-early; stores $7 \mathrm{~d}$. Plant: vigor strong, stolon number adequate, 16/plant; yield medium-high, 1,057 g/plant; growth habit erect, open; flowers above canopy, fruiting trusses prostrate; tolerant to two-spotted spider mite; moderately tolerant to common leaf spot and powdery mildew.

Malga. Dayneutral strawberry adapted to protected cultivation in Europe. Origin: New Fruits, Verona, Italy, by F. Zenti. Irma $\times$ SG8; crossed 2008; selected 2011 in greenhouse, Verona, Italy; tested as SG134. USPP 28,310; 22 Aug. 2017. Fruit: large, 27 g; uniform long-conic; glossy vivid red (RHS 44A); flesh vivid orange (RHS 30B); firm; flavor very good, $7.3^{\circ} \mathrm{Brix}$; calyx small, surface to raised, reflexed; achenes inset; stores $6 \mathrm{~d}$ or more. Plant: stolon number adequate, 6-8/plant; yield high, 1,200 g/plant; growth habit upright, medium density; flowers above canopy.

Marys Peak. Short-day fresh-market or processing cultivar adapted to the Pacific Northwest. Origin: USDA-ARS, Corvallis, OR, by C.E. Finn, B.C. Strik, B.M. Yorgey, T.A. Mackey, P.P. Moore, M. Dossett, P.A. Jones, J. Lee, R.R. Martin, K.L. Ivors, 
and A.R. Jamieson. Pinnacle $\times$ ORUS 1723-3; crossed 2000; selected 2002; tested as ORUS 2427-4; introd. 2017. USPP applied for. Fruit: large, 15-20 g; uniform long wedge; glossy bright red; flesh solid red, very firm, sweet, $8.74{ }^{\circ} \mathrm{Brix}, 3.4 \mathrm{pH}$, $9.34 \mathrm{~g} \cdot \mathrm{L}^{-1}$ citric acid; picks easily with or without cap; ripens midto late-season, 2-4 d after Charm, Tillamook, and Totem. Plant: vigor strong; yield high, greater than Totem; upright, very efficient to harvest due to open growth habit, visible fruit and large fruit size; tolerant to verticillium wilt and Northwest US viruses; moderately susceptible to red stele (Phytophthora fragariae), Races Cdn-4 and Cdn-5, charcoal rot (Macrophomina phaseolina), and fusarium wilt (Fusarium oxysporum).

Melissa. Short-day strawberry adapted to plastic tunnels in Italy. Origin: Nova Siri Genetics, Nova Siri, Metera, Italy, by N. Tufaro. Siris $\times$ Margherita; tested as $488 \times f-11-03$. USPP 28,081 ; 6 July 2017. Fruit: large, $26 \mathrm{~g}$; variably conic to slightly rhomboid; very glossy vivid red (RHS 45B, RHS 46B); flesh orange-red (RHS 34A, RHS 34B); flavor good, $9{ }^{\circ} \mathrm{Brix}, 3.9 \mathrm{pH}$; calyx medium, raised, spreading; achenes inset; ripens early. Plant: vigor strong, stolons numerous; yield good, higher than Sabrosa, 496 g/plant; growth habit semi-upright, medium density; flowers above canopy, fruiting trusses prostrate; resistant to anthracnose.

NJ99-204-1 (Rutgers Scarlet ${ }^{\text {TM }}$ ). Short-day strawberry adapted to mid-Atlantic. Origin: Rutgers University, New Brunswick, NJ, by G. Jelenkovic, L. Lutz, P. Nitzsche, and W. Hlubik. NJ96-12-1 × Camarosa; selected 1999, New Brunswick; tested as NJ99-204-1. USPP 27,587; 24 Jan. 2017. Fruit: large, 24 g; variable, necked wedge-conic to conic; glossy dark red (RHS 45A-53A); flesh strong red (RHS 46A, 46C); firm; flavor excellent, $8{ }^{\circ} \mathrm{Brix}$; calyx medium, raised, clasping to reflexed; achenes at surface; midseason. Plant: vigor medium; marketable yield good, 607 g/plant; growth habit upright, medium density; flowers at canopy, fruiting trusses prostrate.

Petaluma. Short-day strawberry adapted to coastal Southern and Central California. Origin: The Regents of the University of California, Oakland, CA, by D. Shaw and K. Larson. Cal 5.97-7 × Cal 5.165-1; crossed 2008; selected 2009, Irvine, CA; tested as Cal 8.20-602 and C231. USPP 26,683; 3 May 2016. Fruit: very large, 33 g; uniform medium to long conic; glossy bright orange-red (Munsell 7.5R 4/11); flesh bright orange-red (Munsell 5R 4/11); very firm; flavor very good; calyx medium, inset to surface, spreading to reflexed; achenes at surface to inset; ripens early. Plant: vigor medium, stolons numerous, 22/plant; yield very high, 2,307 g/plant; growth habit upright, open; flowers at or above canopy, fruiting trusses prostrate; moderately resistant to powdery mildew and verticillium wilt; tolerant to two-spotted spider mite and California strawberry viruses; moderately resistant to phytophthora crown rot and common leaf spot; moderately susceptible to anthracnose fruit rot.

Ruby June. Short-day strawberry with dayneutral tendencies, adapted to coastal Central California. Origin: Lassen Canyon Nursery, Redding, CA, by J. Bagdasarian. 2G16 × 10B131; crossed 2008; selected 2010, Watsonville, CA; tested as 33K46. USPP 27,190; 27 Sept. 2016. Fruit: medium to large, $30 \mathrm{~g}$; conic with few tips and creases; glossy red (Pantone 1797C); flesh variable light orange-red; firm; sweet; flavor very good; calyx small to medium, surface, spreading to reflexed; achenes inset to surface; ripens early. Plant: vigor medium to strong, stolon number adequate; yield medium high, $919 \mathrm{~g} /$ plant; growth habit semi-upright, foliage dense; flowers at or above canopy, fruiting trusses prostrate; resistant to fusarium wilt.

\section{Rutgers Scarlet $^{\text {TM }}$. See NJ99-204-1.}

Safari. Short-day strawberry adapted to subtropics, Spain, and California. Origin: Plantas de Navarra, Navarra, Spain, by A.
Pierron-Darbonne. 98-126 × 02-105; crossed 2006; selected 2007, Central Mexico; tested as 06.44H.216. USPP 26,710; 10 May 2016. Fruit: mid-size, 22 g; variable conic; semi-glossy dark vivid redorange (RHS 33A-34A); flesh variable red-orange (RHS 31C-33B), core light orange (RHS 31C-31D); firm; $8.3{ }^{\circ}$ Brix, $3.7 \mathrm{pH}$; calyx large, at surface to raised, reflexed; achenes inset; ripens early. Plant: vigor medium, stolon number adequate, 8/plant; yield good, $929 \mathrm{~g} /$ plant; growth habit semi-upright, open; flowers at canopy, fruiting trusses prostrate.

Sahara. Short-day strawberry adapted to Mediterranean and subtropical climates. Origin: Plantas de Navarra, Navarra, Spain, by A. Pierron-Darbonne. $02-125 \times 03.98$; crossed 2006; selected 2007; tested as 06.43H.79. USPP 26.289; 5 Jan. 2016. Fruit: very large, $38 \mathrm{~g}$; long conic; glossy vivid red-orange (RHS 41A-43B); flesh variable red-orange (RHS 41C, 41D, 43C); firm; $7.9^{\circ} \mathrm{Brix}, 3.8$ $\mathrm{pH}$; calyx medium, at surface, reflexed; achenes inset; ripens very early. Plant: vigor medium, stolon number adequate, $8 /$ plant; growth habit upright, globose, open; flowers at canopy, fruiting trusses prostrate.

Scarlet. Short-day strawberry with dayneutral tendencies, adapted to coastal Central California. Origin: Lassen Canyon Nursery, Redding, CA, by J. Bagdasarian. Sweet Ann $\times 2$ F72; crossed 2008; selected 2010, Watsonville, CA; tested as 17J34. USPP 27,034; 9 Aug. 2016. Fruit: very large, $40 \mathrm{~g}$; long conic with few creases; very glossy light to medium orange-red (Pantone 179C); flesh variable light red (Pantone 178C); very firm; sweet; flavor excellent; calyx medium, surface, reflexed; achenes at surface; ripens semi-early; stores $7 \mathrm{~d}$. Plant: vigor medium to strong, stolon number adequate, 17/plant; yield high, 1,483 g/plant; growth habit semi-upright; foliage dense; flowers above canopy, fruiting trusses prostrate; resistant to fusarium wilt.

Vivaldi. Short-day strawberry adapted to protected cultivation, Southern Europe. Origin: Fresh Forward Holding, Zetten, the Netherlands, by E.J. Meulenbroek. E1993-053 × Sonata; crossed 2003; selected 2005 in a controlled environment, Elst, Gelderland, the Netherlands; tested as FF-1005. USPP 26,873; 28 June 2016. Fruit: size medium, $18 \mathrm{~g}$; conic; glossy vivid red (RHS 44A); flesh vivid red-orange (RHS 41A); firm; juicy; sweet; pleasant aroma; calyx medium, inset to surface, spreading to reflexed; achenes at surface to inset; ripens semi-early; shelf life long, $10 \mathrm{~d}$. Plant: vigor medium to strong; yield high, 1,145 g/plant; growth habit compact, semi-upright, medium density; flowers at or below canopy, fruiting trusses prostrate; resistant to botrytis fruit rot, phytophthora crown rot; tolerant to bacterial angular leafspot; moderately susceptible to powdery mildew.

Yambu. Short-day strawberry adapted to plastic tunnels in the Netherlands. Origin: Fresh Forward Holding, Zetten, the Netherlands, by E.J. Meulenbroek. E1991-023 × Honeoye; crossed 2001; selected 2003 in a controlled environment, Elst, Gelderland, the Netherlands. USPP 28,048; 23 May 2017. Fruit: size medium, 18-19 g; uniformly conic; glossy red-orange (RHS 34A); flesh redorange (RHS 34B and RHS 33A); firm; flavor pleasant; calyx medium-large, surface, reflexed; achenes at surface; ripens early with long season; shelf life excellent, $8 \mathrm{~d}$. Plant: vigor medium; yield medium high, $900 \mathrm{~g} / \mathrm{plant}$; growth habit compact, semiupright, medium density; flowers at canopy, fruiting trusses prostrate; resistant to botrytis fruit rot and phytophthora crown rot; somewhat resistant to powdery mildew.

Yasmin. Dayneutral strawberry adapted to Israel. Origin: Ministry of Agriculture and Rural Development, Agricultural Research Organization, The Volcani Center, Bet Dagan, Israel, by N. Dai, Z. Tanami, S. Slotzky, and A. Daos. ARO $105 \times$ ARO 701; crossed 2005; selected 2007, Bet Dagan; tested as 7110. USPP 28,250; 8 Aug. 2017. Fruit: large, $25 \mathrm{~g}$; variably wedged to short-conic; glossy, very dark red (RHS 42A); flesh medium red (RHS 42D) and 
white (RHS 155B); firm; sweet, 8-9.5 ${ }^{\circ}$ Brix, 3.75-3.9 pH; calyx medium, inset, reflexed; achenes inset; ripens very early, 10 Nov. Plant: vigor strong, stolons numerous; yield high; growth habit round, compact, medium density; flowers above canopy, fruiting trusses prostrate; tolerant to powdery mildew; susceptible to red spider mite.

Yoli. Dayneutral strawberry adapted to coastal Central California. Origin: Sweet Darling Sales, Aptos, CA, by J. Larse. $1621 \times 1285$; crossed 2005; selected in Watsonville, CA; tested as 104522. USPP 28,341; 29 Aug. 2017. Fruit: size medium, 21 g; uniformly long conic; moderately glossy red (RHS 41A); flesh slightly uneven red, RHS 41A; firmness variable; aromatic; mildly acidic, moderately sweet, $8.2{ }^{\circ}$ Brix; calyx small, at surface, spreading; achenes at surface; ripens March-October, peak June; 75\% salable, stores 9-13 d. Plant: vigor medium, stolon number adequate, 8/plant; yield low, 497 g/plant; growth habit semi-upright, medium density; flowers above canopy, fruiting trusses erect; rain/weather tolerance moderate.

\section{INDEX}

0322E82NB NECTARINE

2343 Jay Day PEACH

A132-926 $\left(\right.$ Colibri $\left.^{\circledR}\right)$ BLUEBERRY

AAC Eden RED RASPBERRY

Advabemap RED RASPBERRY

Advabereen RED RASPBERRY

Advaberimar RED RASPBERRY

Advabertwee RED RASPBERRY

Alpine Delight PEACH

American PEACH

ANABP 01 APPLE

Andes Nec-1 NECTARINE

ANP-0118 PEAR

ANP-0131 PEAR

APF-122 BLACKBERRY

APF-205T ( Stark $^{\circledR}$ Black Gem ${ }^{\circledR}$ ) BLACKBERRY

APF-236T (Baby Cakes ${ }^{\mathrm{TM}}$ ) BLACKBERRY

Apridelice APRICOT

Aprinew APRICOT

Aprireve APRICOT

Arcadia $^{\mathrm{TM}}$. BLUEBERRY

Archer STRAWBERRY

Arctic Zee NECTARINE

Arlingham Squash PEAR

Armida PEAR

Arthur V ALMOND ROOTSTOCK

Asfcot0201 APRICOT

Atago PEAR

AtlasBlue $^{\text {TM }}$ BLUEBERRY

Atomic Red NECTARINE

August Chief NECTARINE

August Moon NECTARINE

Avanti ${ }^{\mathrm{TM}}$ BLUEBERRY

Awrel PEAR

Baby Cakes ${ }^{\mathrm{TM}}$ BLACKBERRY

Bella Baby PUBESCENT PRUNOPHORA HYBRID

Bella Jean PUBESCENT PRUNOPHORA HYBRID

Bella Red PUBESCENT PRUNOPHORA HYBRID

Bella Sweet PUBESCENT PRUNOPHORA HYBRID

BestEver PEAR

BiancaBlue $^{\text {TM }}$ BLUEBERRY

BL-14 APPLE

Black Cascade BLACKBERRY

BlackJack ${ }^{\mathrm{TM}}$ BLACKBERRY

Blackred XXI PLUM

Bountiful Blue ${ }^{\circledR}$ BLUEBERRY

Bowden NECTARINE
Bravo $^{\mathrm{TM}}$ APPLE

Brights Hybrid $^{\circledR} 5$ ALMOND ROOTSTOCK

Burnectthirtyone NECTARINE

Burnecttwentynine NECTARINE

Burpeachforty PEACH

Burpeachthirtyeight PEACH

Burpeachthirtynine PEACH

Burpeachthirtyseven PEACH

Burpeachthirtysix PEACH

Cabernet Splash ${ }^{\mathrm{TM}}$ BLUEBERRY

Cabrillo STRAWBERRY

Cakereve NECTARINE

Calaveras PEACH

Calinda STRAWBERRY

Candysweet XII NECTARINE

Carlsbad PUBESCENT PRUNOPHORA HYBRID

Carmen PEAR

Celina PEAR

Cepuna PEAR

CH201 PEAR

Chaoyue 1 BLUEBERRY

Charlene STRAWBERRY

Cheeky PEAR

Choju (Chouju) PEAR

Choke PEAR

Chokers PEAR

CIV323 APPLE

Clavey PEACH

Colibri ${ }^{\circledR}$ BLUEBERRY

Columbia Sunrise BLACKBERRY

Compassion GRAPE

Coralblue BLUEBERRY

Crimson Fire PEACH

Crispdiva PEACH

Crispdream PEACH

Crisponda PEACH

Cutie Pie ${ }^{\text {TM }}$ BLUEBERRY

Debby Green ${ }^{\text {TM }}$ PEAR

Deliza ${ }^{\circledR}$ PEAR

Diligent STRAWBERRY

DrisBlackEight BLACKBERRY

DrisBlackEleven BLACKBERRY

DrisBlackFifteen (BlackJack ${ }^{\mathrm{TM}}$ ) BLACKBERRY

DrisBlackFourteen BLACKBERRY

DrisBlackNine BLACKBERRY

DrisBlackSixteen BLACKBERRY

DrisBlackTen BLACKBERRY

DrisBlackThirteen (Elvira ${ }^{\mathrm{TM}}$ ) BLACKBERRY

DrisBlackTwelve (Chance ${ }^{\mathrm{TM}}$ ) BLACKBERRY

Durham PERSIAN WALNUT

Early Giulia' ${ }^{\mathrm{TM}}$ PEAR

EB 10-1 BLUEBERRY

EB 8-50 BLUEBERRY

EB 9-12 BLUEBERRY

EB 9-2 BLUEBERRY

EB 9-4 BLUEBERRY

Echo BLUEBERRY

Eclipse BLACKBERRY

Elvira $^{\text {TM }}$ BLACKBERRY

EMH PEAR ROOTSTOCK (QUINCE)

Enchantment GRAPE

Endura $^{\text {TM }}$ BLUEBERRY

FCM12-045 BLUEBERRY

FCM12-087 BLUEBERRY

FCM12-097 BLUEBERRY

FCM12-131 BLUEBERRY

FEM 1 APPLE

FEM 8 APPLE

FF03-015 BLUEBERRY

FF03-178 BLUEBERRY

FL03-228 BLUEBERRY 
FL06-203 BLUEBERRY

FL06-377 BLUEBERRY

FL06-556 BLUEBERRY

FL07-399 BLUEBERRY

Flame STRAWBERRY

Flat Delight One PEACH

Flat Delight Two PEACH

Flatdiva PEACH

Florida Beauty STRAWBERRY

FLX-2 BLUEBERRY

Fronteras STRAWBERRY

FUCIV51 APPLE

Fuji SAN-CIV ${ }^{\circledR}$ APPLE

Gala 2013 APPLE

Gala Schnico Red APPLE

Galaxy BLACKBERRY

Gem PEAR

Glen Dee RED RASPBERRY

Golden Gem APRICOT

Golden Zest PEACH

Granite $^{\mathrm{TM}}$ BLUEBERRY

Green Horse PEAR

Grenada STRAWBERRY

GulfAtlas PEACH

Gumbo BLUEBERRY

Hakko (Hakkou) PEAR

Hall's Beauty BLACKBERRY

Hawfield PEAR

Hermosa PUBESCENT PRUNOPHORA HYBRID

Horse Pear PEAR

Hortensia PEAR

HS Red APPLE

Huiwang No. 1 BLUEBERRY

Huntington PUBESCENT PRUNOPHORA HYBRID

Ice Zee PEACH

Ichiban Nashi' ${ }^{\mathrm{TM}}$ PEAR

Imara ${ }^{\circledR}$ RED RASPBERRY

Isaaq $^{\circledR}$ APPLE

Jaac BLUEBERRY

JFS-KW207 APPLE

Jive STRAWBERRY

Julcsi RED RASPBERRY

June Honey PEACH

Jupiter Blue ${ }^{\text {TM }}$ BLUEBERRY

Kader PEACH

Kay Diamond VIII NECTARINE

Keecrisp ${ }^{\mathrm{TM}}$ BLUEBERRY

Kizuri APPLE

Krista PEACH

Kwanza ${ }^{\circledR}$ RED RASPBERRY

Kweli ${ }^{\circledR}$ RED RASPBERRY

Laguna PUBESCENT PRUNOPHORA HYBRID

Lanya ${ }^{\circledR}$ PEAR

Leila NECTARINE

Lucia STRAWBERRY

Lucy Red ${ }^{\mathrm{TM}}$ PEAR

Lucy Sweet ${ }^{\mathrm{TM}}$ PEAR

Lurechild APPLE

Luregust APPLE

Luresweet APPLE

Mac12/45 APRICOT

Mac12/54 APRICOT

Malga STRAWBERRY

Malibu PUBESCENT PRUNOPHORA HYBRID

Malvern Hills PEAR

Malvern Pear PEAR

Manon PEAR

Mapema ${ }^{\circledR}$ RED RASPBERRY

Marys Peak STRAWBERRY

Masena BLUEBERRY

Mazee PEACH
Melissa STRAWBERRY

Migo $^{\circledR}$ PEAR

MinnB42 APPLE

Misharazu (Mishirasu) PEAR

Mizao BLACKBERRY

MN55 APPLE

Moorcroft PEAR

Mored APPLE

NAJ152 APRICOT

NCPX1 PEAR

Nectaflash NECTARINE

Nectajoy NECTARINE

Nectaking NECTARINE

Nectana NECTARINE

Nectarelse NECTARINE

Nectarnovala NECTARINE

NJ99-204-1 STRAWBERRY

NJA151 APRICOT

Nzsummer3 APRICOT

OBF0627 BLUEBERRY

Offield PEAR

Old Squash PEAR

Old Taynton Squash PEAR

Oldfield PEAR

Oleville PEAR

Ollville PEAR

Opportunity GRAPE

P.F. Fashionably Late PEACH

Paragon PEAR

Patrecia BLUEBERRY

PE1UNIBO PEAR

PE2UNIBO PEAR

PE3UNIBO PEAR

PE4UNIBO PEAR

Pearl Princess III PEACH

Pearl Princess IV PEACH

Pearl Princess IX PEACH

Pearl Princess XIII PEACH

Pearlicious X NECTARINE

Petaluma STRAWBERRY

Pink Chief APPLE

$\mathrm{Piqa}^{\circledR} \mathrm{Boo}^{\circledR}$ PEAR

Pismo PUBESCENT PRUNOPHORA HYBRID

Plumcandy XI PLUM

Plumcandy XII PLUM

Plumcandy XIII PLUM

Plumred XII PLUM

Plumsweet XIX PLUM

Plumsweet XVII PLUM

Plumsweet XVIII PLUM

Plumsweet XX PLUM

Polar Gem NECTARINE

Polar Kist NECTARINE

Polar Magic NECTARINE

Polar Snow NECTARINE

Polar Zee NECTARINE

Prema34 APPLE

PREMP009 PEAR

PREMP109 PEAR

PREMP33 PEAR

PREMP52 PEAR

Pyriam PEAR ROOTSTOCK Pyro $^{\text {TM }}$ 2-33 PEAR ROOTSTOCK

QTee ${ }^{\circledR}$ PEAR

Radiance BLUEBERRY

Rave $^{\text {TM }}$ APPLE

Red Princess II PEACH

Red Princess III PEACH

Redondo PUBESCENT PRUNOPHORA HYBRID

Reed NECTARINE

Regalstar APPLE 
Rhenus 3 PEAR ROOTSTOCK

Rich Magic PUBESCENT PRUNOPHORA HYBRID

Rich Pride PEACH

Ridley 1812 BLUEBERRY

Ridley 4408 BLUEBERRY

Ridley 4609 BLUEBERRY

Rosa's Blush BLUEBERRY

Ruby June STRAWBERRY

Safari STRAWBERRY

Sahara STRAWBERRY

Salish $^{\text {TM }}$ APPLE

SAM 1 ALMOND ROOTSTOCK

Santa Catalina RED RASPBERRY

Santa Clara RED RASPBERRY

Santa Teresa RED RASPBERRY

Sauzee Giant PEACH

Sauzee Jewel PEACH

Scarlet Ovation BLUEBERRY

Scarlet STRAWBERRY

Shuofeng BLACKBERRY

SMN-461 BLUEBERRY

SMN-72 BLUEBERRY

SMN-86 BLUEBERRY

Smooth Delight One NECTARINE

Smooth Delight Two NECTARINE

Snow Baby PEACH

Snow Fox PEACH

Snow Gypsy PEACH

Snow Ryder PEACH

Snow Sprite PEACH

SPA493 APPLE

Spring Bliss PEACH

Squash Pear PEAR

StB14/22 APRICOT

Stinking Bishop PEAR

Suaprieleven APRICOT

Suaprithirteen APRICOT

Suapritwelve APRICOT

Sunnectwentythree NECTARINE

Supechnineteen PEACH

Supechtwenty PEACH

Supechtwentyone PEACH

Suplumfifty PLUM

Suplumfortyeight PLUM

Suplumfortynine PLUM

Suplumfortyseven PLUM

Sweet Aurora PEACH

Sweet Firegem NECTARINE

Sweetember PEACH

Taz PEACH

TCL3 APPLE

TO-1088 BLUEBERRY

Trinidad PUBESCENT PRUNOPHORA HYBRID

Turandot PEAR

Twilight BLUEBERRY

Uta PEAR

VacBril BLUEBERRY

Vacsid1 BLUEBERRY

Valor ${ }^{\circledR}$ BLUEBERRY

Velvetine ${ }^{\circledR}$ PEAR

Vivaldi STRAWBERRY

Westfresh APPLE

Weston PUBESCENT PRUNOPHORA HYBRID

White Horse PEAR

White Longland PEAR

Winter Bell BLUEBERRY

WUR200 APPLE

Xinxin 1 BLUEBERRY

Yambu STRAWBERRY

Yasmin STRAWBERRY

Yoli STRAWBERRY
Zee Rich PEACH

ZF08-070 BLUEBERRY

\section{ADDENDA}

\section{BLACKBERRY}

A-1960 (Heaven Can Wait ${ }^{\mathrm{TM}}$ ). USPP 26,405; 9 Feb. 2016 (List 47). Amara. USPP 26,413; 16 Feb. 2016 (List 48).

APF-153 (Prime-Ark ${ }^{\mathrm{TM}}$ Freedom). USPP 26,990; 2 Aug. 2016 (List 47). APF-190 (Prime-Ark ${ }^{\top M}$ Traveler). USPP 28,598; 7 Nov. 2017 (List 48). Camila. USPP 26,368; 2 Feb. 2016 (List 48).

Columbia Giant. USPP 25,532; 12 Sept 2017 (List 48).

Emilia. USPP 26,902; 5 July 2016 (List 48).

Osage. USPP 26,120; 24 Nov. 2015 (List 47).

\section{BLUEBERRY}

Baby Blues name was rejected by U.S. Patent and Trademark Office. Mini Blues was submitted as a replacement and accepted. Mini Blues. USPP 28,233; 1 Aug. 2017 (List 48).

FF04-14. USPP 27,623; 31 Jan. 2017 (List 48).

Norman. USPP 28,502; 10 Oct. 2017 (List 48).

OBF0604 (originally listed as 06-04) (MegasBlue ${ }^{\mathrm{TM}}$ ). USPP 26,796; 7 Jun. 2016 (List 48)

OBF0622 (originally listed as 06-22) (Titanium $^{\text {TM}}$ ). USPP 26,795; 7 Jun. 2016 (List 48).

Ridley $1111=$ commercially grown as Opi (List 48).

Ridley $1403=$ commercially grown as Eureka (List 48), tested as M-08-14-03.

Ridley $3402=$ commercially grown as Meridian (List 48).

Ridley 4514 = commercially grown as Firstblush (List 48).

TH-917 (Miss Jackie ${ }^{\mathrm{TM}}$ ). USPP 27,531; 10 Jan. 2017 (List 48).

T-1101 (Krewer ${ }^{\mathrm{TM}}$ ). USPP 28,623; 14 Nov. 2017 (List 48).

\section{GRAPE}

A-1710 (Tickled Pink ${ }^{\mathrm{TM}}$ ). USPP 25,152; 9 Dec. 2014 (List 47).

Faith. USPP 25,696; 14 July 2015 (List 47).

Gratitude. USPP 25,746; 28 July 2015 (List 47).

Hope. USPP 25,697; 14 July 2015 (List 47).

Joy. USPP 25,726; 21 July 2015 (List 47).

\section{NECTARINE}

Amoore Sweet. USPP 26,367; 2 Feb. 2016 (List 47).

Bowden. USPP 26,402; 9 Feb. 2016 (List 47).

\section{PEACH}

Royal Zest Four. USPP 28,079; 6 June 2017 (List 48).

Royal Zest One. USPP 28,045; 23 May 2017 (List 48).

Royal Zest Three. USPP 27,710; 28 Feb. 2017 (List 48).

Royal Zest Two. USPP 28,172; 11 July 2017 (List 48).

Smooth Texan One. USPP 28,171; 11 July 2017 (List 48).

Smooth Texan Three. USPP 28,078; 6 June 2017 (List 48).

Smooth Texan Two. USPP 28,360; 5 Sept. 2017 (List 48).

Smooth Zest One. USPP 28,202; 18 July 2017 (List 48).

Smooth Zest Two. USPP 28,435; 26 Sept. 2017 (List 48).

Souvenirs. USPP 26,920; 12 July 2016 (List 47).

PERSIAN WALNUT

Solano. USPP 25,466; 28 Apr. 2015 (List 47).

\section{RASPBERRY}

Crimson Giant red raspberry. USPP 23,375; 5 Feb. 2013 (List 46). Crimson Night red raspberry. USPP 24,949; 7 Oct. 2014 (List 47). Double Gold red raspberry. USPP 24,811; 26 Aug. 2014 (List 47). NR7 red raspberry. USPP 22,141 22,141; 13 Sept. 2011 (List 47). Vintage red raspberry. USPP 24,198; 28 Jan. 2014 (List 46).

STRAWBERRY

Florida127. USPP 25,574; 26 May 2015 (List 48). 